\title{
Potential Neuroprotective Effect of Nanomicelle Curcumin on Learning and Memory Functions Following Subacute Exposure to Bisphenol a in Adult Male Rats
}

\section{Somaye Fallahnezhad}

Mashhad University of Medical Sciences

Faezeh Ghorbani-Taherdehi

Mashhad University of Medical Sciences

Azade Nadim

Mashhad University of Medical Sciences

Mehrnaz Kafashzadeh

Sabzevar University of Medical Sciences

Mehrnoosh Kafashzadeh

Sabzevar University of Medical Sciences

Mahmoud Gorji-Valokola (D Mahmoud.gorji1359@yahoo.com )

Tehran University of Medical Sciences https://orcid.org/0000-0002-2757-769X

\section{Research Article}

Keywords: Bisphenol A, Neurotoxicity, Memory, Curcumin, Rat

Posted Date: September 23rd, 2021

DOl: https://doi.org/10.21203/rs.3.rs-918387/v1

License: (c) (i) This work is licensed under a Creative Commons Attribution 4.0 International License.

Read Full License 


\section{Abstract}

Objective

Bisphenol A (BPA) is an endocrine-disrupting chemical that widely used in plastics production. It can influence on the brain tissue. Curcumin has a strong protective activity against brain disorders. The purpose of this study was to evaluate the protective effect of nanomicelle curcumin (NmCur) on BPAinduced learning and memory disorders in rats.

Material and methods

In this study, after determining the dose of BPA, rats were randomly divided into 8 groups (8 rats in each group); sesame oil, dextrose $5 \%$, sesame oil + dextrose $5 \%$, NmCur (50 mg/kg), BPA (50 mg/kg), and 50 $\mathrm{mg} / \mathrm{kg}$ BPA plus 10,25 , or $50 \mathrm{mg} / \mathrm{kg} \mathrm{NmCur}$, respectively. All materials administered via gavage. Behavioral tests were estimated by shuttle-box, open-field, and Morris water maze devices. Then, stress oxidative, pro-inflammatory cytokines, oxidative stress-scavenging enzymes levels, as well as expression of MAPK proteins, glutamate receptors, and memory-related proteins were determined in the hippocampus and cortex tissues.

Results

BPA significantly increased expression of ROS, MDA, TNF-a, IL-6, IL-13, SOD, GST, p-P38, and p-JNK; however, considerably decreased GSH, GPx, GR, CAT, p-AKT, p-ERK1/2 levels. In addition, it down regulated expression of $p-N R 1, p-N R 2 A, p-N R 2 B, p-G l u A 1, B D N F$, and $p-C R E B$ in rat cortex and hippocampus tissues. BPA significantly also changed behavioral activity. Conversely, BPA (50 mg/kg) plus NmCur (25 and $50 \mathrm{mg} / \mathrm{kg}$ ) significantly reversed all BPA-induced adverse effects.

Conclusion

The results of this study support that nanomicelle curcumin exhibited preventive effects against neurotoxicity and learning and memory impairment induced by subacute exposure to bisphenol $\mathrm{A}$.

\section{Introduction}

Bisphenol A (4, 4-Isopropylidene-2-diphenol/BPA), is as one of non-steroid endocrine-disrupting chemicals that contains of two hydroxyphenyl groups [1]. Annually, more than 6 billion pounds of BPA produced in the world for construction of polycarbonate plastics and epoxy resins, such as food containers, water pipes, baby feeding, beverage bottles, dental sealants, eyeglass lenses, dyes, and paper products $[2,3]$. The ester bonds between BPA molecules in high-temperature and acidic or basic conditions undergo hydrolysis and monomers migrate into food (the main source of exposure), water, atmosphere, and environment. For instance, the rate of separation of BPA monomers from plastic containers into water was observed between 0.2 and $0.8 \mathrm{ng} / \mathrm{h}$ that if the water temperature rises, the separation speed of BPA monomers from containers will increase dramatically 55 times [4]. It has been stated that the BPA intake 
through food products and packaging is between 0.48 and $4.8 \mu \mathrm{g} / \mathrm{kg} /$ day [5]. The daily oral exposure to BPA that is expressed in the form of the no-observed-adverse-effect level (NOAEL) and reference safe daily limit is $50 \mathrm{mg} / \mathrm{kg}$ and $50 \mu \mathrm{g} / \mathrm{kg}$, respectively [6,7].

BPA considered as an industrial chemical material, which structurally is similar to $17-\beta$-estradiol (E2). So, it can be considered as a synthetic xenoestrogen and weakly effect on classical nuclear estrogen receptor a (ERa and ER $\beta$ ) [5, 8]. In addition, due to its lipophilic property, it can be absorbed following ingestion and has moderate bioaccumulation ability in almost every tissue with the highest concentration of fatty acids, especially adipose, liver, and brain tissues [5, 8-13]. BPA metabolized through hydroxylation, glucuronidation, and sulfuration reactions in the liver, testes, and brain tissues, which quickly converts to highly water soluble metabolites and excretes in the kidney, urine, intestine, and feces $[14,15]$. In outside the liver, oxidation of BPA via a microsomal cytochrome P450 enzyme complex system leads to production of a highly reactive intermediate, BA34Q [16]. Therefore, BPA exposure can lead to numerous adverse effects, including cardiotoxicity [14], hepatotoxicity, immune-toxicity, genotoxicity, mutagenicity, carcinogenicity, and neurotoxicity [17-20].

Neuron cells in the adult brain do not have the power of reproduce except in two specific zones, including the subventricular zone (SVZ) of the lateral ventricle (LV) and in the subgranular zone (SGZ) of the dentate gyrus (DG), which are particularly vulnerable to different types of injuries and diseases [21, 22]. On the other words, there are progenitor cells, which constantly are dividing, in the SGZ of the DG region that could be generated new interneurons and granule cells $[23,24]$. The neuronal networks, synaptic plasticity, and newly generated neurons in hippocampal CA1 pyramidal neurons, containing ER $\beta$, have major role in function of learning and memory and novelty detection, so that, any damage in these networks can affect the cognitive performance [25,26]. BPA can easily pass across the blood brain barrier (BBB), inhibits the proliferation and differentiation of neural and oligodendrocyte progenitor cells, and disrupts the $D G$ formation and the myelination process in the rat hippocampal and prefrontal region [27-29], leading to neurotoxicity [30] in different life stages and species [31].

In fact, it is noteworthy that the most important factor of induction of toxicity associated with BPA attributed to production of reactive oxygen species (ROS) and oxidative stress [32] in the differential tissues, such as heart [14], liver, epididymal sperm [33, 14], and especially brain [34]. Because in the brain, the neural cells have low oxygen storage and high capacity for ROS production and lipid peroxidation, which could affect on neurogenesis activity and dendritic structures in the hippocampal formation, leading to alteration function of learning and memory [35]. In addition to ROS, inflammation as an important factor in many diseases accelerated cognitive deficit. Two important structures for memory, attention, emotion, and perception functions are the hippocampus and basal ganglia, which include many enzymes involved in inflammatory processes [36]. Pro-inflammatory cytokines, including TNF-a, IL6 , and IL-1 3 , provoke the production of free radicals [37, 38], causes neuro-inflammation, and impairs learning and memory performance [39]. Nevertheless, the different types of natural ROS-scavenging enzymes are superoxide dismutase (SOD), glutathione peroxidase (GPx), and catalase (CAT). In addition, GSH (reduced form) is a biologically important intracellular thiol and free radical scavenger activity, 
which can be reproduced from the oxidized form, glutathione disulfide (GSSG), through glutathione reductase $(\mathrm{GR})[40,41]$.

So far, many studies have been done in this regard. For example, it has already been demonstrated that BPA exposure reduces the activity of detoxifying enzymes (like SOD, GPx, and CAT) that lead to an increase production of oxidative stress, ROS, and MDA, as an important indicator of lipid peroxidation, levels [42] and a decrease GSH content $[43,44]$. These changes in the brain result in necrosis, apoptosis, and cancer [45], especially in cerebellum [9], hypothalamus [10], cortex, and hippocampus tissues [1113], hampering the proliferation of neural progenitor cells and obliging neural cell death [46]. In addition, other similar studies have shown that BPA exposure ( $40 \mu \mathrm{g} / \mathrm{kg} /$ day) for 8 weeks also impaired the spatial learning and memory in the male mice [47] by altering the processes of neural plasticity and following inhibits the formation of new memories in the brain of male adult mice [6]. Moreover, the administration of BPA at perinatal period can lead to spatial learning and memory acquisition deterioration [48, 49]. Another study displayed that acute administration of BPA at a dose of $0.04 \mathrm{mg} / \mathrm{kg}$ for $2 \mathrm{~h}$ impaired memory of visual and spatial information and decreased the density of dendritic spine in pyramidal cells of the hippocampus CA1 region in the adult brain [6].

Apoptosis is programmed cell death that if left unchecked, they can lead to many disorders in different body's cells and tissues [50]. The increasing evidence indicates that various mechanisms, such as Ca2+induced ROS generation, MAPK activation (such as p-JNK and p-P38), and NF-KB translocation led to neuronal damage induced by BPA in hippocampal neuronal cells [51-53]. The ROS and oxidative stress could also motivate both astrocytes and microglial cells, as well as NF- $\kappa \mathrm{B}$ that stimulate the secretion of pro-inflammatory cytokines (including IL-1 $\beta$, IL- 6 , TNF- $\alpha$, TGF- $\beta$ and NO) and provoke the production of free radicals and amyloid- $\beta(A \beta)$ protein $[37,38]$. The $A \beta$ plaques accumulation could also motivate the microglia, astrocyte, and monocyte cells to produce neurotoxic compounds like glutamate [39]. BPArelated oxidative stress decreased expression of glutamate receptors (NMDA and AMPA) and suppressed activation of memory-related proteins (CREB and BDNF) $[52,54-56]$ in the hippocampus tissue, leading to an impairment of learning and memory in adult male rats [57,32]. Thus, it impaired the structures and functions of many enzymes and proteins involved in cell signaling, resulting in deterioration of neurogenesis, synaptic plasticity, and learning and memory in male and female animals [58-60].

In support of the view that antioxidants reduce oxidative stress, ROS, and pro-inflammatory cytokines, various studies have been conducted [61-63]. Several antioxidant agents, including $\mathrm{N}$-acetylcysteine [30], vitamin C [44], and melatonin [43] have decreased BPA-induced oxidative stress and cognitive impairments [64]. Thus, the use of antioxidants, which can pass from BBB, can have therapeutic applications against BPA-associated oxidative stress and pro-inflammatory cytokines-induced destructions. Based on this, many researches have been focused in recent decades to discover the new therapeutic agents with better efficacy in order to reduce or limit the neuronal damage caused by the harmful factors and enhance hippocampal neurogenesis and cognitive function $[65,66]$. One of these approaches is the use of agent with multi-modal interaction capability, such as anti-oxidant, antiinflammatory, anti-apoptotic, and neuroprotective properties [67]. 
From the distant past until now, the use of medicinal plants has various applications by many people in the world. One of the most popular herbal medicines is Curcuma, which to date has been identified more than 100 species, including Curcuma longa (also called Curcuma domestica), Curcuma aromatica, and Curcuma xanthorrhiza $[68,69]$. It is widely cultivated in tropical and sub-tropical regions of the world, especially in Asian countries, such as India, China, Indonesia, Japan, Taiwan, and Thailand [70, 71], that used as drug, spice, and food products. Curcumin (diferuloylmethane), in Farsi called Zardchoobeh [72], is main hydrophobic, polyphenolic, and flavonoidic bioactive component in the form of pure crystals and bright yellow pigment. It extracted from the dried rhizomes of the Curcuma longa Linn (turmeric), belonging to the ginger family Zingiberaceae $[73,74]$. Based on several clinical trials studies, it was discovered that the recommended, safe, acceptable, and tolerable daily oral intake dose of curcumin with the optimal therapeutic properties is up to $12 \mathrm{~g}$ /day $[75,76]$. Due to its biological compatibility and without severe side effects on natural cells and tissues, over the past few decades, considerable attention of many researchers have been paid to curcumin and its derivatives. In addition to items listed above, they showed diversity of biological and pharmacological activities viz., the anti-oxidant, antiinflammatory, anti-apoptosis, etc. activities in both in vitro and in vivo studies $[74,77]$. These curcumin effects have been ascribed to the fundamental features in its structure [78]. In the other words, the existence of electron donating polar substituents, such as phenolic and methoxy groups, improved the potency of the synthesized compounds in all their properties [79].

Past studies have shown that The supplementation of curcumin improved memory and learning function in mice and rats [80-82]. Moreover, curcumin administration can be led to lowering inflammatory cytokines, such as TNF- $\alpha$ and IL-1 $\beta$, IL-6, and IL-8 via inhibition of TLR4, NF-kB, and MAPK signaling pathway $[83,84,75]$. In similar study, curcumin treatment was significantly attenuated TNF-a and apoptosis by suppression of the p38 and JNK MAPK signaling pathway in chronic colitis-affected rats [85], mice liver [86], and different cell lines [87, 88]. Administration of curcumin at a dose of $1 \mathrm{~g} / \mathrm{d}$ for 8 weeks also improved antioxidant capacity, while decreased lipid peroxidation in 117 adults with metabolic syndrome disorders [89]. Other similar studies have conducted that curcumin administration considerably improved GSH content and antioxidant enzyme activities, including SOD, GPX, and CAT, but it declined MDA concentration in rat's kidney treated with gentamicin, cyclosporine, and methotrexate [90-92].

Despite of all the above-declared benefits, the use of curcumin has limitations owing to its extremely low water solubility, low intestinal and cellular absorption, poor oral bioavailability, rapid metabolism and elimination, rapid degradation in alkaline $\mathrm{pH}$ environment, and sensitivity to metal ions, heat and light [14, $93,77]$. Based on these problems, curcumin in most studies may not be able to achieve important results. Accordingly, in recent decades, numerous approaches, e.g. the use of the nanotechnology-based different drug delivery systems and multiple structural modification strategies to overcome these limitations have been done [14,94]. The use of nanotechnology makes compounds in various shapes and sizes [95]. Diverse types of delivery systems via a variety of natural or synthetic compounds, including phytosomes, liposomes, polymers, lipids, proteins, conjugates, cyclodextrins, micelles, dendrimers, and nanoparticles have been also used [96-98]. For instance, putting curcumin inside of the micelles can augment 
bioavailability up to 185 times, without inducing any adverse effects in healthy persons [99]. In addition, the structural modification approaches have been referred to change of the hydrogen donor group, the $\beta$ diketone moiety, the phenyl rings, and the alternative groups on them, resulting in production of curcumin derivatives and/or analogues [96-98]. So that, some of them have amended the water solubility, stability, bioavailability, cellular absorption, efficacy, and prolonged circulation and retention time of curcumin [9698] in both in vitro and in vivo studies. Based on these changes, numerous commercial formulations of curcumin, such as curcumin nanoparticles, curcumin in lecithin phosphatidylcholine carrier, and solid lipid curcumin nanoparticles have made [100].

In this study, a commercial formulation of nanomicelles curcumin (NmCur) was used, which each soft gel capsules contains curcumin, demethoxycurcumin (DMC), and bisdemethoxycurcumin (BDMC). One of the most important points that can be cited is that NmCur has the constant formulation in condition of simulated gastric and intestinal fluid (SGF and SIF) and released after at least $4 \mathrm{~h}$. It was also proved that in stomach, the NmCur is entirely dissolved in acidic stomach environment $(\mathrm{pH} \mathrm{1-2)}$ and nanomicelles remained stable up to $6 \mathrm{~h}$, transferred to the intestine $(\mathrm{pH} 6)$, and finally absorbed by different mechanisms [101]. In one study observed that NmCur formulation displayed better absorption and stability, excellent permeation and cellular uptake, and better anti-inflammatory activity than free curcumin in both in vivo and in vitro studies [101]. Therefore, it was observed that the commercialized NmCur with name of SinaCurcumin, which prepared by Exir Nano Sina Company (Tehran, Iran), has better oral solubility, bioavailability, and stability as compared to free curcumin and two other commercial products [101].

Based on the above points, the purpose of this evaluation was to estimate the protective effects of nanomicelle curcumin, as a curcumin derivative, on subacute neurotoxicity and learning and memory impairment induced by BPA in the hippocampus and cortex regions in an experimental model.

\section{Materials And Methods}

\subsection{Chemicals}

The analytical reagent grade BPA (CAS \# 80-05-7) with purity $>90 \%$ was obtained from SRL, Mumbai, India. A commercial formulation of nanomicelles curcuminoid (NmCur) was used, which is called SinaCurcumin ${ }^{\circledR}$, introducing by Exir Nano Sina Company in Tehran, Iran (IRC: 1228225765).. Ketamine and xylazine purchased from Merck (Rotexmeica, Germany). L-Glutathione reduced (GSH) $\geq 98.0 \%$ and SOD taken from Sigma-Aldrich (St Louis, Missouri). Other chemicals such as ethanol, methanol, $\mathrm{n}$ butanol, phosphoric acid, potassium chloride, thiobarbituric acid (TBA), phosphate buffered saline (PBS), 5, 50-dithiobis (2-nitrobenzoic acid) (DTNB), trichloroacetic acid (TCA), etc. were purchased in very high purities from Merck (Germany).

\subsection{Animals and treatment}


The number of 96 adult male Wistar rats with the weight about 220-250 g (two-month-old) were provided by the Animal Center, School of Pharmacy, Mashhad University of Medical Sciences. Animals were preserved in standard conditions with light/dark cycle of 12 hours, at the temperature of $23 \pm 1^{\circ} \mathrm{C}$, and free access to water and food throughout all stages of the experiment. All the experimental protocols were accepted by Ethical Committee of Mashhad University of Medical Sciences

(IR.MUMS.REC.1394.281) and this experiment was conducted at the Department of Pharmacodynamics and Toxicology, School of Pharmacy, Mashhad University of Medical Sciences, Mashhad, Iran [14]. In this study, the basis of work was divided into two parts, including the pilot (to determine the dose of BPA) and the main experimental (to determine the protective effect of NmCur on neurotoxicity and learning and memory impairment induced by BPA) studies.

\subsubsection{Pilot study}

In the pilot study, rats were randomly divided into 4 groups (each group 8 rats): control group received sesame oil (Sea) (vehicle of BPA) and experimental groups received 10, 25, and $50 \mathrm{mg} / \mathrm{kg}$ BPA with Sea. BPA and Sea gavaged once a day, 7 days per week for 4 weeks. After 4 weeks, the rats anaesthetized by intraperitoneal (IP) injection with ketamine/xylazine (60 and $6 \mathrm{mg} / \mathrm{kg}$, respectively) and the brain tissues removed and maintained in $-80^{\circ} \mathrm{C}$. Then, biochemical changes, such as ROS, MDA, and GSH, as well as pro-inflammatory cytokines (TNF-a, IL-6, and IL-1 $\beta$ ) levels were assessed in hippocampus and cortex tissues (Fig. 1).

\subsubsection{Experimental study}

According to pilot study in this study, it was proven that a dose of $50 \mathrm{mg}$ of BPA has toxic effects, which this dose was used to continue working. In the experimental study, animals were randomly divided into 8 groups (8 rats in each group), including (1) sesame oil (control 1 group, vehicle of BPA) (Sea), (2) dextrose 5\% (control 2 group) (Dex), (3) Sea + Dex (control 3 group), (4) NmCur (50 mg/kg), (5) BPA (50 $\mathrm{mg} / \mathrm{kg}$ ), and (6, 7, and 8) $50 \mathrm{mg} / \mathrm{kg}$ BPA plus 10, 25, or $50 \mathrm{mg} / \mathrm{kg} \mathrm{NmCur,} \mathrm{respectively.} \mathrm{BPA} \mathrm{and} \mathrm{NmCur}$ were dissolved in Sea and Dex, respectively. The BPA and NmCur administered via gavage once a day, 7 times per week, for 4 weeks. BPA was administrated an hour following NmCur administration. At the end of 4 weeks' treatment, the hippocampus and cortex tissues were removed and used for determination of ROS level, MDA concentration, GSH content, and pro-inflammatory cytokines, as well as expression of phosphorus types of p38, JNK, AKT, ERK1/2, NMDA, AMPA, BDNF, and CREB proteins. Also, biochemical analysis of SOD, CAT, GST, GR, and GPx enzymatic activities were evaluated in these tissues (Fig. 2).

\subsection{Biochemical assays}

\subsubsection{Measurement of ROS concentration in the hippocampus and cortex tissues}

The determination of the ROS level was done according to Muhammad et al. (2017) [102] method, but with a slight change on the operation. This method of measuring ROS was mainly based on the 
generation of 2'7' dichlorofluorescein (DCF) from the oxidation of 2'7'-dichlorodihydrofluorescein diacetate (DCFH-DA). Briefly, each of the homogenized tissues was separately diluted with a ratio of 1:20 in ice-cold Lock's buffer, until the final concentration of each tissue was adjusted to $2.5 \mathrm{mg}$ tissue $/ 500 \mu$. The reaction mixture contained $1 \mathrm{ml}$ the Lock's buffer mixture with $\mathrm{pH} 7.4,0.2 \mathrm{~mL}$ homogenates from hippocampal or cortical tissue, and $10 \mathrm{~mL}$ DCFH-DA ( $5 \mathrm{mM})$. Then, the mixture was covered and incubated for $15 \mathrm{~min}$ at room temperature to the formation of form fluorescent DCF from DCFH-DA, which was assessed through a microplate reader at an excitation of $484 \mathrm{~nm}$ and an emission of $530 \mathrm{~nm}$. Initially, in the absence of homogenate, a blank parallel was used to calculation of DCF formation, as background fluorescence. Results of ROS levels were expressed as DCF formed (pmol)/min/amount of protein $(\mathrm{mg})$ in each of the homogenized tissues.

\subsubsection{Measurement of MDA concentration in the hippocampus and cortex tissues}

The Fernandez et al. (1997) method was used to measure the MDA concentration [15]. In summary, after 4 weeks, the different regions of the brain mentioned above were separated and cleaned in normal saline solution. The MDA concentration, as lipid peroxidation index and an indicator of oxidative stress, was evaluated. Each of the different sections of brain was separately homogenized (POLYTRON-PT 10-35, Kinematica, Switzerland) for 2 min at $4^{\circ} \mathrm{C}$ in $1.15 \%$ potassium chloride $(\mathrm{KCl})$ for making a $10 \%$ homogenate. After that, $500 \mu \mathrm{L}$ of each sample was added to $3 \mathrm{ml}$ phosphoric acid (1\%) and $1 \mathrm{ml} \mathrm{TBA}$ $(6 \%)$ and then heated in a boiling water bath for $45 \mathrm{~min}$. Reaction of MDA with TBA creates a pink color. The pink color complex is measured spectrophotometrically at $532 \mathrm{~nm}$, which showed equivalent to the concentration of MDA in sample.

\subsubsection{Measurement of GSH content in the hippocampus and cortex tissues}

The GSH content were evaluated by the Moron et al. (1979) method [16]. Briefly, after 4 weeks of treatment, different sections of the brain listed above were removed and cleaned in normal saline solution. These sections were homogenized to provide $10 \%$ homogenate in ice-cold PBS with $\mathrm{pH} 7.4$. Then, $1300 \mu \mathrm{l}$ homogenated tissue plus $300 \mu \mathrm{l} \mathrm{TCA}(10 \% \mathrm{w} / \mathrm{v})$ were vortexed for $1 \mathrm{~min}$ and then centrifuged at $2500 \mathrm{~g}$ for $10 \mathrm{~min}$. Supernatant was separated and added $2 \mathrm{ml} \mathrm{PBS}$ with pH 8.0 and $500 \mu \mathrm{l}$ DTNB. The DTNB created a yellow-colored TNB, because of mixing with sulfhydryl group of GSH. After 10 min, mixed compounds were transferred to glass test tube and the absorbance was read at $412 \mathrm{~nm}$ by a spectrophotometer (Jenway 6105 UV/VIS, UK).

\subsubsection{Measurement of TNF- $\bigotimes$, IL-6, and IL-1 $\beta$ concentrations in the hippocampus and cortex tissues}

Summary, the hippocampal and cortical tissues were homogenized by ultrasound and then centrifuged at $2000 \mathrm{~g}$ at $4^{\circ} \mathrm{C}$ for $10 \mathrm{~min}$. The TNF- $\alpha$, IL-6, and II- $1 \beta$ levels in the supernatants were determined by ELISA kits (R\&D Systems, Minneapolis, MN, USA) in accordance with the manufacturer's guidelines [103]. 


\subsubsection{Determination of SOD enzyme activity in the hippocampus and cortex tissues}

The SOD activity was assessed via the method of Kakkar et al. (1984) [104]. In summary, tissues were homogenized in 20 volumes of ice-cold $10 \mathrm{mM}$ PBS with pH 8.0 and centrifuged at $10.000 \mathrm{~g}$ for 10 min at $4^{\circ} \mathrm{C}$. After that, supernatants were separated and added to $0.4 \mathrm{mM}$ Xanthine, $0.24 \mathrm{mM}$ nitroblue tetrazolium, and $0.049 \mathrm{U} / \mathrm{mL}$ xanthine oxidase and then incubated for $20 \mathrm{~min}$ at $37^{\circ} \mathrm{C}$. The reaction was stopped by adding $69 \mathrm{mM}$ sodium dodecyl sulfate. Absorbance was measured at $560 \mathrm{~nm}$. The SOD enzyme activity is expressed as unit/mg protein, so that one unit of SOD activity is described as the amount of enzyme that led to $\% 50$ inhibition of nitro bluetetrazolium (NBT) reduction.

\subsubsection{Determination of GST enzyme activity in the hippocampus and cortex tissues}

The GST activity was determined through the method of Lowry et al. (1951) [105]. In briefly, the reaction mixture was consisting of $2.75 \mathrm{ml}$ PBS (0.1 M, pH 6.5), $0.1 \mathrm{ml} \mathrm{GSH}(1.0 \mathrm{mM}), 0.05 \mathrm{ml}$ CDNB (1.0 mM), and $0.1 \mathrm{ml}$ renal PMS $(10 \% \mathrm{w} / \mathrm{v})$ in a total volume of $3.0 \mathrm{ml}$. At the end, the absorbance was read at 340 $\mathrm{nm}$ and enzyme activity assessed as nmol CDNB conjugate formed $/ \mathrm{min} / \mathrm{mg}$ protein using a molar extinction coefficient of $9.6 \times 10^{3} / \mathrm{Mcm}$.

\subsubsection{Determination of CAT enzyme activity in the hippocampus and cortex tissues}

The CAT activity was evaluated by the modified method of Aebi (1984) [106] and Kawamura et al. (1994) [107]. In summary, tissues were homogenized with 20 volumes of ice-cold RIPA buffer (0.1 M PBS with pH 7.4 containing of $5 \mathrm{mM}$ EDTA, $0.01 \%$ digitonin, and $0.25 \%$ sodium cholate) and centrifuged at $10,000 \mathrm{~g}$ for 30 min at $4^{\circ} \mathrm{C}$. A phosphate buffer $(50 \mathrm{mM}$ with pH 7.0 containing of EDTA ( $5 \mathrm{mM})$ and $\mathrm{H}_{2} \mathrm{O}_{2}(10 \mathrm{mM})$ pre-incubated for $10 \mathrm{~min}$ at $37^{\circ} \mathrm{C}$ ) was added to the supernatant and the decomposition of $\mathrm{H}_{2} \mathrm{O}_{2}$ directly assayed by measuring the decrease in absorbance at $240 \mathrm{~nm}$ for $2 \mathrm{~min}$. The CAT (Wako Chemical Co.) from bovine liver was used as a standard. Change in the absorbance of 0.01 as unit/min was defined as one unit of CAT.

\subsubsection{Determination of GPx enzyme activity in the hippocampus and cortex tissues}

The GPx activity was estimated according to the technique of Kabuto et al. (2003) [108]. In summary, the tissues were first washed with a cold isotonic normal saline solution. The reaction mixture was consisting of $1.44 \mathrm{ml}$ potassium phosphate buffer $(0.1 \mathrm{M}, \mathrm{pH} 7.4), 0.1 \mathrm{ml}$ EDTA $(0.5 \mathrm{mM}), 0.1 \mathrm{ml}$ sodium azide $\left(\mathrm{NaN}_{3}\right)(1.0 \mathrm{mM}), 0.05 \mathrm{ml} \mathrm{GPx}(1.0 \mathrm{EU} / \mathrm{ml}), 0.1 \mathrm{ml} \mathrm{GSH}(1.0 \mathrm{mM}), 0.1 \mathrm{ml} \mathrm{NADPH}(0.1 \mathrm{mM}), 0.1 \mathrm{ml} \mathrm{H} \mathrm{O}_{2}$ $(0.019 \mathrm{M})$, and $0.025 \mathrm{ml}$ renal PMS $(10 \% \mathrm{w} / \mathrm{v})$ in a total volume of $2.0 \mathrm{ml}$. All stages were done at $22-25$ ${ }^{\circ} \mathrm{C}$. Finally, the absorbance at $340 \mathrm{~nm}$ was registered above a period of $5 \mathrm{~min}$. The enzyme activity was 

$\times 10^{3} / \mathrm{Mcm}$.

\subsubsection{Determination of GR enzyme activity in the hippocampus and cortex tissues}

The GR activity was evaluated through the method of Carlberg and Mannervik (1985) [109]. In first, the reaction mixture was consisting of $1.7 \mathrm{ml}$ sodium phosphate buffer $(0.1 \mathrm{M}, \mathrm{pH} 7.6), 0.1 \mathrm{ml}$ EDTA (0.5 $\mathrm{mM}), 0.05 \mathrm{ml}$ oxidized glutathione $(1 \mathrm{mM}), 0.1 \mathrm{ml}$ NADPH $(0.1 \mathrm{mM})$, and $0.05 \mathrm{ml}$ renal PMS (10\% w/v) in a complete capacity of $2.0 \mathrm{ml}$. Enzyme activity was determined by measuring the vanishing of NADPH at $340 \mathrm{~nm}$ via spectrophotometer (model 4001/4) and assessed as nmol NADPH oxidized/min/mg protein using molar extinction coefficient of $6.22 \times 10^{3} / \mathrm{Mcm}$.

\subsection{Behavioral studies}

In this study, the effect of BPA on spatial and fear learning and memory evaluated in Morris water maze (MWM) test and passive avoidance training test (PAT) or shuttle-box test, respectively. In addition, its effect on locomotor activity was assessed in the free exploration open-field test.

\subsubsection{Morris water maze (MVM) test}

This test is used to examine the spatial learning and memory. The MWM analysis was described and performed according to Vahdati Hassani et al. (2020) with a few modifications. This apparatus is contained of a circular pool, made of black metal sheets, at a size of $136 \times 60 \mathrm{~cm}$ (diameter circle $\times$ height), which was divided into four equal quadrants and labeled north (N), south (S), east (E), and west (W). In addition, it was filled with water $\left(22 \pm 1^{\circ} \mathrm{C}\right)$ to a depth of $25 \mathrm{~cm}$. A black Plexiglas platform with a diameter of $13 \mathrm{~cm}$ is installed $2 \mathrm{~cm}$ below the water level in the center of one of the quadrants. Some fixed visual cues that can be seen by rat were hung on the walls around the device. The testing room was dimmed and the room temperature was completely controlled and kept at $22 \pm 1^{\circ} \mathrm{C}$. A computerconnected video camera was installed on top of the device to scout the position and analyze the collected data of each rat [4].

\subsubsection{Acquisition test}

During the training trials period (day 24-28), in the acquisition test protocol, each rat performed four tests per block per day for five consecutive days. Rats were let to swim for $60 \mathrm{sec}$ to discover the hidden escape platform and after finding the platform, rats were stayed on it for $15 \mathrm{sec}$; if a rat could not detect the platform for $60 \mathrm{sec}$, it was manually located on the platform for $15 \mathrm{sec}$. This $15 \mathrm{sec}$ of resting time is to identify the environment. After the end of each test, the rat was dried with towel, returned to its holding cage, and immediately placed back to the colony room. The escape latency (sec) to detect the hidden platform, the escape pathlength or the total swimming distance (cm, distance traveled to the hidden 
platform, as the basic motor function), and the swim speed (cm/sec) were automatically recorded by the mounted video camera on top of the device [4].

\subsubsection{Probe test}

On the twenty-ninth day of treatment (the sixth day of the test or $24 \mathrm{~h}$ after the last training test), the probe test comprising of four trials per block was done. After removing the hidden platform, the rat performed to only one search trial for $60 \mathrm{sec}$ to assess the spatial memory. The starting position for each rat was such that the rat was accidentally immersed in the water, toward the wall, in the center of one of the non-platform quadrants. The total time spent for detecting the hidden platform, as the escape latency, was recorded that was inversely related to spatial learning and memory ability. The travelled distance during the probe test was also automatically recorded by the video-camera tracking software connected to a computer (Noldus EthoVision XT, Noldus Information Technology, Wageningen, Netherlands) [4]. All experimental tests were carried out in 8:00 and 16:00 to remove confounding due to time-difference effects. The number of rats was 8 for each group.

\subsubsection{Passive avoidance training test (PAT)}

Two days after the MVM test, the PAT was performed. Generally, the PAT evaluates two (step-down and step-through) avoidance behaviors. The PAT, which performs with the shuttle-box apparatus, is used to measure fear learning and memory in animal models of neurological disturbances to elude from a plaguesome excitation, such as a foot-shock. The PAT protocol used in this study was slightly modified according to Taherian et al. (2021) method [110]. In summary, this apparatus forms a box containing two equal separate compartments (a dark and a light chambers) that made of transparent acrylic resin epoxy plexiglass sheet panels in the size of $20 \mathrm{~cm} \times 20 \mathrm{~cm} \times 30 \mathrm{~cm}$ (length $\times$ width $\times$ height). These boxes are connected through a sliding (guillotine) door in the size of $7 \mathrm{~cm} \times 9 \mathrm{~cm}$ that can be raised up to $10 \mathrm{~cm}$. A parallel stainless steel grid, at a size of $2.5 \mathrm{~mm}$ diameter and $1 \mathrm{~cm}$ intervals, connected to a shock simulator, which can produce the electrical signals and transmit to grid, located in the floor of the dark chamber. This test has three steps, including habituation, training (acquisition trial), and retention stages.

\subsubsection{Habituation phase}

In the first step, in the day 31, the rat for habituate with the device was gently placed in the light chamber and following that a 10-second delay, the sliding door was raised. The rat was let to enter the dark chamber and stayed in the experimental rooms for $10 \mathrm{~min}$. After $10 \mathrm{~min}$, the rat was immediately comeback to its home cage. Then, 30 min after the first stage of the habituation, another habituation test was performed according to the first stage and finally the rat was immediately returned to its home cage. Rats that waited for more than $120 \mathrm{~s}$ to introduce into the dark box were excluded from this test.

\subsubsection{Training phase (acquisition trial)}

This step was conducted 30 min after from the second habituation trial. The procedure is as follows that rat was slowly placed in the light chamber and the middle guillotine lid was opened. The rat tends to enter 
the dark chamber depending on its innate desire. After the rat completely entered the dark chamber (four paws in) (exploration time), the middle guillotine lid was closed. Next, a single electric current (intensity: 1 mA; frequency: $50 \mathrm{~Hz}$; duration: $3 \mathrm{sec}$ ) (Borj Sanat Co., Tehran, Iran) was instantly imposed via an electrical generating apparatus to the steel grids of the dark chamber floor to induce shock to the rat's foot. Twenty seconds after foot shock, the rat was removed from the apparatus, placed back to its home cage, and immediately returned to the colony room. The maximum training phase for each rat was three times.

\subsubsection{Retention (retrieval) test}

The last stage or the memory retention phase was done $24 \mathrm{~h}$ after training procedure (on the thirty-two day), but the electrical shock was not delivered to the rats' foot. After placing the rat in the light box, the door was opened with a 10-second delay. Then, the interval time between rat movement behavior from light box to the dark box, which known as the step-through latency (STL) or the time latency, was recorded as an inhibitory avoidance memory. The cut-off time of this step for STL measurement for all animals that stayed in the light chamber was $300 \mathrm{sec}$ or this test was ended when the rat entered to the dark box. Each rat separately performed all the behavioral steps in the same sequential order and all steps were manually carried out between 8:00 a.m. to 2:00 p.m. to remove confounding due to the negative impact of time differences. The number of rats in each group was 8 . All trials were digitally recorded by a camera, which located directly above the device. The camera was connected to a computer that automatically analyzed all events (Noldus EthoVision XT, Noldus Information Technology, Wageningen, Netherlands). The boxes were cleaned with a moistened sponge with $100 \%$ ethanol and then dried with a clean towel to remove odors of the previous rat after behavioral testing each animal.

\subsubsection{Open-field test}

The open-field test, as a free-exploration apparatus, is performed to evaluate behavioral functions, e.g. locomotor activity, hyperactivity, and stereotypical and exploratory behaviors. In this study, the experiment was carried out to further evaluate the rat's motor function with or without BPA treatment. The test was performed according to the method of Taherian et al. (2021) [110], but with a few changes. Briefly, the open-field device was prepared from white wood at a size of $45 \mathrm{~cm} \times 45 \mathrm{~cm} \times 45 \mathrm{~cm}$ (length $\times$ width $\times$ height). Each rat was located in the center of the cage and for three consecutive days, each rat was let to explore the environment for $10 \mathrm{~min}$ for adapting to the environment before the main test day. On the day 35 , all rats were only tested once for $5 \mathrm{~min}$ in the device. The rat's locomotor activity was evaluated by evaluating the number of peripheral (those adjacent to the walls), central, and total square crossings via a digital camera for 5 min and next, assessed by EthoVision 8.5. In fact, the three measures were referred to as peripheral $(\mathrm{PL})$, central $(\mathrm{CL})$, and total $(\mathrm{TL})$ locomotor activity, respectively. All behavioral tests were manually tested between 8:00 a.m. to 2:00 p.m. After behavioral trial each animal, the open-field apparatus was cleaned via a moistened sponge with $100 \%$ ethanol and then dried with a clean towel to remove odors of the previous rat. 
The rats could not see the investigator or experimenter during the all conducted behavioral tests and all data analysis were also performed using a trained observer, which blind to experimental groups.

\subsection{Western blot analysis in the hippocampus and cortex tissues}

Western blot assays of phosphorylation types of protein Kinase B (AKT), extracellular signal-regulated protein kinases 1 and 2 (ERK), p38-mitogen-activated protein kinase (P38), c-jun NH2 terminal kinases (JNK), N-Methyl-D-aspartic acid or N-Methyl-D-aspartate (NMDA; subunits of NR1, NR2A, and NR2B), aamino-3-hydroxy-5-methyl-4-isoxazolepropionic acid (AMPA; subunit of GluA1), and cAMP-response element binding protein (CREB), and non-phosphorylation type of brain-derived neurotrophic factor (BDNF) were carried out on protein extracts from hippocampus and cortex tissues. About $200 \mathrm{mg}$ of tissue samples were homogenized in homogenization buffer containing of $50 \mathrm{mM}$ Tris-HCL (pH 7.4), 2 mM EDTA, 2 mM EGTA, 10 mM NaF, 1 mM sodium orthovanadate (Na3VO4), 10 mM $\beta$-glycerolphosphate, $0.2 \% \mathrm{~W} / \mathrm{V}$ sodium deoxycholate, $1 \mathrm{mM}$ phenylmethylsulfonyl fluoride (PMSF), and protease inhibitor cocktail (1\% protease and phosphatase inhibitor cocktail) (Sigma, P8340) in ice and then centrifuged at $10,000 \mathrm{~g}$ for $10 \mathrm{~min}$ at $4^{\circ} \mathrm{C}[27,14]$. The total protein content was measured from supernatant using the Bradford protein assay kit (Bio-Rad). Briefly, same amounts of proteins in supernatants $(50 \mu \mathrm{g})$ were separated by $12 \%$ SDS-polyacrylamide gel (SDS-PAGE gel), transferred to polyvinylidene difluoride (PVDF) membranes (Millipore), and blocked with $5 \%$ skim milk or \% 1 BSA in Trisbuffered saline Tween 20 (TBS-Tween 20 or TBST) for $2 \mathrm{~h}$ at $37^{\circ} \mathrm{C}$ (room temperature) to inhibit binding of non-specific proteins. Then, the PVDF membranes were incubated at $37^{\circ} \mathrm{C}$ for 120 min with primary rabbit monoclonal antibodies from Cell Signaling Technology (Beverly, MA, USA) including anti-p-P38 MAPK (\#4061), anti-p-JNK (\#9255), anti-p-ERK1/2 (\#9106), anti-p-AKT (\#9271), anti-p-NMDA NR1 (\#3381), anti-p-NMDA NR2A (\#4206), anti-p-NMDA NR2B (\#4208), anti-p-AMPA (\#8084), anti-p-CREB (\#9196), and anti-BDNF (\#47808) at a concentration of 1:1000 in TBST. The PVDF membranes were washed $(3 \times 5$ min in TBST) and incubated with the secondary antibodies (anti-rabbit lgG) conjugated with horseradish peroxidase enzyme (HRP) (\#7074) at a concentration of 1:3000 in TBST at $37^{\circ} \mathrm{C}$ for 90 min with mild vibration. Next, the PVDF membranes were washed ( $3 \times 5$ min in TBST). Finally, the enhanced chemiluminescence (ECL) reagent (Pierce ECL Western Blotting Substrate) and Alliance 4.7 Gel Doc (UK) were used to visualize the protein bands. The intensity of bands was analyzed using UVtec software (UK). The levels of all proteins were normalized against beta-actin (\#4967) protein levels [14].

\subsection{Statistical analysis}

All data were expressed as the mean \pm standard deviation (SD). The statistical analysis was done by Oneway and two-way Analysis of Variance (ANOVA) followed by Tukey-Kramer test or post hoc test using SPSS version 16.0 software and/or GraphPad Prism version 6.00 for Windows, GraphPad Software, La Jolla California USA. $\mathrm{P}<0.05$ was statistically regarded significant.

\section{Results}




\subsection{Effect of BPA on ROS content in different sections of rat brain tissue}

Our results showed that treatment with BPA at a dose of $50 \mathrm{mg} / \mathrm{kg}$ meaningfully increased ROS generation in the hippocampus and cortex tissues in comparison to control group $(P<0.001)$ (Fig. 3$)$.

\subsection{Effect of BPA on MDA and GSH levels in different sections of rat brain tissue}

Figure 4 showed that, there is an important enlargement in level of MDA at a dose of $50 \mathrm{mg} / \mathrm{kg}$ BPA group $(P<0.001)$ in the hippocampus tissue and a significantly increase in MDA level at doses of $25(P<$ $0.05)$ and $50(P<0.001) \mathrm{mg} / \mathrm{kg}$ BPA group in the cortex tissue compared to the control group. Moreover, in the hippocampus and cortex tissues, an important decrease observed in level of GSH in high dose of BPA $(50 \mathrm{mg} / \mathrm{kg})$ group in comparison to the control group $(\mathrm{P}<0.001)$.

\subsection{Effect of BPA on pro-inflammatory cytokines in different sections of rat brain tissue}

In the pilot test, it has found that BPA significantly elevated pro-inflammatory cytokines expression, including TNF-a (25 and $50 \mathrm{mg} / \mathrm{kg})(\mathrm{P}<0.05$ and $\mathrm{P}<0.001)$, IL-6 $(50 \mathrm{mg} / \mathrm{kg})(\mathrm{P}<0.001)$, and IL-1 $\beta(25$ and $50 \mathrm{mg} / \mathrm{kg})(P<0.01$ and $P<0.001)$ levels in the hippocampus tissue in comparison to control group. In addition, TNF-a $(50 \mathrm{mg} / \mathrm{kg})(\mathrm{P}<0.001)$, IL-6 (25 and $50 \mathrm{mg} / \mathrm{kg})(\mathrm{P}<0.01$ and $\mathrm{P}<0.001)$, and IL-1 $\beta$ (50 $\mathrm{mg} / \mathrm{kg})(\mathrm{P}<0.001)$ levels increased in the cortex tissue vs control group (Fig. 5).

\subsection{Effect of BPA and NmCur on ROS content in different sections of rat brain tissue}

The in vivo results confirmed that administration of BPA $(50 \mathrm{mg} / \mathrm{kg})$ important enlarged generation of ROS in the hippocampus and cortex tissues than control groups $(P<0.001)$. While NmCur considerably ameliorated ROS generation in both the hippocampus $(25$ and $50 \mathrm{mg} / \mathrm{kg})(P<0.05$ and $P<0.001)$ and cortex $(50 \mathrm{mg} / \mathrm{kg})(\mathrm{P}<0.001)$ tissues, when used with BPA at a dose of $50 \mathrm{mg} / \mathrm{kg}$ for 4 weeks compared to BPA (50 mg/kg) group (Fig. 6).

\subsection{Effect of BPA and NmCur on MDA and GSH parameters in different sections of rat brain tissue}

As shown on Fig. 7, there is a significant increase in MDA concentration $(P<0.001)$ and an important decrease in GSH content $(P<0.001)$ in the BPA $(50 \mathrm{mg} / \mathrm{kg})$ group in different part of rat brain (hippocampus and cortex tissues) in comparison to control groups. In addition, a significant decrease in MDA concentration and an important increase in GSH content were observed at groups that received 25 and $50 \mathrm{mg} / \mathrm{kg} \mathrm{NmCur} \mathrm{plus} \mathrm{BPA}(50 \mathrm{mg} / \mathrm{kg})(\mathrm{P}<0.05, \mathrm{P}<0.01$, and $\mathrm{P}<0.001)$ in comparison with BPA (50 $\mathrm{mg} / \mathrm{kg}$ ) group in both tissues. 


\subsection{Effect of BPA and NmCur on pro-inflammatory cytokines in different sections of rat brain tissue}

Our other results presented that, in the hippocampus and cortex tissues, BPA significantly increased expression of pro-inflammatory cytokines, such as TNF-a, IL-6, and IL-1 $\beta$ levels than control groups ( $<<$ 0.001). Conversely, treatment with BPA (50 mg/kg) plus NmCur (25 and $50 \mathrm{mg} / \mathrm{kg}$ ), especially at a dose of $50 \mathrm{mg} / \mathrm{kg} \mathrm{NmCur}$, significantly reversed the levels of these cytokines when compared with the BPA group $(P<0.05, P<0.01$, and $P<0.001$ ) (Fig. 8).

\subsection{Effect of BPA and NmCur on enzyme activities in different sections of rat brain tissue}

Another result of this study displayed that BPA at a dose of $50 \mathrm{mg} / \mathrm{kg}$ was significantly increased the mean of SOD ( $P \otimes 0.01$ and $P \otimes 0.001)$ and GST (P凶0.001) enzyme activities. While considerably diminished the mean of $\mathrm{GPx}(\mathrm{P} \otimes 0.001), \mathrm{GR}(\mathrm{P} \otimes 0.001$ and $P \otimes 0.01)$, and CAT $(\mathrm{P} \otimes 0.001)$ enzyme activities compared to control groups in hippocampus and cortex tissues. Co-therapy of BPA (50 mg/kg) and NmCur (50 mg/kg) also induced a significant reduce in the mean of SOD (P $\nabla 0.01)$ and GST (P $\nabla$ 0.05) enzyme activities, whereas an important increase observed in the mean of GPx (P $\otimes 0.001), G R(P \otimes$ 0.05), and CAT ( $P \otimes 0.01$ ) enzyme activities in the hippocampus tissue. In addition, the activity of enzymes in the tissue of cortex showed that co-administration of BPA (50 mg/kg) and NmCur at doses of

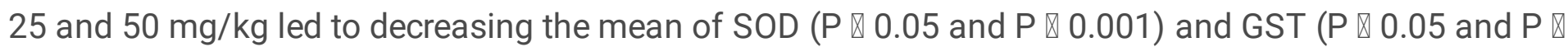
0.01 ) enzyme activities, while increasing the mean of CAT ( $P \otimes 0.05$ and $P \otimes 0.01$ ) enzyme activity in comparison with BPA group, as well as $50 \mathrm{mg} / \mathrm{kg}$ BPA plus $50 \mathrm{mg} / \mathrm{kg}$ NmCur enlarged the mean of GPx $(P \otimes 0.01)$ and $G R(P \otimes 0.01)$ enzyme activities than BPA group (Fig. 9).

\subsection{Effect of BPA and NmCur on rat behavioral performance}

\subsubsection{Effect of BPA and NmCur on passive avoidance learning and memory in rat: Shuttle-box test}

Based on data from the shuttle-box test shows that BPA (50 mg/kg) markedly diminished step through latency $(S T L)$ than control groups $(P<0.001)$. Nevertheless, combination therapy of BPA $(50 \mathrm{mg} / \mathrm{kg})$ and NmCur (25 and $50 \mathrm{mg} / \mathrm{kg}$ ) significantly increased STL and enlarged fear learning and memory compared to BPA $(50 \mathrm{mg} / \mathrm{kg})$ group $(\mathrm{P}<0.05, \mathrm{~F}(7,56)=7.802$, and $\mathrm{P}<0.001)$ (Fig. 10).

\subsubsection{Effect of BPA and NmCur on locomotor activity in rat: Open-field test}

As shown in Fig. 11, BPA at a dose of $50 \mathrm{mg} / \mathrm{kg}$ significantly displayed a reduction of the peripheral (A) and total (C) locomotor activity, however, an increase of the central (B) locomotor activity than control groups $(P<0.001)$. In addition, the co-therapy of BPA $(50 \mathrm{mg} / \mathrm{kg})$ and NmCur $(25$ and $50 \mathrm{mg} / \mathrm{kg})$ 
considerably improved peripheral (A), central (B), and total (C) locomotor activity in comparison to BPA group $(50 \mathrm{mg} / \mathrm{kg})(P<0.05, P<0.01, F(7,56)=34.17(A), 15.11(B), 8.377(C)$, and $P<0.001)$.

\subsubsection{Effect of BPA and NmCur on memory dysfunctions in rat: Morris water maze (MVM) test}

The supplementary test of MWM was performed to confirm the results of the shuttle box test on BPAinduced learning and memory impairments. Administration of $50 \mathrm{mg} / \mathrm{kg}$ BPA noticeably elevated escape latency (the time to find the hidden platform) in training trial (Fig. 12A), while significantly declined the time spent in the target quadrant in probe trial (Fig. 12B). Data analysis demonstrated that BPA treatment $(50 \mathrm{mg} / \mathrm{kg}) \times$ training days significantly also changed the average of escape latency time (sec) than control groups (Fig. 12A) (on day 3, BPA $65.23 \pm 5.47 \mathrm{sec}$, control, $44.67 \pm 6.01 \mathrm{sec}$; on day 4, BPA $57.31 \pm$ $5.47 \mathrm{sec}$, control, $42.19 \pm 7.62 \mathrm{sec}$; on day 5 , BPA $49.07 \pm 7.15 \mathrm{sec}$, control, $36.63 \pm 7.48 \mathrm{sec}$, respectively). In addition, the travelled distance in the target quadrant $(\mathrm{cm})$ was significantly increased interactions of BPA administration $\times$ training days compared to control groups on the all days' acquisition trial (Fig. 12C) (on day 1 , BPA, $940.14 \pm 78.25 \mathrm{~cm}$, control, $512.48 \pm 96.48 \mathrm{~cm}$; on day 5 , BPA $560.19 \pm 46.60 \mathrm{~cm}$, control, $210.36 \pm 52.60 \mathrm{~cm})$. Exposure with BPA $(50 \mathrm{mg} / \mathrm{kg}$ ) was also noticeably lessened the time spent in the target quadrant (sec) (Fig. 12B) (BPA, $14.69 \pm 4.17 \mathrm{sec}$, control, $29.61 \pm 5.67 \mathrm{sec}$ ) and the travelled distance in the target quadrant (cm) (Fig. 12D) (BPA, $224 \pm 15.0 \mathrm{~cm}$, control, $460 \pm 18.0 \mathrm{~cm}$ ) when in comparison to control groups. The escape latency time (sec) in co-therapy of BPA (50 mg/kg) and NmCur ( 25 and $50 \mathrm{mg} / \mathrm{kg}$ ) $\times$ training days during final 3 days of acquisition trial was decreased compared to BPA group (Fig. 12A). Moreover, the travelled distance $(\mathrm{cm})$ in simultaneous treatment of BPA $(50 \mathrm{mg} / \mathrm{kg})$ and NmCur at dose of $50 \mathrm{mg} / \mathrm{kg}$ and doses of 25 and $50 \mathrm{mg} / \mathrm{kg} \times$ training days during on 1 day and final 4 days of acquisition trial, respectively was declined when in comparison to BPA group (Fig. 12C). Coadministration of BPA (50 mg/kg) and NmCur at doses of 25 and $50 \mathrm{mg} / \mathrm{kg}$ markedly increased the time (sec) spent and the travelled distance $(\mathrm{cm})$ in the target quadrant during the probe trial than BPA group (Fig. 12B and Fig. 12D). In addition, there was no important difference of swimming speed among all groups in the MWM test during all days (5 days) of training and probe trial (Fig. 12E and Fig. 12F).

\subsection{Effect of BPA and NmCur on the different types of proteins in rat hippocampus and cortex tissues: Western blot analysis}

As shown in Fig. 13, BPA at a dose of $50 \mathrm{mg} / \mathrm{kg}$ exhibited lower expression of p-AKT and p-ERK1/2 proteins, however, it displayed higher expression of p-P38 and p-JNK proteins than the control (Dex + Sea) and NmCur (50 mg/kg) groups. Co-administration of BPA and NmCur at a dose of $50 \mathrm{mg} / \mathrm{kg}$ significantly enlarged proteins expression of $\mathrm{p}-\mathrm{AKT}$ and $\mathrm{p}$-ERK1/2, whereas decreased proteins expression of p-P38 and p-JNK in comparison with BPA group in different regions of rat brain tissue (Fig. 13). In addition, administration of NmCur alone ( $50 \mathrm{mg} / \mathrm{kg}$ ) and BPA alone $(50 \mathrm{mg} / \mathrm{kg}$ ) than control (Dex + Sea) group increased and reduced, respectively, expression of a variety of glutamate receptors, including NMDA (NR1, NR2A, and NR2B) and AMPA (GluA1) (Fig. 14), and memory-related proteins, such as BDNF and CREB proteins (Fig. 15), in the rat hippocampus and cortex tissues. Moreover, treatment of BPA alone (50 
$\mathrm{mg} / \mathrm{kg}$ ) in comparison to NmCur (50 $\mathrm{mg} / \mathrm{kg}$ ) group led to an important reduction in the expression of all the proteins listed above. Nevertheless, administration of BPA (50 mg/ $\mathrm{kg}$ ) and NmCur (50 mg/kg) than BPA (50 $\mathrm{mg} / \mathrm{kg})$ group resulted in a significant upregulation in the expression of all the proteins listed above (Figs. 14 and 15).

A summary of the results obtained in this study is shown in Fig. 16.

\section{Discussion}

Synapses, as major modulatory system, in the hippocampus regulate normal learning and memory processes, especially spatial cognitive functions [111]. In fact, A cognitive process that encodes, reserves, and reminds the received data is memory [112]. Memory as a three-step process, including acquire, integrate, and retrieve information considers, which acts a major task in learning and relationship with the surrounding environment. Memory impairment can be induced by different factors, including stressful conditions [113,114], some drugs (such as anticonvulsants and sedative agents) [115], improper lifestyle, for instance, high alcohol consumption [116], low physical activity [117], and high fat diet [118], and some environmental toxins, e.g. BPA. BPA accumulates into the mitochondrial membrane and disrupts the cellular respiration cycle that led to an overexpression of ROS and mitochondrial apoptotic signaling pathway [119], especially in the heart, liver, kidney, and brain $[52,46,120,14]$. In the hippocampus and cortex areas, the BPA-induced ROS motivates MDA production, which effects on the neuronal integrity and function, resulting in inducing learning and memory impairment [121]. It also is noteworthy that chronic systemic inflammation and/or prolonged neuro-inflammatory responses can result in endothelial destruction in BBB area, an increase of penetration of peripheral monocytes into the perivascular spaces [122], a stimulation of microglia cells, an impairment of synaptic and neuronal plasticity, and inducement of neural apoptosis and memory impairments $[123,51]$. As previously mentioned, BPA by reducing of ROS-scavenging enzymes and antioxidant levels through disturbance of redox status between quinone and hydroquinone/catechol forms of BPA induced neurotoxicity in the rat striatum and other nervous tissues [104-106].

Accordingly, in this study, the effective toxic dose of BPA pursuant to the pilot study, a dose of $50 \mathrm{mg} / \mathrm{kg}$, was determined. Our experimental data confirmed that oral administration of BPA at a dose of $50 \mathrm{mg} / \mathrm{kg}$ for 4 weeks significantly increased ROS and MDA levels, however noticeably moderated GSH content compared to control groups in rat hippocampus and cortex tissues. In line with our work, in another study, Khadrawy et al. (2016) was proved that the administration of 10 and $25 \mathrm{mg} / \mathrm{kg}$ BPA for $6-10$ weeks was important increased MDA concentration and NO level, whereas decreased GSH content in the hippocampus and cortex of adult male albino rats in a dose- and time-dependent manner [107]. In our previous study, similar results were also obtained for heart tissue [14]. Our other results showed that BPA significantly induced levels of SOD, GST, TNF-a, IL-6, and IL-1 $\beta$, while considerably attenuated levels of GPx, GR, and CAT in rat hippocampus and cortex tissues. 
In addition to the stated above, several studies have been cited that NMDA and AMPA receptors are played a role in the formation of excitatory synapses and rapid synaptic transmission between neurons controlling synaptic plasticity and spatial learning and memory formation [124, 125]. Over-stimulating of NMDA receptor can increase calcium influx, which then induces short- or long-term alterations in the hippocampus, e.g. long-term potentiation (LTP) [126]. Moreover, a wide variety of other proteins (BDNF and CREB) $[52,54-56]$ and signaling pathways (MAPKs and AKT) [127] are also involved in these processes. The BDNF, as a member of the neurotrophins group, prompts the MAPK/ERK signaling pathways, neural survival, growth, and differentiation and improves synaptic plasticity and repair mechanisms $[128,129]$. In addition to the BDNF, the CREB, as a translation factor, has a significant effect in neuronal survival [130]. So that these proteins play an important role in regulating learning and memory performance $[131-133,130]$. In the other words, the relationship between these two factors can be expressed as follows: the BDNF activates CREB phosphorylation [134], which helps the transcription of BDNF and its receptor, TrKB $[135,136]$, increases Bcl-2 activity, as an anti-apoptotic protein, which fixes the integrity of the mitochondrial outer membrane, inhibits apoptosis via decreasing levels of BAX and Casp-3, as apoptotic proteins [137], and elevates cellular GSH level [138]. The MAPKs family (ERK-1, ERK2 , JNK, and p38) involved in controlling diverse physiological activities, including stress and inflammation responses and apoptosis. The ERKs is known to regulate transcription factors, such as CREB [139]. In the other words, activated ERKs are translocated into the nucleus and regulated the expression of several genes [140-142], which resulted in the formation and stabilization of long term memory in hippocampus CA1 area $[139,143]$.

The induction of hippocampal neuronal apoptosis and dysfunction of glutamate receptors and learning and memory-related proteins have been confirmed by BPA [52]. According to present study and in accordance with previous studies, western blot analysis displayed that BPA (50 mg/kg) significantly reduced expression of p-AKT and p-ERK1/2, whereas increased expression of p-P38 and p-JNK proteins in the mentioned different regions of rat brain. Moreover, treatment of BPA (50 mg/kg) led to an important reduction in the expression of p-NR1, p-NR2A, p-NR2B, p-GluA1, p-CREB and BDNF. Several studies have proved that exposure with BPA created apoptosis through increasing the activation of MAPK (ERK/JNK/p38) and AKT signaling pathways in rat sertoli cells [127] and HT-22 cells [52]. The administration of BPA also reduced synaptic plasticity and diminished expression of NR1, NR2A, NR2B, GluR1, and ER $\beta$ in male mice and rat hippocampus, leading to impairment of learning and memory [144, $48,57,145]$. The exposure of pregnant female Sprague Dawley rats to a very low dose of BPA $(2.5$ $\mu \mathrm{g} / \mathrm{kg} /$ day) impacted on ER-a phosphorylation in a sex-dependent manner, especially male fetuses [146], resulting in decreasing the BDNF levels [147]. In addition, other studies have shown that BPA treatment significantly decreased BDNF level $[148,149]$. Therefore, it can be stated that inhibition of MAPK/AKT/NMDA/AMPA/CREB/BDNF signaling pathway in the hippocampus lead to the learning and memory impairment [54], which is in accordance with the results of our study.

In fact, it can be claimed that possible mechanisms of BPA-caused learning and memory impairment are related to inhibition of synaptogenesis process, spinal synaptic remodeling, and glutamate receptors expression in the medial prefrontal cortex and hippocampus regions of rodents and primates [150-152]. 
One way to detect these disorders is by evaluating behavioral studies in animals. So that it has been proven that animals, especially mice and rat, mainly in the first minute of entering to a new environment, naturally reveal the highest desire to explore a novel environment. This behavior has been proven in various behavioral tests. Behavioral tests, including passive avoidance test (PAT) (shuttle-box) and Morris water maze (MWM) test are typically used for evaluation of two (step-down and step-through) avoidance behaviors and spatial learning and memory function, respectively. Open-field test also investigate to evaluation of locomotor activity, exploratory habits, and emotional behaviors [32]. Based on the many studies that have been published in this field $[153,154][155]$ and results obtained in our study, it has been proven that BPA treatment $(50 \mathrm{mg} / \mathrm{kg}$ ) markedly attenuated fear learning and memory performances and locomotor activity, which detected through reducing the STL and peripheral and total locomotor activity, respectively. Whereas it enlarged central locomotor activity than control groups. It also noticeably extended the time to finding the hidden platform in training trial, the average of escape latency time (sec), and the travelled distance in the target quadrant $(\mathrm{cm})$ in the all days' acquisition trial, however significantly declined the time spent in the target quadrant (sec) in probe trial when in comparison to control groups. Nevertheless, there was no significant difference in swimming speed among all groups in the MWM test.

Consistent with our results, Jašarević et al. (2013) recently also reported that exposure to BPA (5 and 50 $\mathrm{mg} / \mathrm{kg} /$ day) in perinatal period severely compromised the spatial navigation and exploratory behaviors in male deer mice offspring [155]. In addition, the exposure to BPA disrupted hippocampus-related learning and memory and synaptic plasticity by the decrease of spine density, synaptic plasticity, and NR2A and GluR1 expression in juvenile Sprague-Dawley rats. These disorders were meaningfully identified by reducing memory retrieval to finding the hidden platform through the MWM test [145]. Other studies have also found that treatment of BPA increased spatial memory impairment and latency time related to hippocampus in the MWM test in 3- and 8-week-old mice [48], 2-weeks-young adult mice [153], 4-week-old rats [156], and adult rats [49]. Administration of BPA for 8 weeks was impaired the passive avoidance memory of the male mice between adolescence and young adulthood [47]. BPA treatment considerably diminished neurogenesis, synaptic plasticity, and dendritic spine density of hippocampal CA1 region neurons in little pups and cultured CA1 neurons, as well as adult male Sprague-Dawley rats and the young adult mice, leading to spatial memory impairment. So that, latency time and distance to finding the hidden platform meaningfully enlarged, however, the time spent in target quadrant and platform crossings important decreased, which identified by the MWM method [153, 154]. In another study, longterm exposure of BPA enhanced time spent in the central area (at doses of $0.4,4$, or $40 \mathrm{mg} / \mathrm{kg}$ ) and the traveled distance to finding the hidden platform (at dose of 0.4 or $40 \mathrm{mg} / \mathrm{kg}$ ) for 12 weeks. However, it diminished the step-down latency, synaptic density, and NR1 and GluR1 expression in the male mice hippocampus CA1 region [32]. Furthermore, BPA at a dose of $100 \mu \mathrm{g} / \mathrm{kg}$ for 15 days increased the distance and latency time in discovering the hidden platform, showing reduction of the spatial learning and memory performance, as determined by the MWM test, in adult male Wistar rats [157].

Many natural or synthetic chemical agents that are used to enhance cognitive functions could have more or less side effects or low effectiveness, so the replacement them with other compounds, which 
accompanied with fewer side effects and better efficacy may be a desirable choice. Several antioxidants, owing to cross the BBB, are known for their effectiveness against neuronal cell death and memory disorders correlated with oxidative stress. Many of these substances are natural sources of polyphenolic compounds in plants, vegetables, fruits, green tea, olive oil, red wine, etc. [158, 159]. One of the most important herbal compounds is curcumin that considers as an attractive alternative therapy tool for many neurological diseases [160, 161, 3], including learning and memory deficits [162]. Because it can improve the neurogenesis, neuronal differentiation, neuronal plasticity, and learning and memory performance by numerous possible mechanisms, e.g. the diminishment of oxidative stress, the improvement of mitochondrial performance, the amplification of nitric oxide level, and moderation of acetylcholinesterase enzyme activity [163-165]. So that, it can be affected on different type's memory, such as short and longterm memory, working memory, episodic memory, spatial memory, and fear memory [165].

Hereupon, in accordance with previous studies, it was proved that the most characteristic of curcumin's antioxidant effects related to its phenolic structure, which has electron-capturing effects that can destabilize oxidative stress, ROS, and MDA levels, while increase GSH content $[90,79]$. In another study also observed that curcumin declined oxidative stress in mouse brain and N27 rat dopaminergic neural cell line (1RB3AN27 cell line) in model of Parkinson's disease $[28,166]$. Several other similar studies have conducted that curcumin administration significantly improved GSH content and antioxidant enzyme activities, including SOD, GPx, and CAT, but it declined MDA concentration in rat's kidney treated with gentamicin, cyclosporine, and methotrexate [90-92]. In addition, curcumin administration restored the neurotoxic effect of colistin using increasing the CAT and GSH levels, while decreasing the ROS and MDA concentration in neuroblastoma-2a (N2a) cells [167] and the kidney and brain of adult male albino rats [168]. Moreover, curcumin protects neuronal cell death caused by hemin in the cerebellar granule via the inhibition of ROS production, the improvement of GSH content, and the increase of antioxidant enzymes activity $[169,170]$. Based on, the antioxidant effect of curcumin compared to vitamin $E$ is at least 10 times more activity [171]. In addition, it by lowering inflammatory cytokines (such as TNF-a, IL-1 $\beta$, IL-6, and IL-8, via inhibition of TLR4, NF-kB, and prevention of MAPK (ERK, JNK, and p38) signaling pathway), which are related to several cellular events, including immunity, inflammation, cell survival, and apoptosis, could be led to inhibiting of some diseases, such as Alzheimer's and Parkinson's diseases [83, 84, 75].

As stated in previous studies on the poor performance of free curcumin, based on one of most effective tools to better performance of materials with high adsorption capacities and less conversion to inactive form is using nano-micelles structures $[172,173]$. Some other benefits of using micelle-like structures are included cost-effectiveness of these methods, simple transfer of cargo through biological barriers, better solubility in biological body fluids, controlled release of cargo, protection against hydrolysis or degradation and inactivation of cargo [173]. In addition, nanomicelles owing to their small size through endocytosis can easily passed intestinal cells and transferred their cargo [174]. In this study, for the first time, we established that NmCur at doses of 25 and $50 \mathrm{mg} / \mathrm{kg}$ has the neuroprotective effect in rats exposed to BPA. So that, a significant decrease in ROS, MDA, TNF-a, IL-6, and IL-1 $\beta$ levels and an important increase in GSH content were observed at groups that received 25 and $50 \mathrm{mg} / \mathrm{kg} \mathrm{NmCur}$, especially at a dose of $50 \mathrm{mg} / \mathrm{kg}$ NmCur, plus BPA (50 mg/kg) for 4 weeks in the hippocampus and 
cortex tissues. Co-therapy of BPA (50 mg/kg) and NmCur (at doses of 25 and $50 \mathrm{mg} / \mathrm{kg}$ ) also induced a significant reduce in the mean of SOD and GST enzyme activities, whereas an important increase observed in the mean of GPx, GR, and CAT enzyme activities than BPA group in the hippocampus and cortex tissues. In addition to neuroprotective effect of NmCur on rats that observed in this study, in our previous study has found that NmCur at a dose of $50 \mathrm{mg} / \mathrm{kg}$ significantly attenuated the cardiotoxic effect of BPA by lowering MDA concentration and increasing GSH content in rat heart tissue [14]. In another study has observed that curcumin improved the BPA-induced disturbance of hypothalamus pituitary gonadal hormone by reduction of intracellular nitric oxide radical and MDA levels; however, enlargement of the SOD and CAT antioxidant enzymes [175], which is in agreement with our finding in this study. In addition to the NmCur form, other forms of curcumin about learning and memory impairment were examined. The solid lipid curcumin particle formulation with commercial name of Longvida ${ }^{\circledR}$ can cross from BBB and causes a concentration of 4 times greater than unformulated curcumin [176]. In a study, one randomized, double-blind, placebo-controlled trial study on 60 healthy adults (approximately 60 to 85 years old) revealed that one hour after single-dose exposure of Longvida ${ }^{\circledR}$ (400 mg) important improved the sustained-attention performance and working memory tasks [177]. In a study has also found that nanoformulation of curcumin (15 and $20 \mathrm{mg} / \mathrm{kg} /$ orally) containing bovine serum albumin, as a safe carrier for curcumin, has endothelial transcytosis effects, helps to enter formulation into the cells, decreases passive avoidance memory retrieval deficit induced by pre-test scopolamine (1 mg/kg, i.p.), as the muscarinic receptor antagonist, in male NMRI mice [178].

The evaluation of curcumin's anti-apoptosis action in different studies was observed. For example, curcumin was resulted in the attenuation of apoptosis and inflammatory markers (TNF-a) [85]. curcumin by the suppression of p38 MAPK signaling pathway in rats with chronic colitis [85] and cell lines [87, 88], as well as inhibition of JNK MAPK pathways in the mice liver [86] has also shown the apoptotic effect. In accordance with our previous studies [14], western blot analysis in this study was also proved that coadministration of BPA and NmCur at a dose of $50 \mathrm{mg} / \mathrm{kg}$ significantly up-regulated expression of p-AKT and p-ERK1/2, whereas down-regulated expression of p-P38 and p-JNK in different regions of rat brain tissue. In addition, for the first time in this study, it proved that administration of NmCur alone $(50 \mathrm{mg} / \mathrm{kg})$ and co-administration of NmCur (50 mg/kg) and BPA (50 mg/ $\mathrm{kg}$ ) increased, while BPA alone $(50 \mathrm{mg} / \mathrm{kg})$ reduced expression of p-NR1, p-NR2A, p-NR2B, p-GluA1, p-CREB, and BDNF in the rat hippocampus and cortex tissues.

In several other studies have examined the neuroprotective role of other antioxidants. For instance, lycopene $(10 \mathrm{mg} / \mathrm{kg})$ upregulated MAPK/ERK1/2/CREB/BDNF signaling pathway and improved neuronal survival, and synaptic plasticity and GSH content, however, suppressed ROS and MDA concentrations in hippocampal of adult male albino rats. Therefore, all side effects induced by BPA ( $50 \mathrm{mg} / \mathrm{kg}$ ) was reduced, so that it reflected on improving the learning and cognition memory by decreasing the escape latency in the daily training trials and increasing the time spent in the target quadrant, which detected by MWM test [179]. Another study on adult male Wistar rats has displayed that BPA administration (100 $\mathrm{mg} / \mathrm{kg}$ /orally for 4 weeks) prominently attenuated GSH content and GluA 2/3/4 expression, nevertheless, increased ROS and MDA levels in rat hippocampus. It also markedly enlarged the escape latency time to 
finding the hidden platform during training trial days, whereas noticeably reduced the spent time in target quadrant in probe trials, resulting memory and learning impairment that evaluated by MWM test. However, crocin, as active ingredient in Crocus sativus L. plant, reversed all BPA-treated undesirable effects [4]. The findings of these several studies sufficiently are consistent with the findings of our study. The results of our study on behavioral tests displayed that the combination therapy of BPA $(50 \mathrm{mg} / \mathrm{kg})$ and NmCur (25 and $50 \mathrm{mg} / \mathrm{kg}$ ) considerably increased STL, enlarged fear learning and memory, and improved peripheral and total locomotor activity compared to BPA (50 mg/kg) group. Moreover, in simultaneous treatment of BPA (50 mg/kg) and NmCur $(25$ and $50 \mathrm{mg} / \mathrm{kg}) \times$ training days during final 3 days as well as during on 1 day and final 4 days of acquisition trial, respectively were declined the escape latency time ( $\mathrm{sec}$ ) and the travelled distance $(\mathrm{cm})$ when in comparison to BPA group. While markedly increased the time spent $(\mathrm{sec})$ and the travelled distance $(\mathrm{cm})$ in the target quadrant during the probe trial compared to BPA group. In addition, there was no important difference of swimming speed among all groups in the MWM test during all days (5 days) of training and probe trial. In fact, NmCur was inverted all the adverse effects of BPA. These results are similar to other studies. For example, administration of curcumin in adult rat hippocampus and both HT-22 neuronal and BV2 microglial cells markedly downregulated ROS and MDA productions, $p-J N K / p-N F-K B / A k t$ signaling pathway, and TNF- $\alpha$ and IL-1 $\beta$ expression. Moreover, treatment of curcumin markedly diminished latency time, while enlarged the platform crossings number and the quadrant time spent, which detected using the MVM and Y-maze tasks. It led to the improvement of memory and cognitive impairments correlated with lipopolysaccharide-stimulated microglia cells [180]. The injection of $\mathrm{AlCl} 3$ in the hippocampal CA1 region of male Kunming mice stimulated activation of microglia and astrocyte cells, inducing an enlargement of IL-1 $\beta$, IL-6, and TNF- $a$ that diminished passing times and spatial learning and memory functions, however, increased $A \beta$ production and the escape latency, which measured by the MVM test. Nevertheless, treatment of curcumin on AICl3-induced Alzheimer's disease (AD) was dramatically reversed the items mentioned above in the hippocampus [181]. Therefore, it can be mentioned that these studies are consistent with our obtained results.

Based on the results of various studies [182-184] and the results of this study in relation to free curcumin and curcumin derivatives, e.g. Longvida $₫[176,185,177]$ and nanomicelles curcuminoid, it can be suggested that curcumin treatment can decrease learning and memory impairment owing to its antioxidant, anti-inflammatory, and anti-apoptosis properties. So to speak, these effects of curcumin can be related to scavenging free radicals (as an inducer of stress oxidative), pro-inflammatory cytokines (TNF-a, IL-6, and IL-1 $\beta$ ), and anti-apoptosis ( $p-P 38$ and p-JNK) properties. However, it increases the glutamate receptors (NMDA and AMPA) and learning and memory-related proteins (BDNF and CREB) that can probably protects neural cells, reduces synaptic disturbance, and stimulates hippocampus and cortex neurogenesis [176]. As stated in previous studies, the doses of used curcumin and its derivatives were higher than in our study. So that, our study showed that the nanomicelles form of curcumin is most effective at the highest dose $(50 \mathrm{mg} / \mathrm{kg})$, but at the lowest dose $(25 \mathrm{mg} / \mathrm{kg})$ also showed the highest efficiency and effectiveness compared to the formulation of commercial and free curcumin. Generally, it can be argued that curcumin could preserve neural cells in the CA1 area in a time- and dose-dependent 
manner. So to speak, it can be said that the time-dependent effects of curcumin on memory functions may be exerted via adaptive mechanisms that require time, including neurogenesis, altering synaptic flexibility or gene expression [186]. Nevertheless, the exact mechanism of curcumin effects not yet stated, which needs further studies.

\section{Conclusion}

In conclusion, in this study for the first time, it is marked that oral administration of nanomicelle curcumin ( 25 and $50 \mathrm{mg} / \mathrm{kg}$ ) for 4 weeks significantly down-regulated expression of ROS, MDA, TNF- $\alpha$, IL-6, IL-1ß, SOD, and GST levels, while considerably up-regulated GSH content, GPx, GR, and CAT levels in rat hippocampus and cortex tissues. Western blot analysis also confirmed that nanomicelle curcumin noticeably exhibited higher phosphorylation of AKT and ERK1/2 proteins; however, it displayed lower phosphorylation of P38 and JNK proteins in the mentioned tissues. In addition, nanomicelle curcumin (50 $\mathrm{mg} / \mathrm{kg}$ ) and co-therapy of BPA and nanomicelle curcumin increased the expression of a variety of glutamate receptors, including NMDA (p-NR1, p-NR2A, and p-NR2B) and AMPA (p-GluA1), and the expression of learning and memory-related proteins, such as BDNF and p-CREB, in the mentioned tissues. It markedly extended the step-through latency and fear learning and memory, as well as locomotor activity (peripheral and total events, except central area). In addition, it shortened the time to finding the hidden platform, the average of escape latency time (sec), and the travelled distance in the target quadrant $(\mathrm{cm})$, whereas significantly enlarged the time spent in the target quadrant (sec). However, there was no significant difference of swimming speed among all groups in the MWM test. In fact, our proved for the first time that nanomicelle curcumin has a dose-dependent neuroprotective effect against toxic effects of BPA in rat hippocampus and cortex tissues. Nevertheless, further mechanistic studies are needed in this regard.

\section{Declarations}

\section{Author Declarations section}

\section{Ethics approval}

All the experimental protocols were accepted by Ethical Committee of Mashhad University of Medical Sciences (IR.MUMS.REC.1394.281) and this experiment was conducted the Department of Pharmacodynamics and Toxicology, School of Pharmacy, Mashhad University of Medical Sciences, Mashhad, Iran.

\section{Consent to participate and or Consent for publication}

It is not applicable to this article as this article does not include any studies with human participants done by any of the authors.

\section{Availability of data and materials}


All data created and/or analyzed during our study are available from the corresponding author on rational request.

\section{Conflicts of interest/Competing interests}

The authors declare that they have no conflict of interest in this study.

\section{Funding}

This work was supported from personal financial account of Dr. Mahmoud Gorji-Valokola and grant number 931581 which performed as part of the doctoral dissertation at Mashhad University of Medical Sciences.

\section{Acknowledgement}

The authors wish to thank the Vice Chancellor of Research, Mashhad University of Medical Sciences for their financial support.

\section{Author information}

\section{Affiliations}

\section{Somaye Fallahnezhad, Faezeh Ghorbani-Taherdehi,}

Department of Anatomy and Cell Biology, School of Medicine, Mashhad University of Medical Sciences, Mashhad, Iran

\section{Azade Nadim,}

Department of Pharmaceutics, School of Pharmacy, Mashhad University of Medical Sciences, Mashhad, Iran

\section{Mehrnaz Kafashzadeh, Mehrnoosh Kafashzadeh,}

Cellular and Molecular Research Center, Sabzevar University of Medical Sciences, Sabzevar, Iran

\section{Mahmoud Gorji-Valokola}

Department of Pharmacology, Brain and Spinal Injury Repair Research Center, Tehran University of Medical Science, Tehran, Iran and Department of Pharmacodynamics and Toxicology, School of Pharmacy, Mashhad University of Medical Sciences, Mashhad, Iran

\section{Authors' contributions}

All authors contributed to the study conception and design. Material preparation and data collection were performed by Mahmoud Gorji-Valokola. Data analysis and interpretation was done by Somaye 
Fallahnezhad, Faezeh Ghorbani-Taherdehi, Azade Nadim, Mehrnaz Kafashzadeh, and Mehrnoosh Kafashzadeh. The first draft of the manuscript was written by Mahmoud Gorji-Valokola and Somaye Fallahnezhad. Its major revision was performed by Mahmoud Gorji-Valokola and Somaye Fallahnezhad. All authors read and approved the final manuscript.

\section{Corresponding author}

Correspondence to Mahmoud Gorji-Valokola

\section{Compliance with Ethical Standards section}

\section{Disclosure of potential conflicts of interest}

The authors declare no conflict of interest related to this study.

\section{Research involving Human Participants and/or Animals}

All the experimental protocols and procedures in this study were conducted according to the international guidelines for care and use of laboratory animals and approved by the ethical committee of Mashhad University of Medical Sciences (Ethic cod number: IR.MUMS.REC.1394.281). All experiments were performed at the Department of Pharmacodynamics and Toxicology, School of Pharmacy, Mashhad University of Medical Sciences, Mashhad, Iran.

\section{Informed consent}

It is not applicable in this study.

\section{References}

1. Da Conceicao RR, de Souza JS, de Oliveira KC et al (2017) Anatomical specificity of the brain in the modulation of Neuroglobin and Cytoglobin genes after chronic bisphenol a exposure. Metab Brain Dis 32 (6):1843-1851. doi:10.1007/s11011-017-0066-5

2. Fan YY, Zheng JL, Ren JH et al (2014) Effects of storage temperature and duration on release of antimony and bisphenol A from polyethylene terephthalate drinking water bottles of China. Environ Pollut 192:113-120. doi:10.1016/j.envpol.2014.05.012

3. Akintunde JK, Farouk AA, Mogbojuri O (2019) Metabolic treatment of syndrome linked with Parkinson's disease and hypothalamus pituitary gonadal hormones by turmeric curcumin in Bisphenol-A induced neuro-testicular dysfunction of wistar rat. Biochem Biophys Rep 17:97-107.

doi:10.1016/j.bbrep.2018.12.004

4. Vahdati Hassani F, Masjedi E, Hosseinzadeh H et al (2020) Protective effect of crocin on bisphenol Ainduced spatial learning and memory impairment in adult male rats: Role of oxidative stress and AMPA 
receptor. Iran J Basic Med Sci 23 (9):1146-1154. doi:10.22038/ijbms.2020.41097.9714

5. Vandenberg LN, Hauser R, Marcus M et al (2007) Human exposure to bisphenol A (BPA). Reprod Toxicol 24 (2):139-177. doi:10.1016/j.reprotox.2007.07.010

6. Eilam-Stock T, Serrano P, Frankfurt M et al (2012) Bisphenol-A impairs memory and reduces dendritic spine density in adult male rats. Behav Neurosci 126 (1):175-185. doi:10.1037/a0025959

7. Richter CA, Birnbaum LS, Farabollini F et al (2007) In vivo effects of bisphenol A in laboratory rodent studies. Reprod Toxicol 24 (2):199-224. doi:10.1016/j.reprotox.2007.06.004

8. Calafat AM, Kuklenyik Z, Reidy JA et al (2005) Urinary concentrations of bisphenol A and 4nonylphenol in a human reference population. Environ Health Perspect 113 (4):391-395. doi:10.1289/ehp.7534

9. Corrales J, Kristofco LA, Steele WB et al (2015) Global Assessment of Bisphenol A in the Environment: Review and Analysis of Its Occurrence and Bioaccumulation. Dose Response 13 (3):1559325815598308. doi:10.1177/1559325815598308

10. Hoekstra EJ, Simoneau C (2013) Release of bisphenol A from polycarbonate: a review. Crit Rev Food Sci Nutr 53 (4):386-402. doi:10.1080/10408398.2010.536919

11. Lam SH, Hlaing MM, Zhang $X$ et al (2011) Toxicogenomic and phenotypic analyses of bisphenol-A early-life exposure toxicity in zebrafish. PLoS One 6 (12):e28273. doi:10.1371/journal.pone.0028273

12. Szychowski KA, Wojtowicz AK (2013) [Components of plastic disrupt the function of the nervous system]. Postepy Hig Med Dosw (Online) 67:499-506

13. Fernandez MF, Arrebola JP, Taoufiki J et al (2007) Bisphenol-A and chlorinated derivatives in adipose tissue of women. Reprod Toxicol 24 (2):259-264. doi:10.1016/j.reprotox.2007.06.007

14. Valokola MG, Karimi G, Razavi BM et al (2019) The protective activity of nanomicelle curcumin in bisphenol A-induced cardiotoxicity following subacute exposure in rats. Environ Toxicol 34 (3):319-329. doi:10.1002/tox.22687

15. Fernández J, Pérez-Álvarez JA, Fernández-López JA (1997) Thiobarbituric acid test for monitoring lipid oxidation in meat. Food Chem Toxicol 59 (3):345-353. doi:10.1016/S0308-8146(96)00114-8

16. Moron MS, Depierre JW, Mannervik B (1979) Levels of glutathione, glutathione reductase and glutathione S-transferase activities in rat lung and liver. Biochim Biophys Acta 582 (1):67-78

17. Nagel SC, vom Saal FS, Thayer KA et al (1997) Relative binding affinity-serum modified access (RBASMA) assay predicts the relative in vivo bioactivity of the xenoestrogens bisphenol $A$ and octylphenol. Environ Health Perspect 105 (1):70-76. doi:10.1289/ehp.9710570 
18. Steinmetz R, Brown NG, Allen DL et al (1997) The environmental estrogen bisphenol A stimulates prolactin release in vitro and in vivo. Endocrinology 138 (5):1780-1786. doi:10.1210/endo.138.5.5132

19. Olea N, Pulgar R, Perez P et al (1996) Estrogenicity of resin-based composites and sealants used in dentistry. Environ Health Perspect 104 (3):298-305. doi:10.1289/ehp.96104298

20. Krishnan AV, Stathis P, Permuth SF et al (1993) Bisphenol-A: an estrogenic substance is released from polycarbonate flasks during autoclaving. Endocrinology 132 (6):2279-2286.

doi:10.1210/endo.132.6.8504731

21. Zhao C, Deng W, Gage FH (2008) Mechanisms and functional implications of adult neurogenesis. Cell 132 (4):645-660. doi:10.1016/j.cell.2008.01.033

22. Christie BR, Cameron HA (2006) Neurogenesis in the adult hippocampus. Hippocampus 16 (3):199207. doi:10.1002/hipo.20151

23. Eriksson PS, Perfilieva E, Björk-Eriksson T et al (1998) Neurogenesis in the adult human hippocampus. Nat Med 4 (11):1313-1317. doi:10.1038/3305

24. Weiss S, Reynolds BA, Vescovi AL et al (1996) Is there a neural stem cell in the mammalian forebrain? Trends Neurosci 19 (9):387-393. doi:10.1016/s0166-2236(96)10035-7

25. Counts SE, Alldred MJ, Che S et al (2014) Synaptic gene dysregulation within hippocampal CA1 pyramidal neurons in mild cognitive impairment. Neuropharmacology 79:172-179.

doi:10.1016/j.neuropharm.2013.10.018

26. Vago DR, Kesner RP (2008) Disruption of the direct perforant path input to the CA1 subregion of the dorsal hippocampus interferes with spatial working memory and novelty detection. Behav Brain Res 189 (2):273-283. doi:10.1016/j.bbr.2008.01.002

27. Etemad L, Jafarian AH, Moallem SA (2015) Pathogenesis of Pregabalin-Induced Limb Defects in Mouse Embryos. J Pharm Pharm Sci 18 (5):882-889

28. Yin N, Yao X, Qin Z et al (2015) Assessment of Bisphenol A (BPA) neurotoxicity in vitro with mouse embryonic stem cells. J Environ Sci (China) 36:181-187. doi:10.1016/j.jes.2015.06.004

29. Won SJ, Kim DY, Gwag BJ (2002) Cellular and molecular pathways of ischemic neuronal death. J Biochem Mol Biol 35 (1):67-86

30. Jain S, Kumar CH, Suranagi UD et al (2011) Protective effect of N-acetylcysteine on bisphenol Ainduced cognitive dysfunction and oxidative stress in rats. Food Chem Toxicol 49 (6):1404-1409. doi:10.1016/j.fct.2011.03.032 
31. Anetor J, Anetor G, lyanda A et al (2008) Environmental chemicals and human neurotoxicity: magnitude, prognosis and markers. African Journal of Biomedical Research 11 (1). doi:10.4314/ajbr.v11i1.50675

32. Xu X, Liu X, Zhang Q et al (2013) Sex-specific effects of bisphenol-A on memory and synaptic structural modification in hippocampus of adult mice. Horm Behav 63 (5):766-775. doi:10.1016/j.yhbeh.2013.03.004

33. Yang J, Song S, Li J et al (2014) Neuroprotective effect of curcumin on hippocampal injury in 6OHDA-induced Parkinson's disease rat. Pathol Res Pract 210 (6):357-362. doi:10.1016/j.prp.2014.02.005

34. Karageorgos N, Patsoukis N, Chroni E et al (2006) Effect of N-acetylcysteine, allopurinol and vitamin E on jaundice-induced brain oxidative stress in rats. Brain Res 1111 (1):203-212. doi:10.1016/j.brainres.2006.06.088

35. Huang TT, Leu D, Zou Y (2015) Oxidative stress and redox regulation on hippocampal-dependent cognitive functions. Arch Biochem Biophys 576:2-7. doi:10.1016/j.abb.2015.03.014

36. Sartori AC, Vance DE, Slater LZ et al (2012) The impact of inflammation on cognitive function in older adults: implications for healthcare practice and research. J Neurosci Nurs 44 (4):206-217. doi:10.1097/JNN.0b013e3182527690

37. Reale M, Di Nicola M, Velluto L et al (2014) Selective acetyl- and butyrylcholinesterase inhibitors reduce amyloid- $\beta$ ex vivo activation of peripheral chemo-cytokines from Alzheimer's disease subjects: exploring the cholinergic anti-inflammatory pathway. Curr Alzheimer Res 11 (6):608-622. doi:10.2174/1567205010666131212113218

38. Block ML, Zecca L, Hong JS (2007) Microglia-mediated neurotoxicity: uncovering the molecular mechanisms. Nat Rev Neurosci 8 (1):57-69. doi:10.1038/nrn2038

39. Combs CK, Karlo JC, Kao SC et al (2001) beta-Amyloid stimulation of microglia and monocytes results in TNFalpha-dependent expression of inducible nitric oxide synthase and neuronal apoptosis. $J$ Neurosci 21 (4):1179-1188. doi:10.1523/jneurosci.21-04-01179.2001

40. Sian J, Dexter DT, Lees AJ et al (1994) Alterations in glutathione levels in Parkinson's disease and other neurodegenerative disorders affecting basal ganglia. Ann Neurol 36 (3):348-355. doi:10.1002/ana.410360305

41. Melchiorri D, Reiter RJ, Sewerynek E et al (1996) Paraquat toxicity and oxidative damage. Reduction by melatonin. Biochem Pharmacol 51 (8):1095-1099

42. Michalowicz J (2014) Bisphenol A-sources, toxicity and biotransformation. Environ Toxicol Pharmacol 37 (2):738-758. doi:10.1016/j.etap.2014.02.003 
43. El-Missiry MA, Othman Al, Al-Abdan MA et al (2014) Melatonin ameliorates oxidative stress, modulates death receptor pathway proteins, and protects the rat cerebrum against bisphenol-A-induced apoptosis. J Neurol Sci 347 (1-2):251-256. doi:10.1016/j.jns.2014.10.009

44. Aydoğan M, Korkmaz A, Barlas N et al (2008) The effect of vitamin $C$ on bisphenol A, nonylphenol and octylphenol induced brain damages of male rats. Toxicology 249 (1):35-39.

doi:10.1016/j.tox.2008.04.002

45. Eid JI, Eissa SM, El-Ghor AA (2015) Bisphenol A induces oxidative stress and DNA damage in hepatic tissue of female rat offspring. JOBAZ 71:10-19. doi:10.1016/j.jobaz.2015.01.006

46. Kim K, Son TG, Kim SJ et al (2007) Suppressive effects of bisphenol A on the proliferation of neural progenitor cells. J Toxicol Environ Health A 70 (15-16):1288-1295. doi:10.1080/15287390701434216

47. Xu X, Tian D, Hong X et al (2011) Sex-specific influence of exposure to bisphenol-A between adolescence and young adulthood on mouse behaviors. Neuropharmacology 61 (4):565-573. doi:10.1016/j.neuropharm.2011.04.027

48. Xu XH, Zhang J, Wang YM et al (2010) Perinatal exposure to bisphenol-A impairs learning-memory by concomitant down-regulation of $\mathrm{N}$-methyl-D-aspartate receptors of hippocampus in male offspring mice. Horm Behav 58 (2):326-333. doi:10.1016/j.yhbeh.2010.02.012

49. Gonçalves CR, Cunha RW, Barros DM et al (2010) Effects of prenatal and postnatal exposure to a low dose of bisphenol A on behavior and memory in rats. Environ Toxicol Pharmacol 30 (2):195-201. doi:10.1016/j.etap.2010.06.003

50. Cavallucci V, D'Amelio M (2011) Matter of life and death: the pharmacological approaches targeting apoptosis in brain diseases. Curr Pharm Des 17 (3):215-229. doi:10.2174/138161211795049705

51. Chen L, Deng H, Cui $\mathrm{H}$ et al (2018) Inflammatory responses and inflammation-associated diseases in organs. Oncotarget 9 (6):7204-7218. doi:10.18632/oncotarget.23208

52. Lee S, Suk K, Kim IK et al (2008) Signaling pathways of bisphenol A-induced apoptosis in hippocampal neuronal cells: role of calcium-induced reactive oxygen species, mitogen-activated protein kinases, and nuclear factor-kappaB. J Neurosci Res 86 (13):2932-2942. doi:10.1002/jnr.21739

53. Shi LY, Zhang L, Li H et al (2018) Protective effects of curcumin on acrolein-induced neurotoxicity in HT22 mouse hippocampal cells. Pharmacol Rep 70 (5):1040-1046. doi:10.1016/j.pharep.2018.05.006

54. Wang C, Li Z, Han H et al (2016) Impairment of object recognition memory by maternal bisphenol A exposure is associated with inhibition of Akt and ERK/CREB/BDNF pathway in the male offspring hippocampus. Toxicology 341-343:56-64. doi:10.1016/j.tox.2016.01.010 
55. Chen Z, Li T, Zhang L et al (2018) Bisphenol A exposure remodels cognition of male rats attributable to excitatory alterations in the hippocampus and visual cortex. Toxicology 410:132-141.

doi:10.1016/j.tox.2018.10.002

56. Khan J, Salhotra S, Ahmad S et al (2018) The protective effect of a-lipoic acid against bisphenol Ainduced neurobehavioral toxicity. Neurochem Int 118:166-175. doi:10.1016/j.neuint.2018.06.005

57. Cabaton NJ, Canlet C, Wadia PR et al (2013) Effects of low doses of bisphenol A on the metabolome of perinatally exposed CD-1 mice. Environ Health Perspect 121 (5):586-593. doi:10.1289/ehp.1205588

58. Matsuda S, Matsuzawa D, Ishii D et al (2012) Effects of perinatal exposure to low dose of bisphenol A on anxiety like behavior and dopamine metabolites in brain. Prog Neuropsychopharmacol Biol Psychiatry 39 (2):273-279. doi:10.1016/j.pnpbp.2012.06.016

59. Xu X, Dong F, Yang Y et al (2015) Sex-specific effects of long-term exposure to bisphenol-A on anxietyand depression-like behaviors in adult mice. Chemosphere 120:258-266.

doi:10.1016/j.chemosphere.2014.07.021

60. Jang YJ, Park HR, Kim TH et al (2012) High dose bisphenol A impairs hippocampal neurogenesis in female mice across generations. Toxicology 296 (1-3):73-82. doi:10.1016/j.tox.2012.03.007

61. Patil S, Tawari S, Mundhada D et al (2015) Protective effect of berberine, an isoquinoline alkaloid ameliorates ethanol-induced oxidative stress and memory dysfunction in rats. Pharmacol Biochem Behav 136:13-20. doi:10.1016/j.pbb.2015.07.001

62. Hosseinzadeh H, Sadeghnia HR, Ghaeni FA et al (2012) Effects of saffron (Crocus sativus L.) and its active constituent, crocin, on recognition and spatial memory after chronic cerebral hypoperfusion in rats. Phytother Res 26 (3):381-386. doi:10.1002/ptr.3566

63. Mohammadi HS, Goudarzi I, Lashkarbolouki T et al (2014) Chronic administration of quercetin prevent spatial learning and memory deficits provoked by chronic stress in rats. Behav Brain Res 270:196205. doi:10.1016/j.bbr.2014.05.015

64. Li X, Inoue T, Abekawa T et al (2006) 5-HT1A receptor agonist affects fear conditioning through stimulations of the postsynaptic 5-HT1A receptors in the hippocampus and amygdala. Eur $\mathrm{J}$ Pharmacol 532 (1-2):74-80. doi:10.1016/j.ejphar.2005.12.008

65. Attari F, Nadia Sharifi Z, Movassaghi S et al (2016) Neuroprotective effects of curcumin against transient global ischemia are dose and area dependent. Archives of Neuroscience 3 (2). doi:10.5812/archneurosci.32600

66. Gulinello M, Lebesgue D, Jover-Mengual T et al (2006) Acute and chronic estradiol treatments reduce memory deficits induced by transient global ischemia in female rats. Horm Behav 49 (2):246-260. doi:10.1016/j.yhbeh.2005.07.010 
67. Shakeri A, Sahebkar A (2016) Optimized curcumin formulations for the treatment of Alzheimer's disease: A patent evaluation. J Neurosci Res 94 (2):111-113. doi:10.1002/jnr.23696

68. Esatbeyoglu T, Huebbe P, Ernst IM et al (2012) Curcumin-from molecule to biological function. Angew Chem Int Ed Engl 51 (22):5308-5332. doi:10.1002/anie.201107724

69. Itokawa H, Shi Q, Akiyama T et al (2008) Recent advances in the investigation of curcuminoids. Chin Med 3:11. doi:10.1186/1749-8546-3-11

70. Chattopadhyay I, Biswas K, Bandyopadhyay U et al (2004) Turmeric and curcumin: Biological actions and medicinal applications. Curr Sci:44-53

71. Damalas CA (2011) Potential uses of turmeric (Curcuma longa) products as alternative means of pest management in crop production. Plant omics 4 (3):136-141

72. Rahimi HR, Mohammadpour AH, Dastani M et al (2016) The effect of nano-curcumin on HbA1c, fasting blood glucose, and lipid profile in diabetic subjects: a randomized clinical trial. Avicenna $\mathrm{J}$ Phytomed 6 (5):567-577

73. Staples CA, Dorn PB, Klecka GM et al (1998) A review of the environmental fate, effects, and exposures of bisphenol A. Chemosphere 36 (10):2149-2173

74. Heger M, van Golen RF, Broekgaarden M et al (2014) The molecular basis for the pharmacokinetics and pharmacodynamics of curcumin and its metabolites in relation to cancer. Pharmacol Rev 66 (1):222307. doi:10.1124/pr.110.004044

75. Eckert J, Scott B, Lawrence SM et al (2017) FLLL32, a curcumin analog, ameliorates intestinal injury in necrotizing enterocolitis. J Inflamm Res 10:75-81. doi:10.2147/jir.S131051

76. Shehzad A, Khan S, Shehzad O et al (2010) Curcumin therapeutic promises and bioavailability in colorectal cancer. Drugs Today (Barc) 46 (7):523-532. doi:10.1358/dot.2010.46.7.1509560

77. Nagahama K, Utsumi T, Kumano T et al (2016) Discovery of a new function of curcumin which enhances its anticancer therapeutic potency. Sci Rep 6:30962. doi:10.1038/srep30962

78. Aggarwal BB, Deb L, Prasad S (2014) Curcumin differs from tetrahydrocurcumin for molecular targets, signaling pathways and cellular responses. Molecules 20 (1):185-205.

doi:10.3390/molecules20010185

79. Willenbacher E, Khan SZ, Mujica SCA et al (2019) Curcumin: New Insights into an Ancient Ingredient against Cancer. Int J Mol Sci 20 (8). doi:10.3390/ijms20081808

80. Dong S, Zeng Q, Mitchell ES et al (2012) Curcumin enhances neurogenesis and cognition in aged rats: implications for transcriptional interactions related to growth and synaptic plasticity. PLoS One 7 
(2):e31211. doi:10.1371/journal.pone.0031211

81. Yu SY, Zhang M, Luo J et al (2013) Curcumin ameliorates memory deficits via neuronal nitric oxide synthase in aged mice. Prog Neuropsychopharmacol Biol Psychiatry 45:47-53.

doi:10.1016/j.pnpbp.2013.05.001

82. Cheng KK, Yeung CF, Ho SW et al (2013) Highly stabilized curcumin nanoparticles tested in an in vitro blood-brain barrier model and in Alzheimer's disease Tg2576 mice. Aaps j 15 (2):324-336. doi:10.1208/s12248-012-9444-4

83. Kong F, Ye B, Cao J et al (2016) Curcumin Represses NLRP3 Inflammasome Activation via TLR4/MyD88/NF-KB and P2X7R Signaling in PMA-Induced Macrophages. Front Pharmacol 7:369. doi:10.3389/fphar.2016.00369

84. Zhou Y, Zhang T, Wang X et al (2015) Curcumin Modulates Macrophage Polarization Through the Inhibition of the Toll-Like Receptor 4 Expression and its Signaling Pathways. Cell Physiol Biochem 36 (2):631-641. doi:10.1159/000430126

85. Camacho-Barquero L, Villegas I, Sánchez-Calvo J et al (2007) Curcumin, a Curcuma longa constituent, acts on MAPK p38 pathway modulating COX-2 and iNOS expression in chronic experimental colitis. Int Immunopharmacol 7 (3):333-342

86. Liang Z, Wu R, Xie W et al (2017) Effects of Curcumin on Tobacco Smoke-induced Hepatic MAPK Pathway Activation and Epithelial-Mesenchymal Transition In Vivo. Phytother Res 31 (8):1230-1239. doi:10.1002/ptr.5844

87. Yildizbayrak N, Erkan M (2019) Therapeutic effect of curcumin on acrylamide-induced apoptosis mediated by MAPK signaling pathway in Leydig cells. J Biochem Mol Toxicol 33 (7):e22326. doi:10.1002/jbt.22326

88. Fang g, Chen S, Huang Q et al (2018) Curcumin suppresses cardiac fibroblasts activities by regulating the proliferation and cell cycle via the inhibition of the p38 MAPK/ERK signaling pathway. Mol Med Report 18:1433-1438

89. Panahi Y, Hosseini MS, Khalili N et al (2015) Antioxidant and anti-inflammatory effects of curcuminoid-piperine combination in subjects with metabolic syndrome: A randomized controlled trial and an updated meta-analysis. Clin Nutr 34 (6):1101-1108. doi:10.1016/j.clnu.2014.12.019

90. Seiwa C, Nakahara J, Komiyama T et al (2004) Bisphenol A exerts thyroid-hormone-like effects on mouse oligodendrocyte precursor cells. Neuroendocrinology 80 (1):21-30. doi:10.1159/000080663

91. Liu R, Xing L, Kong D et al (2013) Bisphenol A inhibits proliferation and induces apoptosis in micromass cultures of rat embryonic midbrain cells through the JNK, CREB and p53 signaling pathways. Food Chem Toxicol 52:76-82. doi:10.1016/j.fct.2012.10.033 
92. Xiao Y, Liu R, Xing L et al (2011) Combined developmental toxicity of bisphenol A and genistein in micromass cultures of rat embryonic limb bud and midbrain cells. Toxicol In Vitro 25 (1):153-159. doi:10.1016/j.tiv.2010.10.010

93. Flora G, Gupta D, Tiwari A (2013) Nanocurcumin: a promising therapeutic advancement over native curcumin. Crit Rev Ther Drug Carrier Syst 30 (4):331-368.

doi:10.1615/critrevtherdrugcarriersyst.2013007236

94. Gupta A, Khan S, Manzoor M et al (2017) Anticancer curcumin: natural analogues and structureactivity relationship. In: Studies in natural products chemistry, vol 54. Elsevier, pp 355-401. doi:10.1016/B978-0-444-63929-5.00010-3

95. Subramani PA, Panati K, Narala VR (2017) Curcumin Nanotechnologies and Its Anticancer Activity. Nutr Cancer 69 (3):381-393. doi:10.1080/01635581.2017.1285405

96. Fonseca-Santos B, Dos Santos AM, Rodero CF et al (2016) Design, characterization, and biological evaluation of curcumin-loaded surfactant-based systems for topical drug delivery. Int $\mathrm{J}$ Nanomedicine 11:4553-4562. doi:10.2147/ijn.S108675

97. Karthikeyan A, Senthil N, Min T (2020) Nanocurcumin: A Promising Candidate for Therapeutic Applications. Front Pharmacol 11:487. doi:10.3389/fphar.2020.00487

98. Muqbil I, Masood A, Sarkar FH et al (2011) Progress in nanotechnology based approaches to enhance the potential of chemopreventive agents. Cancers (Basel) 3 (1):428-445. doi:10.3390/cancers3010428

99. Schiborr C, Kocher A, Behnam D et al (2014) The oral bioavailability of curcumin from micronized powder and liquid micelles is significantly increased in healthy humans and differs between sexes. Mol Nutr Food Res 58 (3):516-527. doi:10.1002/mnfr.201300724

100. Adiwidjaja J, McLachlan AJ, Boddy AV (2017) Curcumin as a clinically-promising anti-cancer agent: pharmacokinetics and drug interactions. Expert Opin Drug Metab Toxicol 13 (9):953-972.

doi:10.1080/17425255.2017.1360279

101. Hatamipour M, Sahebkar A, Alavizadeh SH et al (2019) Novel nanomicelle formulation to enhance bioavailability and stability of curcuminoids. Iran J Basic Med Sci 22 (3):282-289. doi:10.22038/ijbms.2019.32873.7852

102. Muhammad T, Ali T, Ikram M et al (2019) Melatonin Rescue Oxidative Stress-Mediated Neuroinflammation/ Neurodegeneration and Memory Impairment in Scopolamine-Induced Amnesia Mice Model. J Neuroimmune Pharmacol 14 (2):278-294. doi:10.1007/s11481-018-9824-3

103. Guo J, Cao X, Hu X et al (2020) The anti-apoptotic, antioxidant and anti-inflammatory effects of curcumin on acrylamide-induced neurotoxicity in rats. BMC Pharmacol Toxicol 21 (1):62. doi:10.1186/s40360-020-00440-3 
104. Kakkar P, Das B, Viswanathan PN (1984) A modified spectrophotometric assay of superoxide dismutase. Indian J Biochem Biophys 21 (2):130-132

105. Lowry OH, Rosebrough NJ, Farr AL et al (1951) Protein measurement with the Folin phenol reagent. J Biol Chem 193 (1):265-275

106. Aebi H (1984) Catalase in vitro. Methods Enzymol 105:121-126

107. Kawamura N, . In: Taniguchi, N. (Ed.), Kasseisanso, Protocol. J (1994) Catalase. Syuzyun-sha, Tokyo,:102-104

108. Kabuto $\mathrm{H}$, Hasuike S, Minagawa $\mathrm{N}$ et al (2003) Effects of bisphenol A on the metabolisms of active oxygen species in mouse tissues. Environ Res 93 (1):31-35

109. Carlberg I, Mannervik B (1985) Glutathione reductase. Methods Enzymol 113:484-490. doi:10.1016/s0076-6879(85)13062-4

110. Taherian N, Vaezi G, Neamati A et al (2021) Vitamin B12 and estradiol benzoate improve memory retrieval through activation of the hippocampal AKT, BDNF, and CREB proteins in a rat model of multiple sclerosis. Iran J Basic Med Sci 24 (2):256-263. doi:10.22038/ijbms.2021.51469.11681

111. Andersen P, Morris R, Amaral D et al (2006) The hippocampus book. Oxford university press,

112. Stern SA, Alberini CM (2013) Mechanisms of memory enhancement. Wiley Interdiscip Rev Syst Biol Med 5 (1):37-53. doi:10.1002/wsbm.1196

113. Sunyer J, Esnaola M, Alvarez-Pedrerol M et al (2015) Association between traffic-related air pollution in schools and cognitive development in primary school children: a prospective cohort study. PLoS Med 12 (3):e1001792. doi:10.1371/journal.pmed.1001792

114. Tzivian L, Winkler A, Dlugaj M et al (2015) Effect of long-term outdoor air pollution and noise on cognitive and psychological functions in adults. Int J Hyg Environ Health 218 (1):1-11.

doi:10.1016/j.ijheh.2014.08.002

115. Terrett G, McLennan SN, Henry JD et al (2014) Prospective memory impairment in long-term opiate users. Psychopharmacology (Berl) 231 (13):2623-2632. doi:10.1007/s00213-014-3432-6

116. Hagger-Johnson G, Sabia S, Brunner EJ et al (2013) Combined impact of smoking and heavy alcohol use on cognitive decline in early old age: Whitehall II prospective cohort study. Br J Psychiatry 203 (2):120-125. doi:10.1192/bjp.bp.112.122960

117. Blondell SJ, Hammersley-Mather R, Veerman JL (2014) Does physical activity prevent cognitive decline and dementia?: A systematic review and meta-analysis of longitudinal studies. BMC Public Health 14:510. doi:10.1186/1471-2458-14-510 
118. Boitard C, Cavaroc A, Sauvant J et al (2014) Impairment of hippocampal-dependent memory induced by juvenile high-fat diet intake is associated with enhanced hippocampal inflammation in rats. Brain Behav Immun 40:9-17. doi:10.1016/j.bbi.2014.03.005

119. Nakagawa $Y$, Tayama S (2000) Metabolism and cytotoxicity of bisphenol A and other bisphenols in isolated rat hepatocytes. Arch Toxicol 74 (2):99-105. doi:10.1007/s002040050659

120. Steinmetz R, Mitchner NA, Grant A et al (1998) The xenoestrogen bisphenol A induces growth, differentiation, and c-fos gene expression in the female reproductive tract. Endocrinology 139 (6):27412747. doi:10.1210/endo.139.6.6027

121. Bhat AH, Dar KB, Anees $S$ et al (2015) Oxidative stress, mitochondrial dysfunction and neurodegenerative diseases; a mechanistic insight. Biomed Pharmacother 74:101-110. doi:10.1016/j.biopha.2015.07.025

122. Buckman LB, Hasty AH, Flaherty DK et al (2014) Obesity induced by a high-fat diet is associated with increased immune cell entry into the central nervous system. Brain Behav Immun 35:33-42. doi:10.1016/j.bbi.2013.06.007

123. Badshah H, Ali T, Kim MO (2016) Osmotin attenuates LPS-induced neuroinflammation and memory impairments via the TLR4/NFKB signaling pathway. Sci Rep 6:24493. doi:10.1038/srep24493

124. Sanderson DJ, McHugh SB, Good MA et al (2010) Spatial working memory deficits in GluA1 AMPA receptor subunit knockout mice reflect impaired short-term habituation: evidence for Wagner's dualprocess memory model. Neuropsychologia 48 (8):2303-2315.

doi:10.1016/j.neuropsychologia.2010.03.018

125. Chater TE, Goda Y (2014) The role of AMPA receptors in postsynaptic mechanisms of synaptic plasticity. Front Cell Neurosci 8:401. doi:10.3389/fncel.2014.00401

126. Prybylowski K, Wenthold RJ (2004) N-Methyl-D-aspartate receptors: subunit assembly and trafficking to the synapse. J Biol Chem 279 (11):9673-9676. doi:10.1074/jbc.R300029200

127. Qi S, Fu W, Wang C et al (2014) BPA-induced apoptosis of rat Sertoli cells through Fas/FasL and JNKs/p38 MAPK pathways. Reprod Toxicol 50:108-116

128. Caserta M, Ben-Soussan TD, Vetriani V et al (2019) Influence of Quadrato Motor Training on Salivary proNGF and proBDNF. Front Neurosci 13:58. doi:10.3389/fnins.2019.00058

129. Segatto M, Fico E, Gharbiya M et al (2019) VEGF inhibition alters neurotrophin signalling pathways and induces caspase-3 activation and autophagy in rabbit retina. J Cell Physiol 234 (10):18297-18307. doi:10.1002/jcp.28462 
130. Bhatt DK, Ramachandran R, Christensen SL et al (2015) CGRP infusion in unanesthetized rats increases expression of c-Fos in the nucleus tractus solitarius and caudal ventrolateral medulla, but not in the trigeminal nucleus caudalis. Cephalalgia 35 (3):220-233. doi:10.1177/0333102414535995

131. Lee J, Duan W, Mattson MP (2002) Evidence that brain-derived neurotrophic factor is required for basal neurogenesis and mediates, in part, the enhancement of neurogenesis by dietary restriction in the hippocampus of adult mice. J Neurochem 82 (6):1367-1375. doi:10.1046/j.1471-4159.2002.01085.x

132. Rossi C, Angelucci A, Costantin L et al (2006) Brain-derived neurotrophic factor (BDNF) is required for the enhancement of hippocampal neurogenesis following environmental enrichment. Eur $\mathrm{J}$ Neurosci 24 (7):1850-1856. doi:10.1111/j.1460-9568.2006.05059.x

133. Wu CW, Chang YT, Yu L et al (2008) Exercise enhances the proliferation of neural stem cells and neurite growth and survival of neuronal progenitor cells in dentate gyrus of middle-aged mice. $J$ Appl Physiol (1985) 105 (5):1585-1594. doi:10.1152/japplphysiol.90775.2008

134. Simonetti M, Giniatullin R, Fabbretti E (2008) Mechanisms mediating the enhanced gene transcription of $\mathrm{P} 2 \mathrm{X} 3$ receptor by calcitonin gene-related peptide in trigeminal sensory neurons. J Biol Chem 283 (27):18743-18752. doi:10.1074/jbc.M800296200

135. Numakawa T, Matsumoto T, Numakawa $Y$ et al (2011) Protective Action of Neurotrophic Factors and Estrogen against Oxidative Stress-Mediated Neurodegeneration. J Toxicol 2011:405194.

doi:10.1155/2011/405194

136. Deogracias R, Espliguero G, Iglesias T et al (2004) Expression of the neurotrophin receptor trkB is regulated by the cAMP/CREB pathway in neurons. Mol Cell Neurosci 26 (3):470-480.

doi:10.1016/j.mcn.2004.03.007

137. Lebesgue D, Chevaleyre V, Zukin RS et al (2009) Estradiol rescues neurons from global ischemiainduced cell death: multiple cellular pathways of neuroprotection. Steroids 74 (7):555-561. doi:10.1016/j.steroids.2009.01.003

138. Amstad PA, Liu H, Ichimiya $\mathrm{M}$ et al (2001) BCL-2 is involved in preventing oxidant-induced cell death and in decreasing oxygen radical production. Redox Rep 6 (6):351-362.

doi:10.1179/135100001101536535

139. Levenson JM, O'Riordan KJ, Brown KD et al (2004) Regulation of histone acetylation during memory formation in the hippocampus. J Biol Chem 279 (39):40545-40559. doi:10.1074/jbc.M402229200

140. Davis S, Vanhoutte P, Pages $C$ et al (2000) The MAPK/ERK cascade targets both Elk-1 and cAMP response element-binding protein to control long-term potentiation-dependent gene expression in the dentate gyrus in vivo. J Neurosci 20 (12):4563-4572. doi:10.1523/jneurosci.20-12-04563.2000 
141. Merienne K, Pannetier S, Harel-Bellan A et al (2001) Mitogen-regulated RSK2-CBP interaction controls their kinase and acetylase activities. Mol Cell Biol 21 (20):7089-7096. doi:10.1128/mcb.21.20.7089-

7096.2001

142. Sananbenesi F, Fischer A, Schrick C et al (2002) Phosphorylation of hippocampal Erk-1/2, Elk-1, and p90-Rsk-1 during contextual fear conditioning: interactions between Erk-1/2 and Elk-1. Mol Cell Neurosci 21 (3):463-476. doi:10.1006/mcne.2002.1188

143. Athos J, Impey S, Pineda VV et al (2002) Hippocampal CRE-mediated gene expression is required for contextual memory formation. Nat Neurosci 5 (11):1119-1120. doi:10.1038/nn951

144. Negishi T, Kawasaki K, Suzaki S et al (2004) Behavioral alterations in response to fear-provoking stimuli and tranylcypromine induced by perinatal exposure to bisphenol A and nonylphenol in male rats. Environ Health Perspect 112 (11):1159-1164. doi:10.1289/ehp.6961

145. Hu F, Li T, Gong H et al (2017) Bisphenol A Impairs Synaptic Plasticity by Both Pre-and Postsynaptic Mechanisms. Adv Sci (Weinh) 4 (8):1600493. doi:10.1002/advs.201600493

146. McCaffrey KA, Jones B, Mabrey N et al (2013) Sex specific impact of perinatal bisphenol A (BPA) exposure over a range of orally administered doses on rat hypothalamic sexual differentiation. Neurotoxicology 36:55-62. doi:10.1016/j.neuro.2013.03.001

147. Tonini C, Segatto M, Gagliardi S et al (2020) Maternal Dietary Exposure to Low-Dose Bisphenol A Affects Metabolic and Signaling Pathways in the Brain of Rat Fetuses. Nutrients 12 (5). doi:10.3390/nu12051448

148. Kundakovic M, Gudsnuk K, Herbstman JB et al (2015) DNA methylation of BDNF as a biomarker of early-life adversity. Proc Natl Acad Sci U S A 112 (22):6807-6813. doi:10.1073/pnas.1408355111

149. Warita K, Mitsuhashi T, Ohta K et al (2013) In vitro evaluation of gene expression changes for gonadotropin-releasing hormone 1, brain-derived neurotrophic factor and neurotrophic tyrosine kinase, receptor, type 2, in response to bisphenol A treatment. Congenit Anom (Kyoto) 53 (1):42-45. doi:10.1111/j.1741-4520.2012.00381.x

150. Elsworth JD, Jentsch JD, Groman SM et al (2015) Low circulating levels of bisphenol-A induce cognitive deficits and loss of asymmetric spine synapses in dorsolateral prefrontal cortex and hippocampus of adult male monkeys. J Comp Neurol 523 (8):1248-1257. doi:10.1002/cne.23735

151. Bowman RE, Luine V, Khandaker H et al (2014) Adolescent bisphenol-A exposure decreases dendritic spine density: role of sex and age. Synapse 68 (11):498-507. doi:10.1002/syn.21758

152. Elsworth JD, Jentsch JD, Vandevoort CA et al (2013) Prenatal exposure to bisphenol A impacts midbrain dopamine neurons and hippocampal spine synapses in non-human primates. Neurotoxicology 35:113-120. doi:10.1016/j.neuro.2013.01.001

Page $37 / 55$ 
153. Kim ME, Park HR, Gong EJ et al (2011) Exposure to bisphenol A appears to impair hippocampal neurogenesis and spatial learning and memory. Food Chem Toxicol 49 (12):3383-3389. doi:10.1016/j.fct.2011.09.017

154. Liu Z-H, Yang Y, Ge M-M et al (2015) Bisphenol-A exposure alters memory consolidation and hippocampal CA1 spine formation through Wnt signaling in vivo and in vitro. Toxicology Research 4 (3):686-694

155. Jašarević E, Williams SA, Vandas GM et al (2013) Sex and dose-dependent effects of developmental exposure to bisphenol A on anxiety and spatial learning in deer mice (Peromyscus maniculatus bairdii) offspring. Horm Behav 63 (1):180-189. doi:10.1016/j.yhbeh.2012.09.009

156. Kuwahara R, Kawaguchi S, Kohara Y et al (2013) Perinatal exposure to low-dose bisphenol A impairs spatial learning and memory in male rats. J Pharmacol Sci 123 (2):132-139. doi:10.1254/jphs.13093fp

157. Hasanluyi EA, Khojasteh SMB, Fazeli M et al Investigating the Neurotoxicity of Bisphenol A on Spatial Learning and Memory in Male Rats.

158. Uttara B, Singh AV, Zamboni P et al (2009) Oxidative stress and neurodegenerative diseases: a review of upstream and downstream antioxidant therapeutic options. Curr Neuropharmacol 7 (1):65-74. doi:10.2174/157015909787602823

159. Nakayama M, Aihara M, Chen YN et al (2011) Neuroprotective effects of flavonoids on hypoxia-, glutamate, and oxidative stress-induced retinal ganglion cell death. Mol Vis 17:1784-1793

160. Mukherjee A, Sarkar S, Jana S et al (2019) Neuro-protective role of nanocapsulated curcumin against cerebral ischemia-reperfusion induced oxidative injury. Brain Res 1704:164-173. doi:10.1016/j.brainres.2018.10.016

161. Xu L, Ding L, Su Y et al (2019) Neuroprotective effects of curcumin against rats with focal cerebral ischemia-reperfusion injury. Int J Mol Med 43 (4):1879-1887. doi:10.3892/ijmm.2019.4094

162. Forni C, Facchiano F, Bartoli M et al (2019) Beneficial Role of Phytochemicals on Oxidative Stress and Age-Related Diseases. Biomed Res Int 2019:8748253. doi:10.1155/2019/8748253

163. Sevastre-Berghian AC, Făgărăsan V, Toma VA et al (2017) Curcumin Reverses the Diazepam-Induced Cognitive Impairment by Modulation of Oxidative Stress and ERK 1/2/NF-KB Pathway in Brain. Oxid Med Cell Longev 2017:3037876. doi:10.1155/2017/3037876

164. Haider S, Naqvi F, Batool Z et al (2015) Pretreatment with curcumin attenuates anxiety while strengthens memory performance after one short stress experience in male rats. Brain Res Bull 115:1-8. doi:10.1016/j.brainresbull.2015.04.001 
165. Sanei M, Saberi-Demneh A (2019) Effect of curcumin on memory impairment: A systematic review. Phytomedicine 52:98-106. doi:10.1016/j.phymed.2018.06.016

166. Seki S, Aoki M, Hosokawa T et al (2011) Bisphenol-A suppresses neurite extension due to inhibition of phosphorylation of mitogen-activated protein kinase in PC12 cells. Chem Biol Interact 194 (1):23-30. doi:10.1016/j.cbi.2011.08.001

167. Dai C, Ciccotosto GD, Cappai R et al (2018) Curcumin Attenuates Colistin-Induced Neurotoxicity in N2a Cells via Anti-inflammatory Activity, Suppression of Oxidative Stress, and Apoptosis. Mol Neurobiol 55 (1):421-434. doi:10.1007/s12035-016-0276-6

168. Hong SB, Hong YC, Kim JW et al (2013) Bisphenol A in relation to behavior and learning of schoolage children. J Child Psychol Psychiatry 54 (8):890-899. doi:10.1111/jcpp.12050

169. Viberg H, Fredriksson A, Buratovic S et al (2011) Dose-dependent behavioral disturbances after a single neonatal Bisphenol A dose. Toxicology 290 (2-3):187-194. doi:10.1016/j.tox.2011.09.006

170. Yu C, Tai F, Song Z et al (2011) Pubertal exposure to bisphenol A disrupts behavior in adult C57BL/6J mice. Environ Toxicol Pharmacol 31 (1):88-99. doi:10.1016/j.etap.2010.09.009

171. Khopde SM, Priyadarsini KI, Guha SN et al (2000) Inhibition of radiation-induced lipid peroxidation by tetrahydrocurcumin: possible mechanisms by pulse radiolysis. Biosci Biotechnol Biochem 64 (3):503509. doi:10.1271/bbb.64.503

172. Anand P, Kunnumakkara AB, Newman RA et al (2007) Bioavailability of curcumin: problems and promises. Mol Pharm 4 (6):807-818. doi:10.1021/mp700113r

173. Shakeri A, Sahebkar A (2016) Opinion Paper: Nanotechnology: A Successful Approach to Improve Oral Bioavailability of Phytochemicals. Recent Pat Drug Deliv Formul 10 (1):4-6. doi:10.2174/1872211309666150611120724

174. Sahay G, Alakhova DY, Kabanov AV (2010) Endocytosis of nanomedicines. J Control Release 145 (3):182-195. doi:10.1016/j.jconrel.2010.01.036

175. Tanabe N, Yoshino H, Kimoto T et al (2012) Nanomolar dose of bisphenol A rapidly modulates spinogenesis in adult hippocampal neurons. Mol Cell Endocrinol 351 (2):317-325.

doi:10.1016/j.mce.2012.01.008

176. Begum AN, Jones MR, Lim GP et al (2008) Curcumin structure-function, bioavailability, and efficacy in models of neuroinflammation and Alzheimer's disease. J Pharmacol Exp Ther 326 (1):196-208. doi:10.1124/jpet.108.137455

177. Cox KH, Pipingas A, Scholey AB (2015) Investigation of the effects of solid lipid curcumin on cognition and mood in a healthy older population. J Psychopharmacol 29 (5):642-651. 
178. SoukhakLari R, Moezi L, Pirsalami F et al (2019) Curcumin-Loaded BSA Nanoparticles Protect More Efficiently Than Natural Curcumin Against Scopolamine-Induced Memory Retrieval Deficit. Basic Clin Neurosci 10 (2):157-164. doi:10.32598/bcn.9.10.255

179. El Morsy EM, Ahmed M (2020) Protective effects of lycopene on hippocampal neurotoxicity and memory impairment induced by bisphenol A in rats. Hum Exp Toxicol 39 (8):1066-1078. doi:10.1177/0960327120909882

180. Khan MS, Muhammad T, Ikram M et al (2019) Dietary Supplementation of the Antioxidant Curcumin Halts Systemic LPS-Induced Neuroinflammation-Associated Neurodegeneration and Memory/Synaptic Impairment via the JNK/NF-KB/Akt Signaling Pathway in Adult Rats. Oxid Med Cell Longev 2019:7860650. doi:10.1155/2019/7860650

181. Liu Z, Jiang $Y$, Wang $Y$ et al (2018) Curcumin improves learning and memory ability via inhibiting activated microglia-mediated inflammation in mouse models of Alzheimer's disease. Int $\mathrm{J}$ Clin Exp Med 11 (11):12204-12210

182. Lu Z, Shen $Y$, Wang $T$ et al (2014) Curcumin promotes neurite outgrowth via reggie-1/flotillin-2 in cortical neurons. Neurosci Lett 559:7-12. doi:10.1016/j.neulet.2013.11.029

183. Kim SJ, Son TG, Park HR et al (2008) Curcumin stimulates proliferation of embryonic neural progenitor cells and neurogenesis in the adult hippocampus. J Biol Chem 283 (21):14497-14505. doi:10.1074/jbc.M708373200

184. Hoppe JB, Haag M, Whalley BJ et al (2013) Curcumin protects organotypic hippocampal slice cultures from Aß1-42-induced synaptic toxicity. Toxicol In Vitro 27 (8):2325-2330.

doi:10.1016/j.tiv.2013.10.002

185. Gota VS, Maru GB, Soni TG et al (2010) Safety and pharmacokinetics of a solid lipid curcumin particle formulation in osteosarcoma patients and healthy volunteers. J Agric Food Chem 58 (4):20952099. doi:10.1021/jf9024807

186. Kamali Dolatabadi L, Emamghoreishi M, Namavar MR et al (2019) Curcumin Effects on Memory Impairment and Restoration of Irregular Neuronal Distribution in the Hippocampal CA1 Region After Global Cerebral Ischemia in Male Rats. Basic Clin Neurosci 10 (5):527-539. doi:10.32598/bcn.9.10.365

\section{Figures}




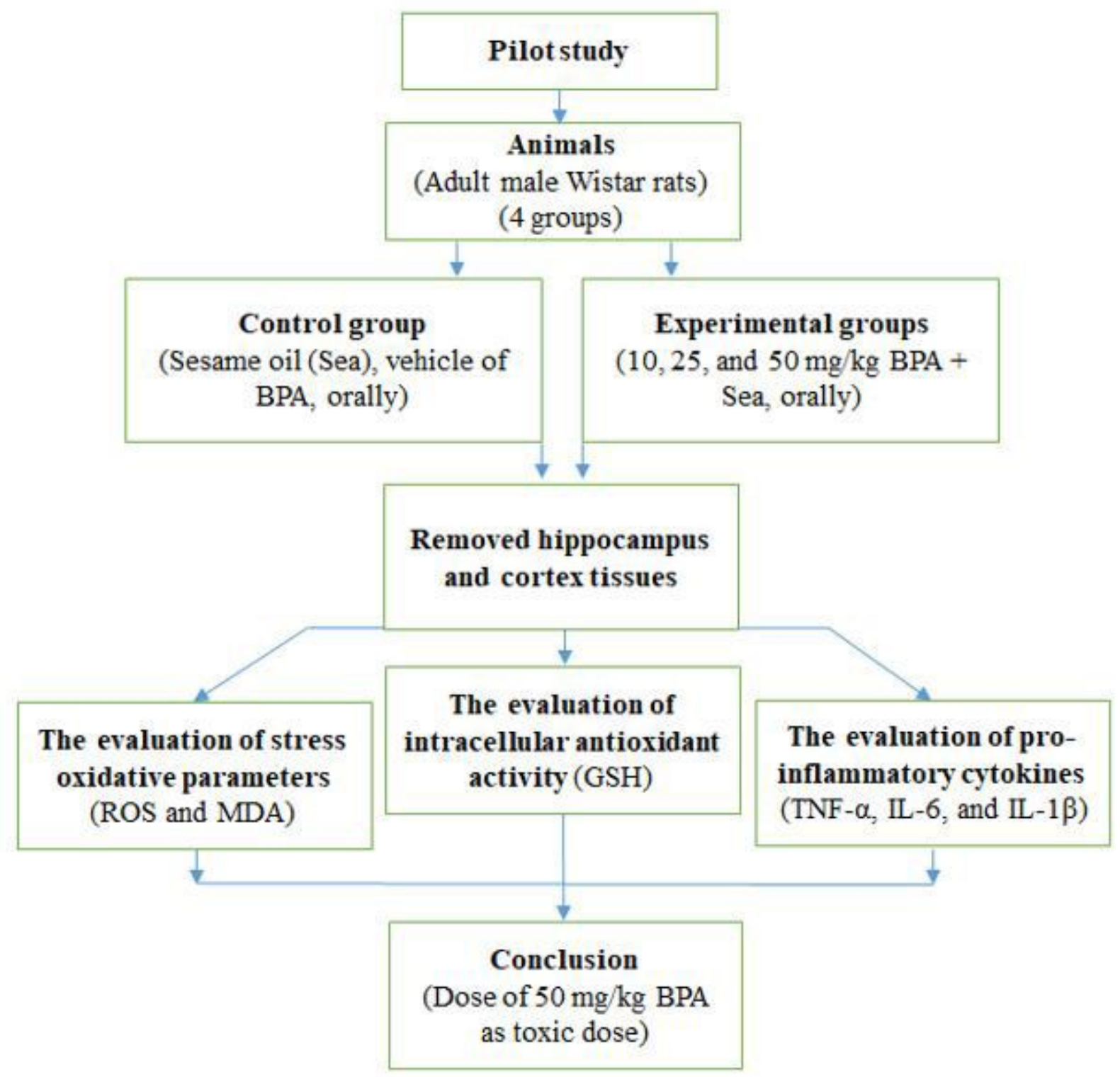

Figure 1

A schematic diagram of the pilot study design 


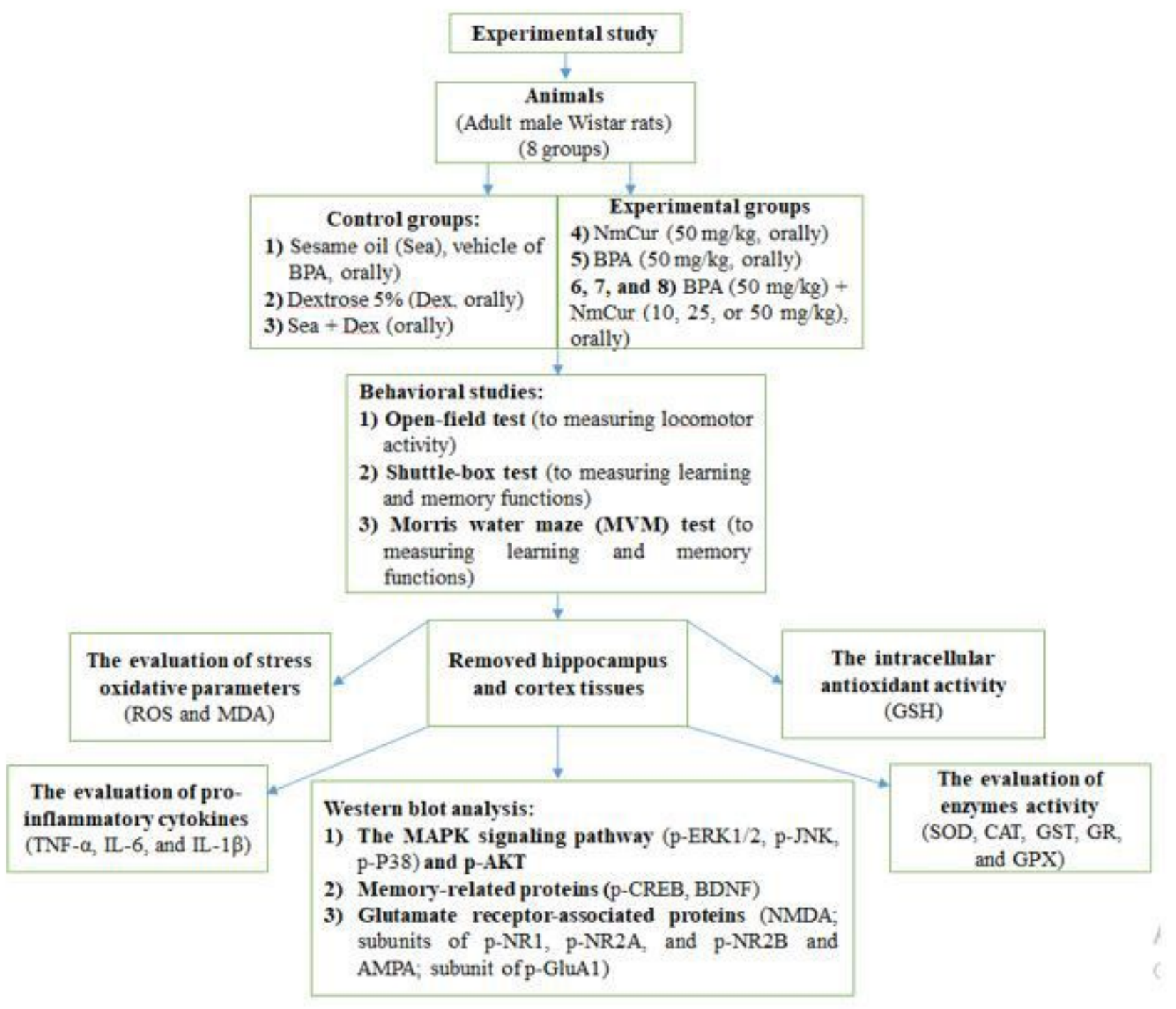

Figure 2

A schematic diagram of the experimental study design

(A)

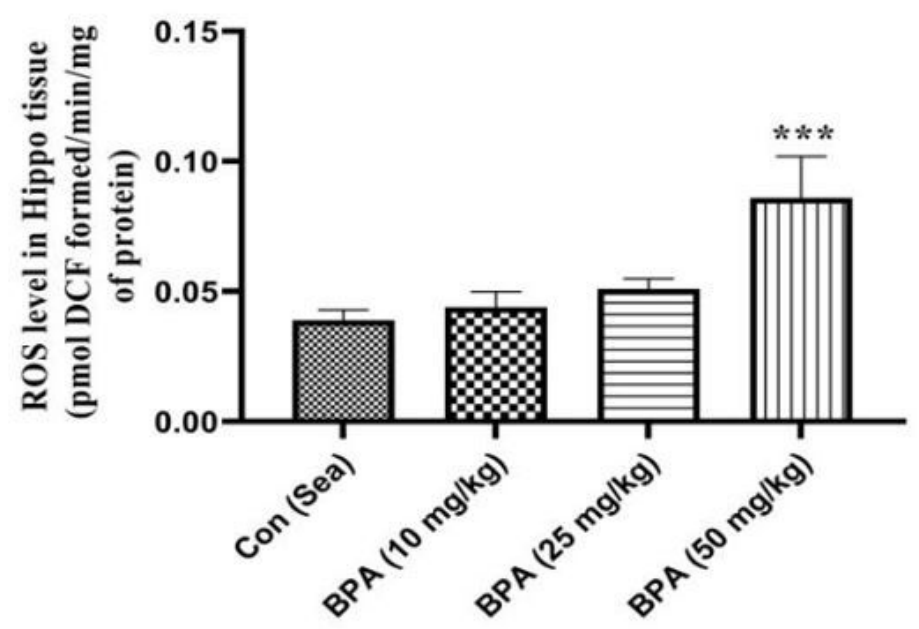

(B)

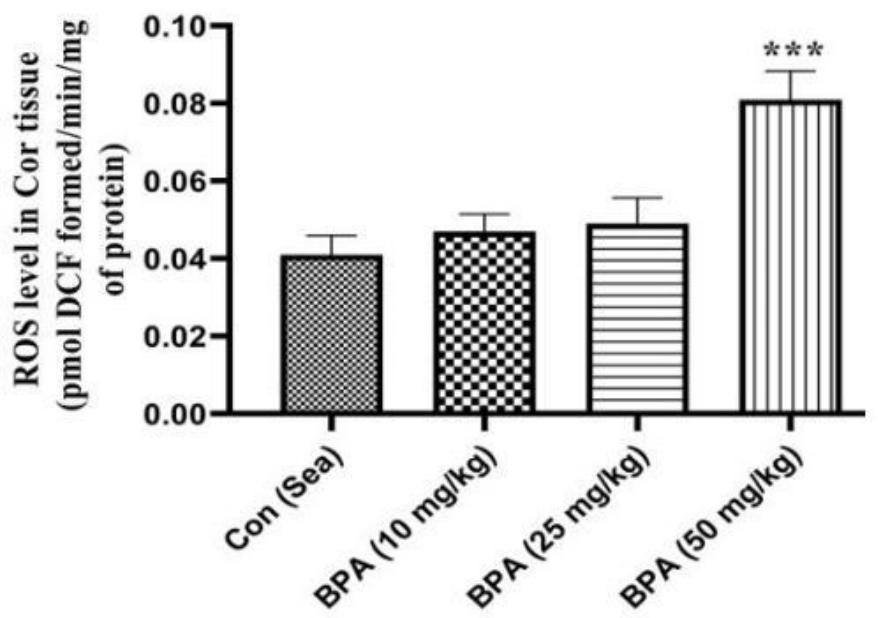




\section{Figure 3}

Effects of different doses of BPA exposure $(10,25$, and $50 \mathrm{mg} / \mathrm{kg}$ ) for 4 weeks on the ROS (A and B) level in the rat's hippocampus and cortex tissues, respectively. Data are shown as mean \pm SD, One-way ANOVA, and Tukey-Kramer test. BPA was administered via gavage once a day and seven times per week. ${ }^{* \star} \mathrm{P}<$ 0.001, compared with control group. Abbreviations: Con, control; Sea, sesame oil; BPA, bisphenol A, $n=8$.

(A)

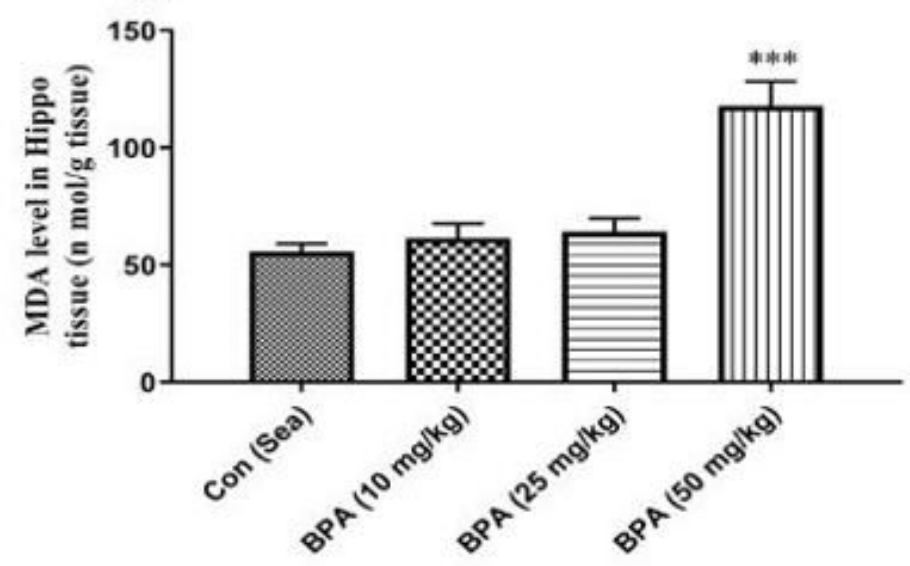

(C)

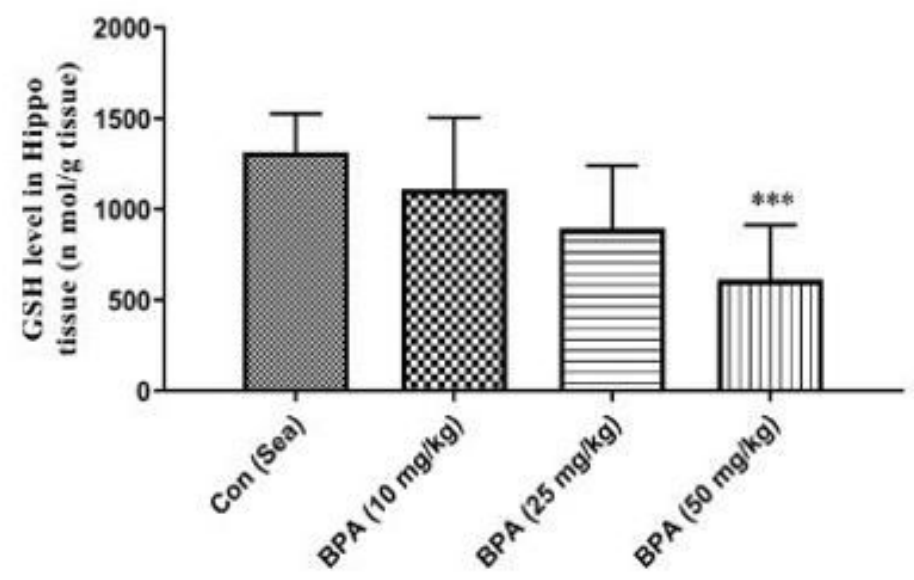

(B)

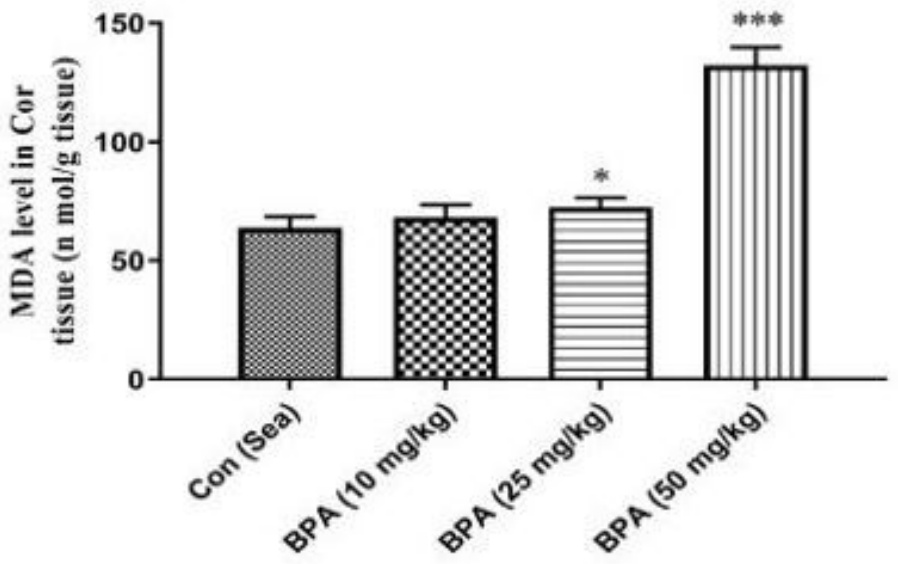

(D)

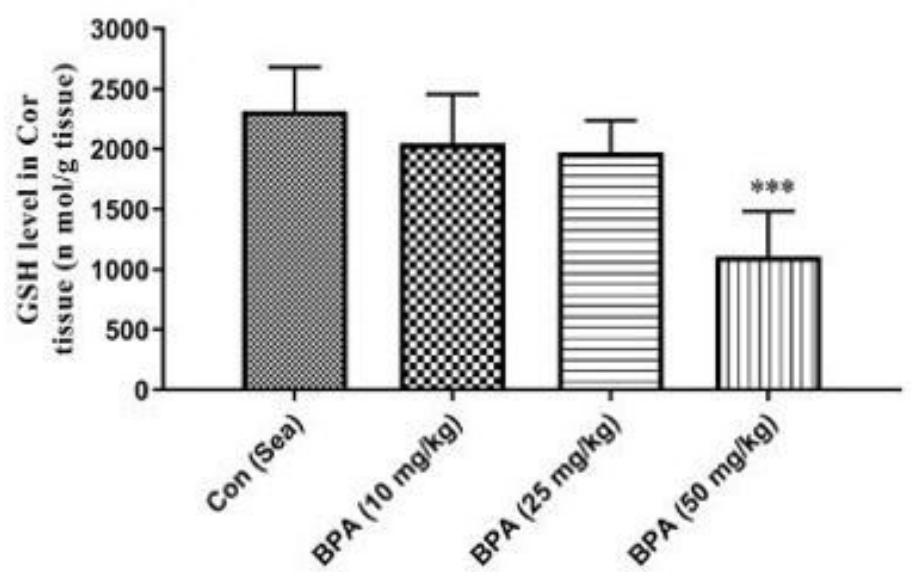

Figure 4

Effects of different doses of BPA exposure $(10,25$, and $50 \mathrm{mg} / \mathrm{kg}$ ) for 4 weeks on the MDA (A and B) and GSH (C and D) levels in the rat's hippocampus and cortex tissues, respectively. Data are shown as mean \pm SD, One-way ANOVA, and Tukey-Kramer test. BPA was administered via gavage once a day and seven times per week. ${ }^{\star} \mathrm{P}<0.05$ and ${ }^{* \star *} \mathrm{P}<0.001$, compared with control group. Abbreviations: Con, control; Sea, sesame oil; BPA, bisphenol A, $n=8$. 

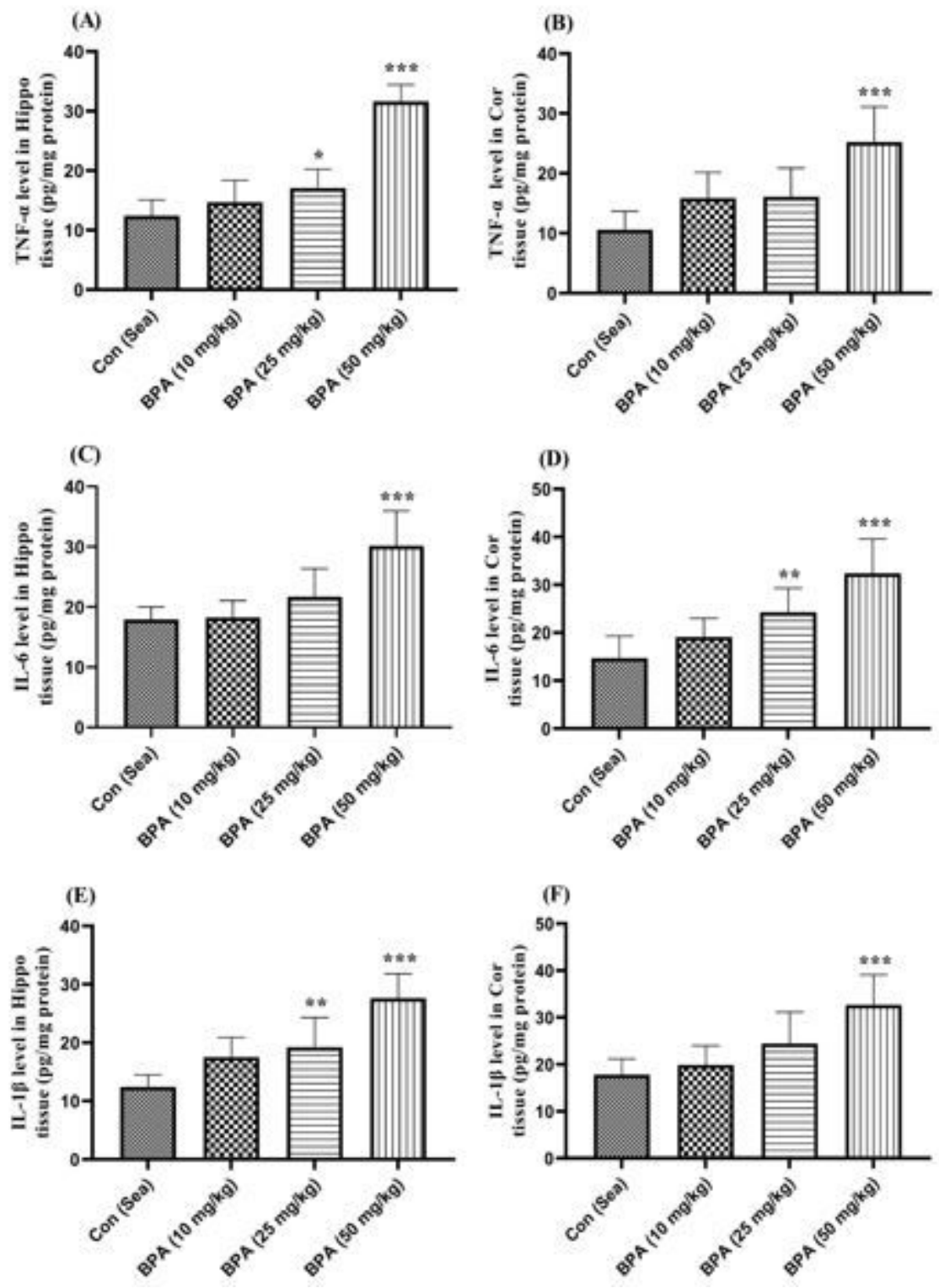

Figure 5

Effects of different doses of BPA exposure $(10,25$, and $50 \mathrm{mg} / \mathrm{kg})$ for 4 weeks on the pro-inflammatory cytokines, including TNF- $a$ (A and B), IL-6 (C and D), and IL-1 $\beta$ (E and F) levels in the rat's hippocampus and cortex tissues, respectively. Data are shown as mean \pm SD, One-way ANOVA, and Tukey-Kramer test. BPA was administered via gavage once a day and seven times per week. ${ }^{*} P<0.05$, ${ }^{\star *} \mathrm{P}<0.01$, and ${ }^{\star * \star} \mathrm{P}<$ 0.001, compared with control group. Abbreviations: Con, control; Sea, sesame oil; BPA, bisphenol A, $n=8$. 
(A)

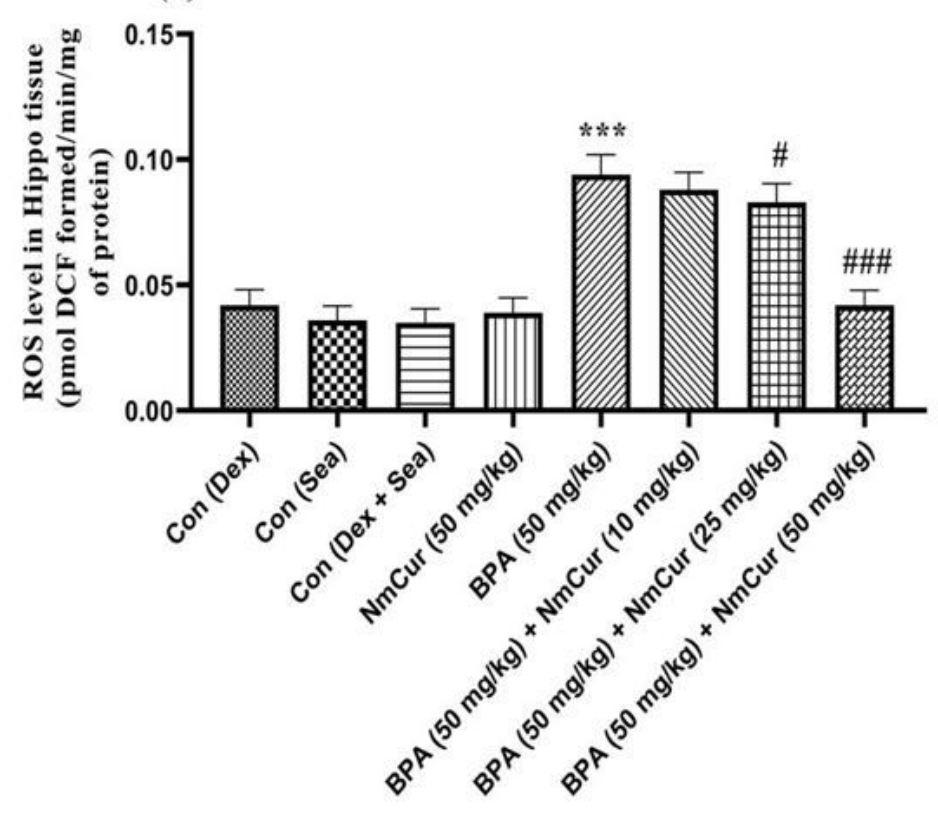

(B)

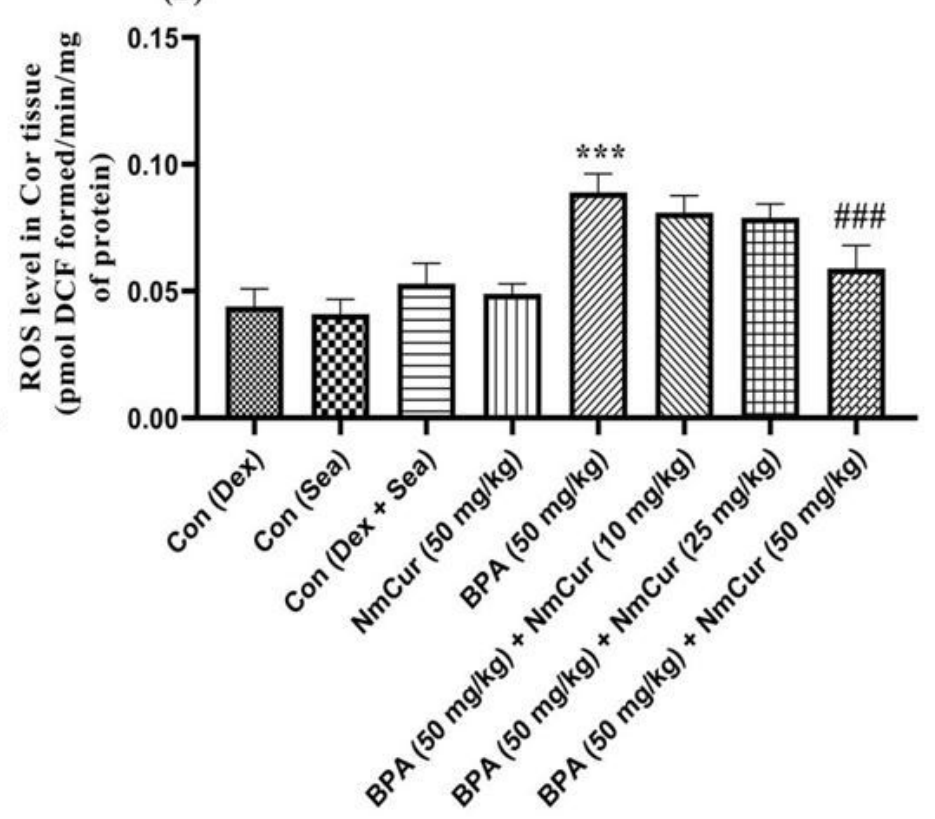

Figure 6

Effects of BPA exposure (50 mg/kg) and different doses of $\operatorname{NmCur~}(10,25$, and $50 \mathrm{mg} / \mathrm{kg}$ ) plus BPA (50 $\mathrm{mg} / \mathrm{kg}$ ) for 4 weeks on the ROS (A and B) level in the rat's hippocampus and cortex tissues, respectively. Data are shown as mean \pm SD, One-way ANOVA, and Tukey-Kramer test. BPA and NmCur were administered via gavage once a day and seven times per week. ${ }^{*} * \mathrm{P}<0.001$, compared with control groups, and \#P< 0.05 , and \#\#\#P $<0.001$, compared with the BPA $50 \mathrm{mg} / \mathrm{kg}$ group. Abbreviations: Con, control; Dex, dextrose 5\%; Sea, sesame oil; BPA, bisphenol A; NmCur, nanomicelle curcumin, $n=8$. 
(A)

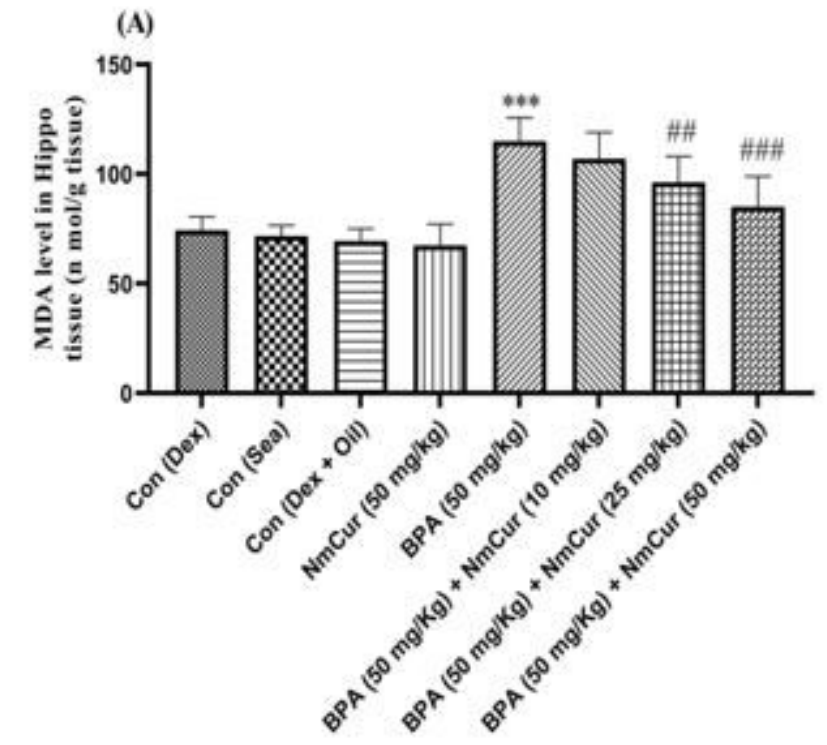

(C)

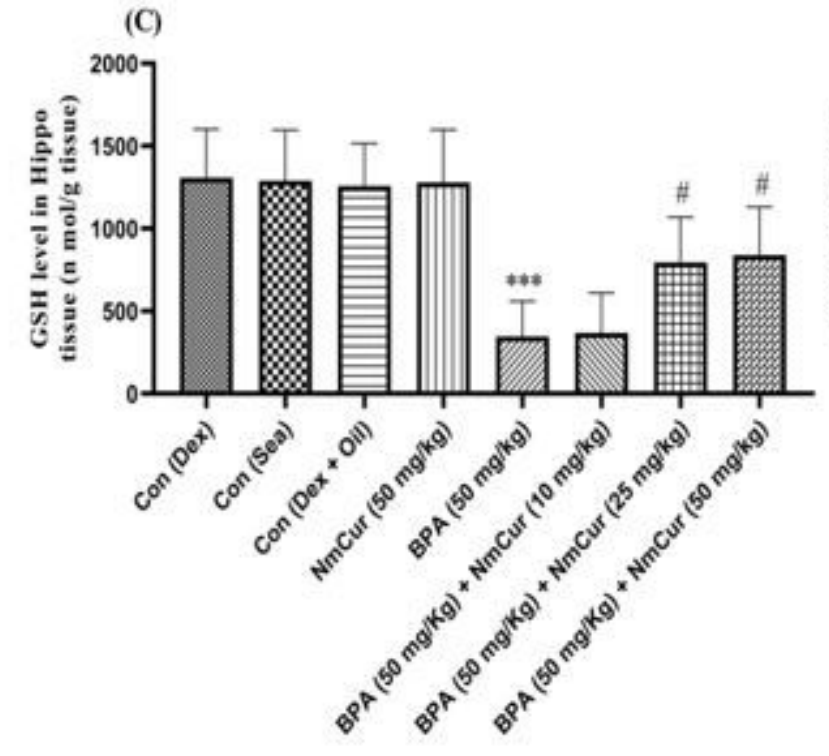

(B)

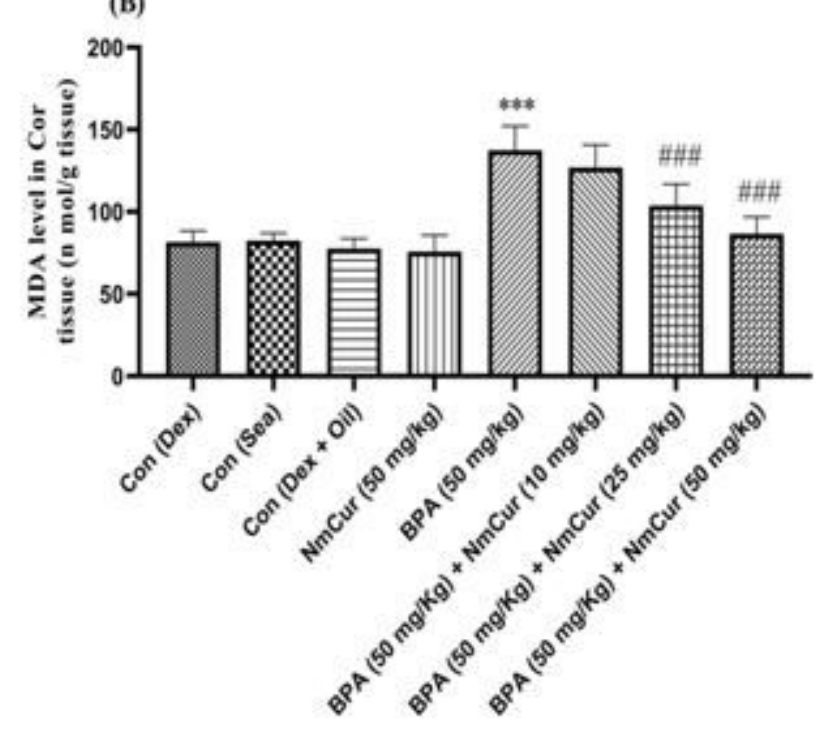

(D)

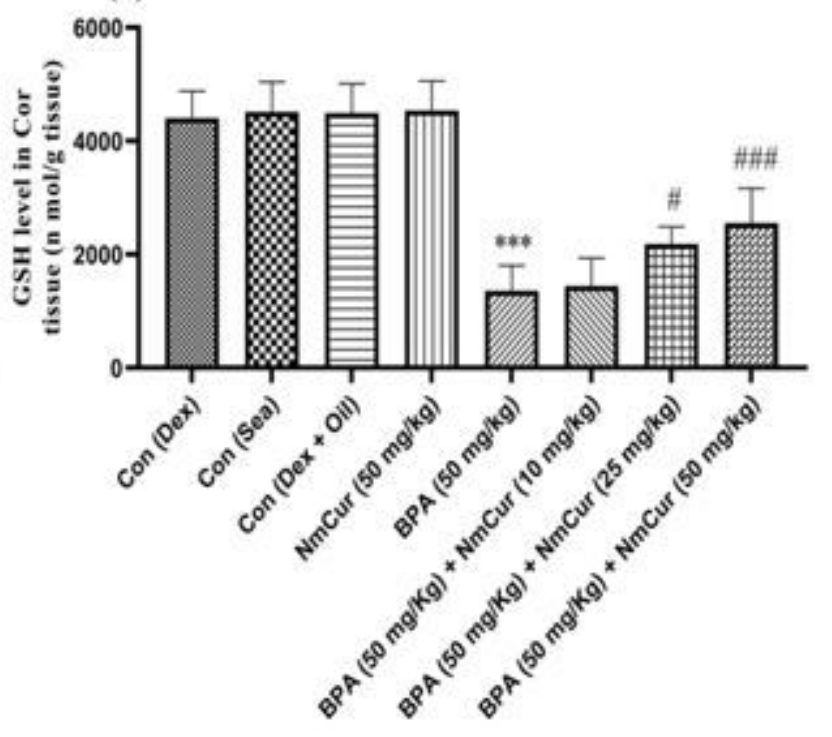

Figure 7

Effects of BPA exposure (50 mg/kg) and different doses of $\operatorname{NmCur~}(10,25$, and $50 \mathrm{mg} / \mathrm{kg}$ ) plus BPA (50 $\mathrm{mg} / \mathrm{kg}$ ) for 4 weeks on the MDA ( $A$ and $B$ ) and GSH (C and D) levels in the rat's hippocampus and cortex tissues, respectively. Data are shown as mean \pm SD, One-way ANOVA, and Tukey-Kramer test. BPA and NmCur were administered via gavage once a day and seven times per week. ${ }^{*} * \mathrm{P}<0.001$, compared with control groups, and \#P $<0.05$, \#\#P $<0.01$, and \#\#\#P $<0.001$, compared with the BPA $50 \mathrm{mg} / \mathrm{kg}$ group. Abbreviations: Con, control; Dex, dextrose 5\%; Sea, sesame oil; BPA, bisphenol A; NmCur, nanomicelle curcumin, $n=8$. 

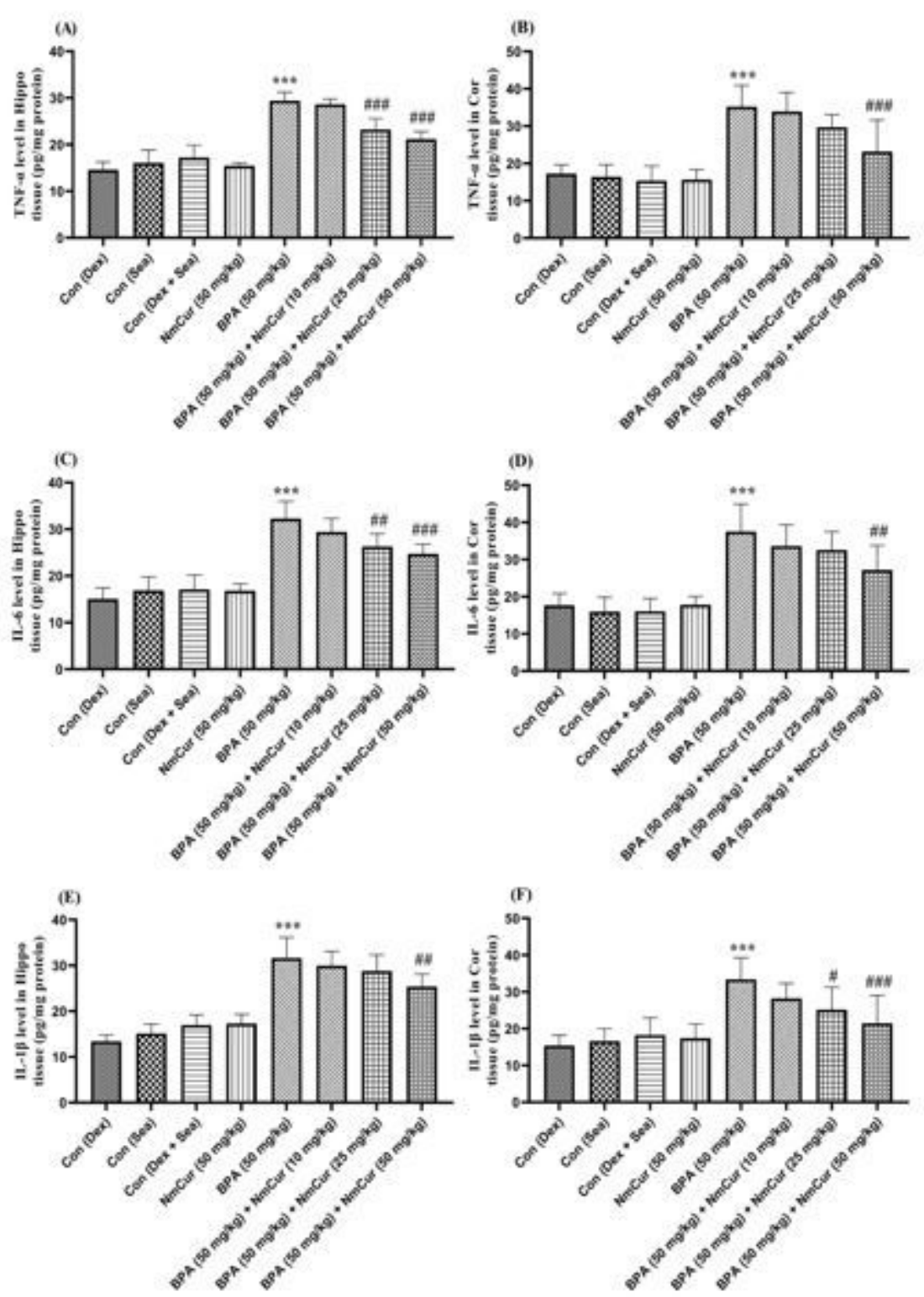

Figure 8

Effects of BPA exposure (50 mg/kg) and different doses of $\operatorname{NmCur~}(10,25$, and $50 \mathrm{mg} / \mathrm{kg}$ ) plus BPA (50 $\mathrm{mg} / \mathrm{kg}$ ) for 4 weeks on the pro-inflammatory cytokines, including TNF- $\mathrm{a}$ (A and B), IL-6 (C and D), and IL$1 \beta$ ( $E$ and $F$ ) levels in the rat's hippocampus and cortex tissues, respectively. Data are shown as mean \pm SD, One-way ANOVA, and Tukey-Kramer test. BPA and NmCur were administered via gavage once a day and seven times per week. ${ }^{\star \star \star} P<0.001$, compared with control groups, and $\# P<0.05$, \#\#P<0.01, and \#\#\#P < 0.001, compared with the BPA $50 \mathrm{mg} / \mathrm{kg}$ group. Abbreviations: Con, control; Dex, dextrose $5 \%$; Sea, sesame oil; BPA, bisphenol A; NmCur, nanomicelle curcumin, $n=8$. 

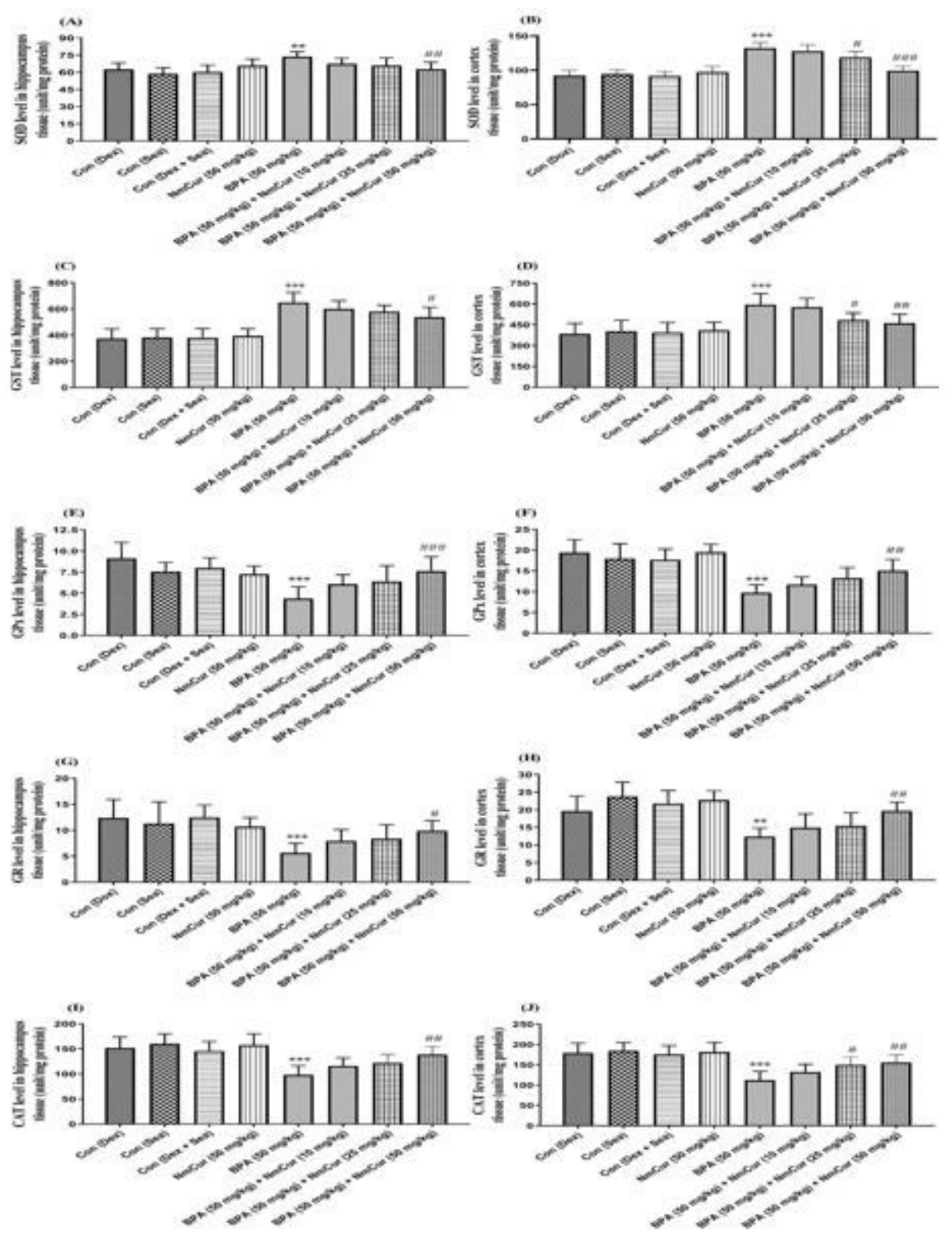

Figure 9

Effects of BPA exposure (50 mg/kg) and different doses of $\operatorname{NmCur~}(10,25$, and $50 \mathrm{mg} / \mathrm{kg}$ ) plus BPA (50 $\mathrm{mg} / \mathrm{kg}$ ) for 4 weeks on levels of the SOD (A and B), GST (C and D), GPx (E and F), GR (G and H) and CAT ( $I$ and $\mathrm{J}$ ) enzymes activity in the rat's hippocampus and cortex tissues, respectively. Data are shown as mean \pm SD, One-way ANOVA and Tukey-Kramer test. BPA and NmCur were administered via gavage once a day and seven times per week. ${ }^{* \star P}<0.01$ and ${ }^{*} * \mathrm{P}<0.001$, compared with control group, and $\# \mathrm{P}<$ 0.05 , \#\#P < 0.01 and \#\#\#P < 0.001, compared with the BPA $50 \mathrm{mg} / \mathrm{kg}$ group. Abbreviations: Con, control; Dex, dextrose 5\%; Sea, sesame oil; BPA, bisphenol A; NmCur, nanomicelle curcumin; SOD, superoxide dismutase; GST, glutathione-S-transferases; GPx, glutathione peroxidase; GR, glutathione reductase; CAT, catalase, $\mathrm{n}=8$. 


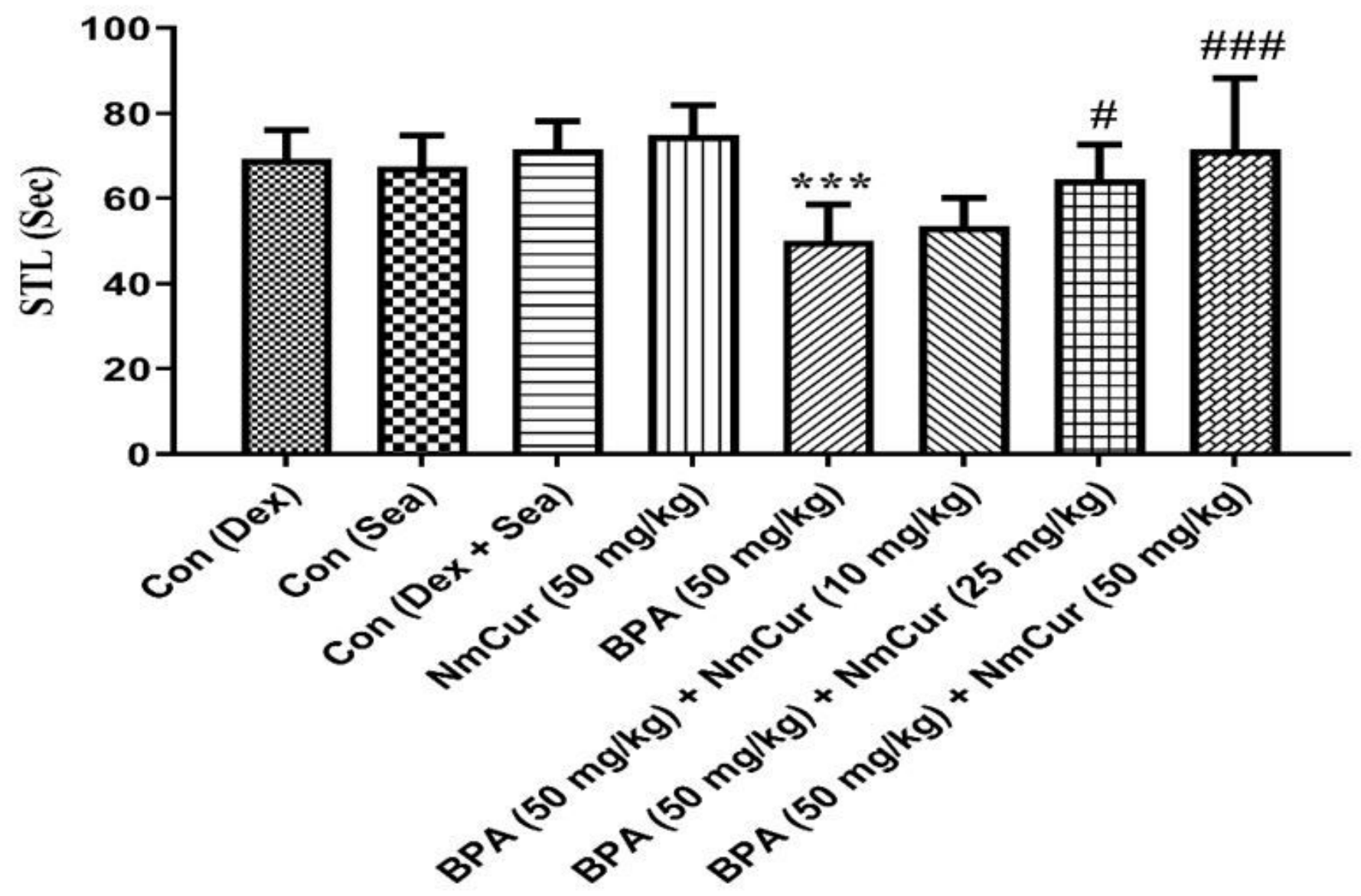

Figure 10

Effects of BPA exposure (50 mg/kg) and different doses of $\operatorname{NmCur~}(10,25$, and $50 \mathrm{mg} / \mathrm{kg}$ ) plus BPA (50 $\mathrm{mg} / \mathrm{kg}$ ) for 4 weeks on passive avoidance test in rat. Data are shown as mean \pm SD, One-way ANOVA and Tukey-Kramer test. BPA and NmCur were administered via gavage once a day and seven times per week. $\star \star \star \mathrm{P}<0.001$ compared with the control groups, and \#P $<0.05$ and \#\#\#P $<0.001$ compared with the BPA group. Abbreviations: Con, control; Dex, dextrose 5\%; Sea, sesame oil; BPA, bisphenol A; NmCur, nanomicelle curcumin; STL, step-through latency, $\mathrm{n}=8$. 

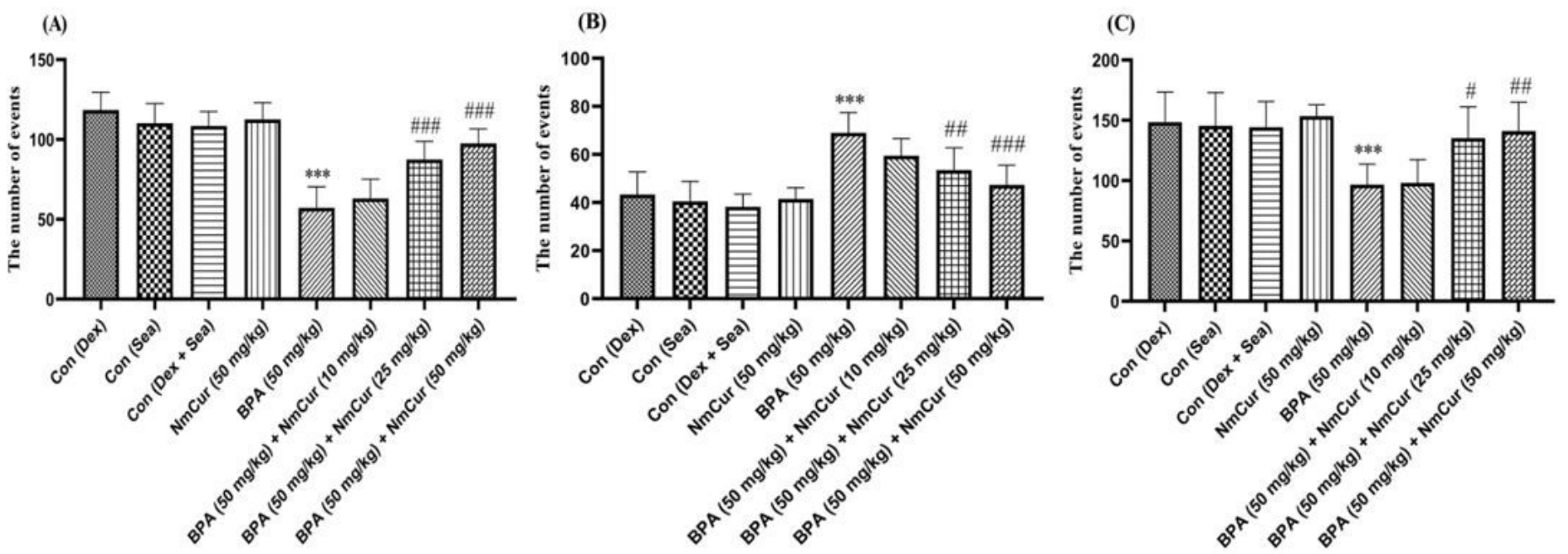

Figure 11

Effects of BPA exposure (50 mg/kg) and different doses of $\operatorname{NmCur~}(10,25$, and $50 \mathrm{mg} / \mathrm{kg}$ ) plus BPA (50 $\mathrm{mg} / \mathrm{kg}$ ) for 4 weeks on peripheral (A), central (B), and total (C) locomotor activity in rat. Data are shown as mean \pm SD, One-way ANOVA and Tukey-Kramer test. BPA and NmCur were administered via gavage once a day and seven times per week. ${ }^{* * *} \mathrm{P}<0.001$ compared with the control groups, and $\# \mathrm{P}<0.05$, \#\#P $<0.01$, and \#\#\#P < 0.001 compared with the BPA group. Abbreviations: Con, control; Dex, dextrose 5\%; Sea, sesame oil; BPA, bisphenol A; NmCur, nanomicelle curcumin, $n=8$. 

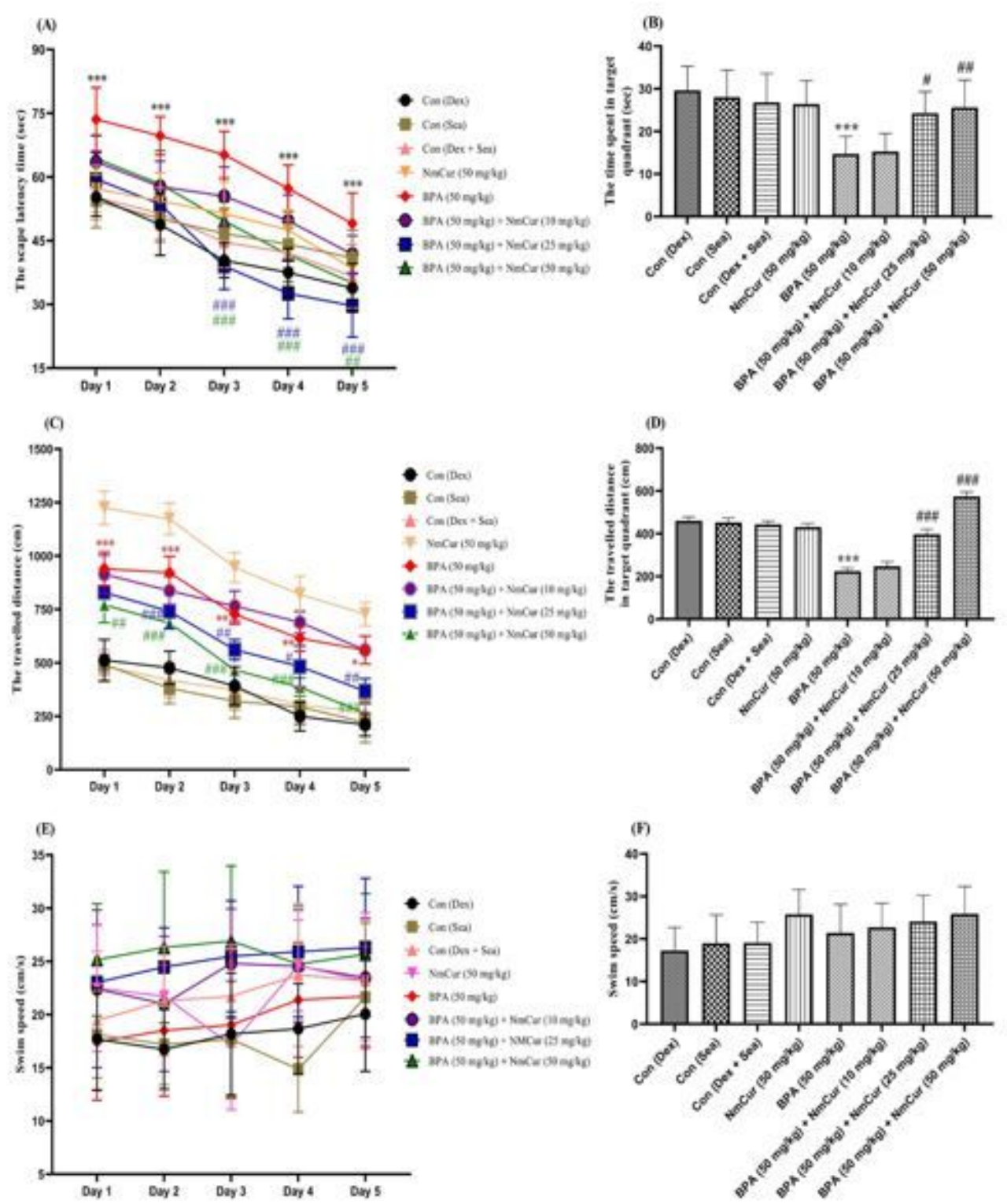

Figure 12

Effects of BPA exposure (50 mg/kg) and different doses of $\operatorname{NmCur~}(10,25$, and $50 \mathrm{mg} / \mathrm{kg}$ ) plus BPA (50 $\mathrm{mg} / \mathrm{kg}$ ) for 4 weeks on the escape latency time (sec) from day 1 to day 5 of training trial (A), the time $(\mathrm{sec})$ spent in the target quadrant $(B)$, traveled distance $(\mathrm{cm})$ from day 1 to day 5 of training trial $(C)$, and traveled distance $(\mathrm{cm})$ in the target quadrant (D) to find the hidden platform in Morris water maze test in rat. In addition, swimming speed $(\mathrm{cm} / \mathrm{s})$ from day 1 to day 5 of training trial $(\mathrm{E})$ and probe test $(\mathrm{F})$ after removing the hidden platform in Morris water maze test in rat were evaluated. Data are expressed as the mean \pm SD, One-way or Two-way ANOVA coupled with Tukey-Kramer multiple comparisons test. BPA and NmCur were administered via gavage once a day and seven times per week. ${ }^{\star} P<0.05,{ }^{*} P<0.01$, and ${ }^{* *} \mathrm{P}<0.001$ compared with the control groups, and $\# \mathrm{P}<0.05$, \#\#P<0.01, and \#\#\#P<0.001 compared with the BPA group. Abbreviations: Con, control; Dex, dextrose 5\%; Sea, sesame oil; BPA, bisphenol $A ;$ NmCur, nanomicelle curcumin, $n=8$. 


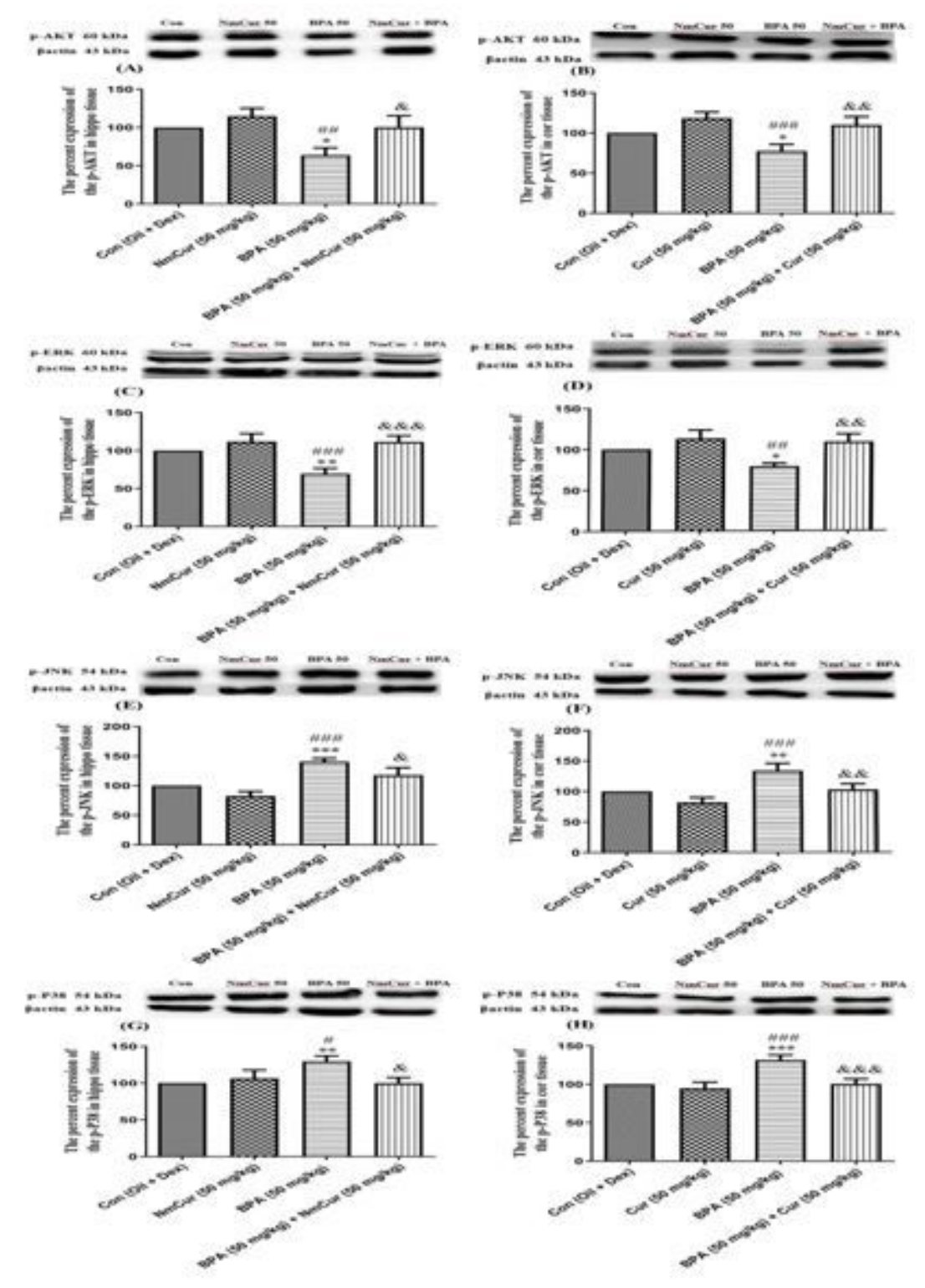

Figure 13

Effects of BPA exposure (50 mg/kg) and different doses of $\operatorname{NmCur~(10,25,~and~} 50 \mathrm{mg} / \mathrm{kg}$ ) plus BPA (50 $\mathrm{mg} / \mathrm{kg}$ ) for 4 weeks on the p-AKT ( $A$ and B), p-ERK (C and D), p-JNK (E and F), and p-P38 (G and H) protein levels in the rat's hippocampus and cortex tissues, respectively. Data are shown as mean $\pm S D$, One-way ANOVA, and Tukey-Kramer. BPA and NmCur were administered via gavage once a day and seven times per week. ${ }^{*} P<0.05,{ }^{\star *} P<0.01$, and ${ }^{* \star *} P<0.001$, compared with the control group, $\# P<0.05$, $\# \# P<0.01$, \#\#\#P<0.001, compared with the NmCur group, and \&P $<0.05, \& \& P<0.01, \& \& \& P<0.001$, compared with the BPA $(50 \mathrm{mg} / \mathrm{kg})$ group. $\beta$-actin was used as the internal control. Abbreviations: Con, control; Dex, dextrose 5\%; Sea, sesame oil; BPA, bisphenol A; NmCur, nanomicelle curcumin, $n=8$. 


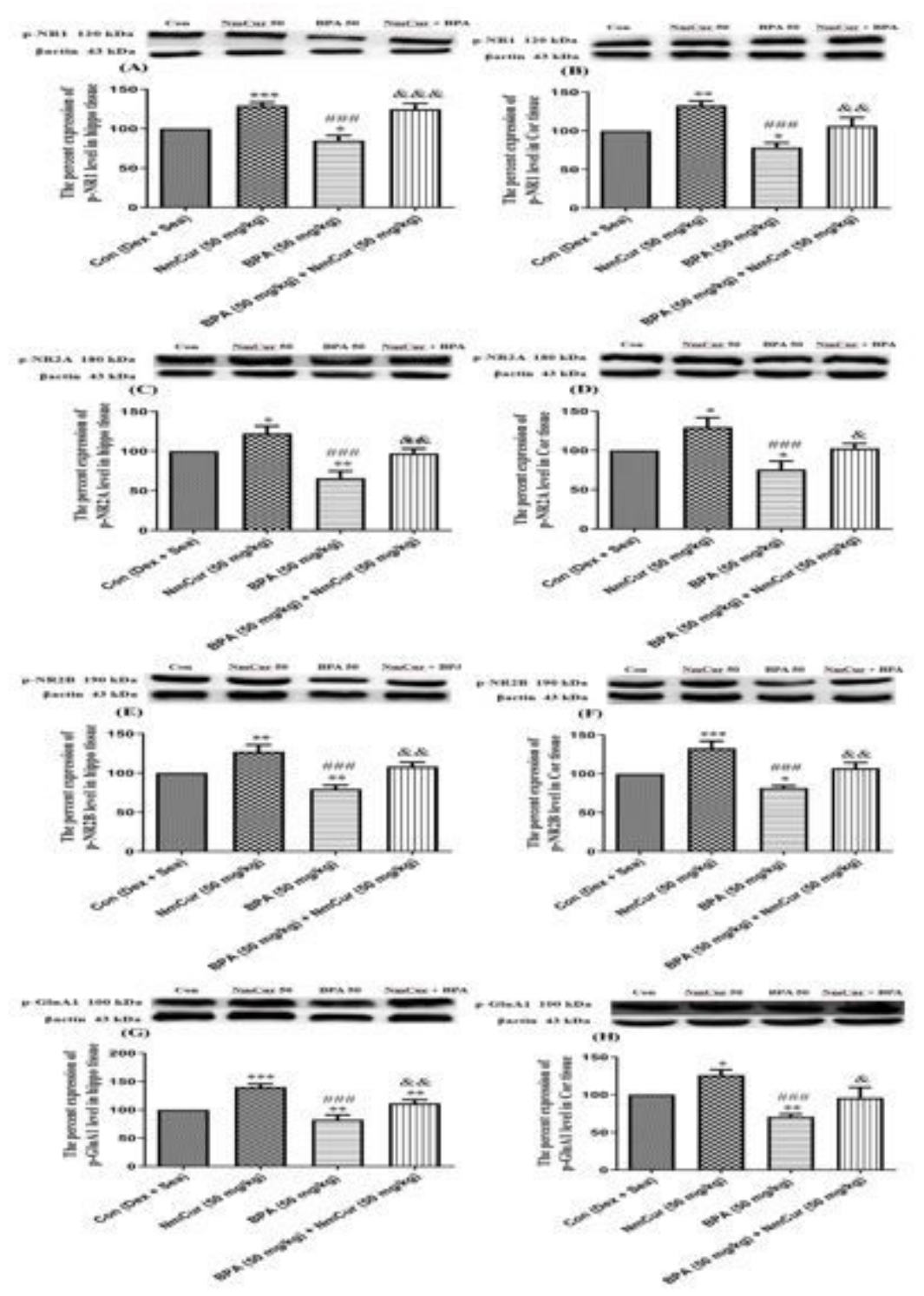

Figure 14

Effects of BPA exposure (50 mg/kg) and different doses of $\operatorname{NmCur~(10,25,~and~} 50 \mathrm{mg} / \mathrm{kg}$ ) plus BPA (50 $\mathrm{mg} / \mathrm{kg}$ ) for 4 weeks on the expression of a variety of glutamate receptors, including NMDA (NR1, NR2A, and NR2B) and AMPA (GluA1) in the rat's hippocampus and cortex tissues. Data are shown as mean \pm SD, One-way ANOVA, and Tukey-Kramer. BPA and NmCur were administered via gavage once a day and seven times per week. ${ }^{*} P<0.05$, ${ }^{\star *} P<0.01$, and ${ }^{* \star *} P<0.001$, compared with the control group, \#\#\#P< 0.001 , compared with the NmCur group, and \&P $<0.05$, \&\&P $<0.01$, \&\&\&P $<0.001$, compared with the BPA $(50 \mathrm{mg} / \mathrm{kg}$ ) group. $\beta$-actin was used as the internal control. Abbreviations: Con, control; Dex, dextrose $5 \%$; Sea, sesame oil; BPA, bisphenol A; NmCur, nanomicelle curcumin, $n=8$. 


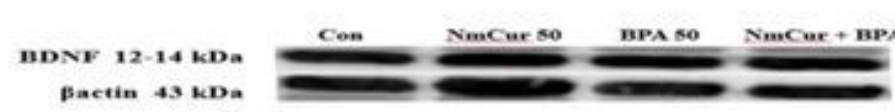

Bactio $43 \mathrm{kD}=$

(A)

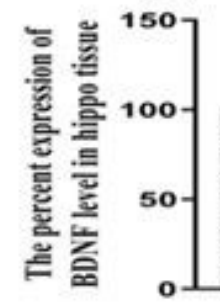

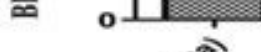
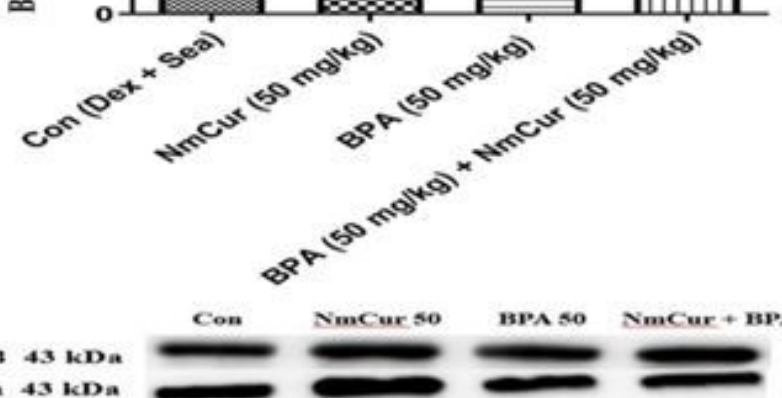

(C)
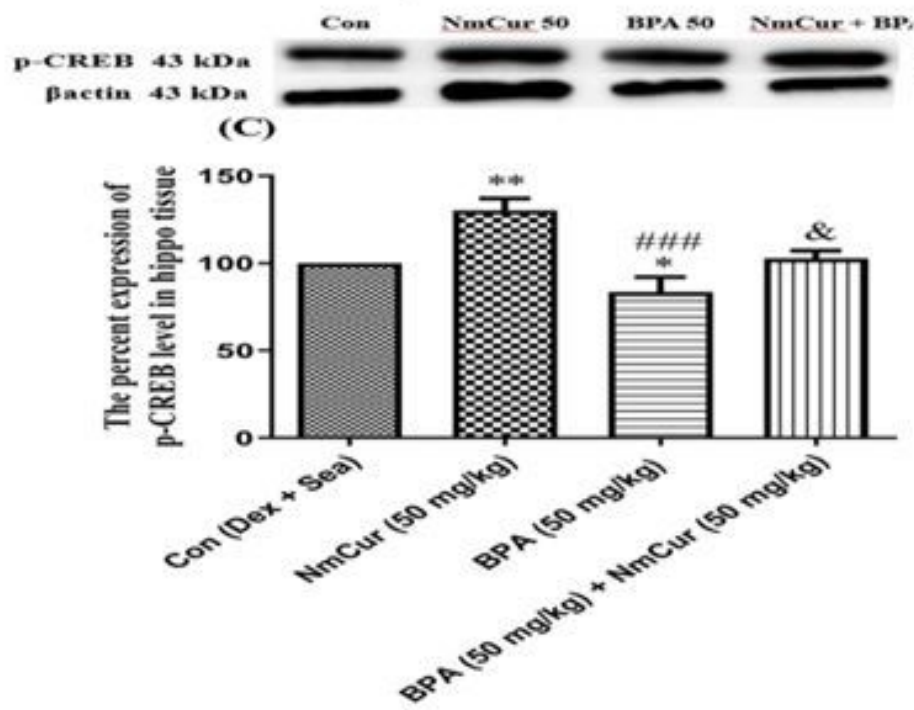

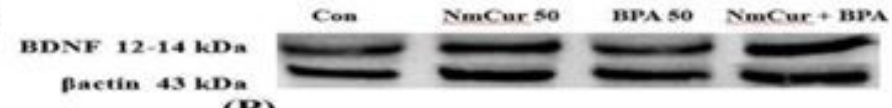

(B)
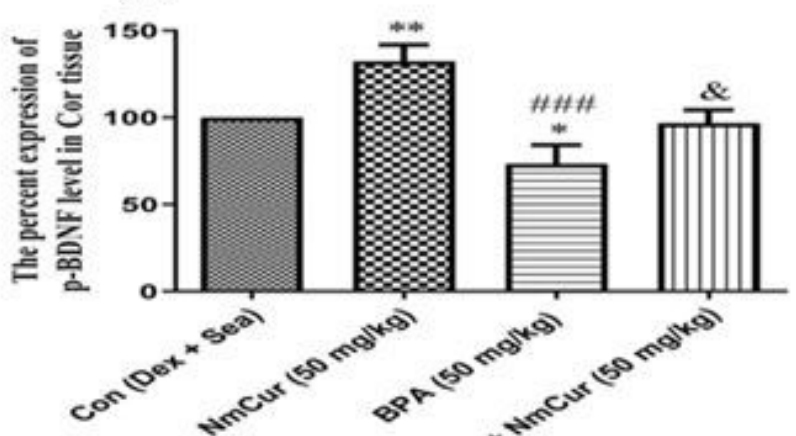

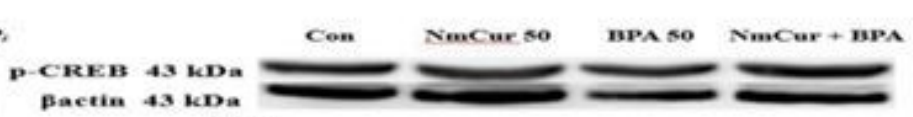

(D)

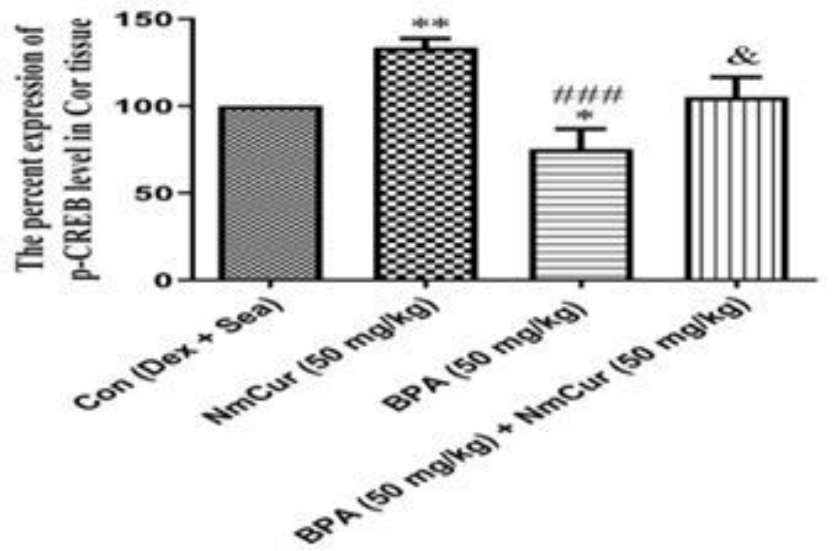

\section{Figure 15}

Effects of BPA exposure (50 mg/kg) and different doses of $\operatorname{NmCur~}(10,25$, and $50 \mathrm{mg} / \mathrm{kg}$ ) plus BPA (50 $\mathrm{mg} / \mathrm{kg}$ ) for 4 weeks on the expression of memory-associated proteins, such as BDNF and CREB, in the rat's hippocampus and cortex tissues. Data are shown as mean \pm SD, One-way ANOVA, and TukeyKramer. BPA and NmCur were administered via gavage once a day and seven times per week. ${ }^{*} \mathrm{P}<0.05$ and ${ }^{*} P \mathrm{P}<0.01$, compared with the control group, \#\#\#P<0.001, compared with the NmCur group, and \&P $<0.05$, compared with the BPA $(50 \mathrm{mg} / \mathrm{kg}$ ) group. $\beta$-actin was used as the internal control. Abbreviations: Con, control; Dex, dextrose 5\%; Sea, sesame oil; BPA, bisphenol A; NmCur, nanomicelle curcumin, $n=8$. 


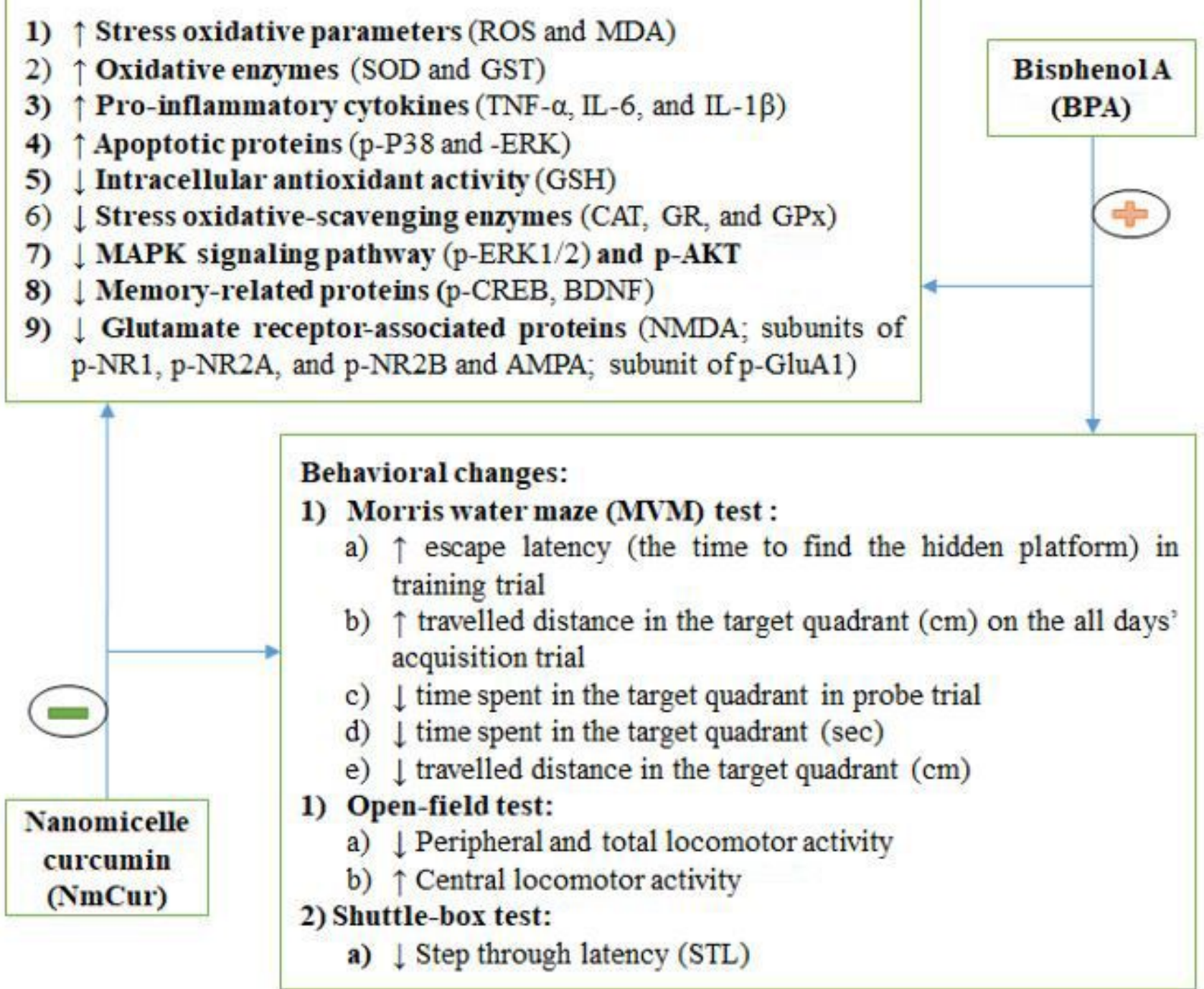

\section{Figure 16}

A schematic diagram of the effect of BPA and NmCur on changes of behavioral responses and cortical and hippocampal tissue in rat. Abbreviations: Con, control; Dex, dextrose 5\%; Sea, sesame oil; BPA, bisphenol A; NmCur, nanomicelle curcumin, ROS, reactive oxygen species; MDA, Malondialdehyde; GSH, Glutathione; SOD, superoxide dismutase; GPx, glutathione peroxidase; CAT, catalase; GR, glutathione reductase; GST, Glutathione S-transferase; TNF-a,tumor necrosis factor alpha; IL-6, Interleukin 6; IL-1ß, Interleukin-1 $\beta$; AKT, protein Kinase B; ERK, extracellular signal-regulated protein kinases 1 and 2; P38, p38mitogen-activated protein kinase; JNK, c-jun NH2 terminal kinases; CREB, cAMP-response element binding protein; BDNF, brain-derived neurotrophic factor; NMDA, N-Methyl-D-aspartic acid or N-Methyl-Daspartate; AMPA, a-amino-3-hydroxy-5-methyl-4-isoxazolepropionic acid; Positive sign definition, induction by BPA; Negative sign definition, inhibition by NmCur. 